\title{
Improving Standards in Bahamian High Schools: \\ Using Geographic Information System as a Pedagogical Tool
}

\author{
By \\ Sophia Miah, B.A.

\begin{abstract}
A Thesis submitted to the
Faculty of Graduate Studies and Research in partial fulfillment of

the requirements for the Degree of Master of Arts
\end{abstract} \\ Department of Geography and Environmental Studies
}

\author{
Carleton University \\ Ottawa, Ontario
}

(C) Copyright

August 2009, Sophia Miah 
Library and Archives

Canada

Published Heritage

Branch

395 Wellington Street

Ottawa ON K1A ON4

Canada
Bibliotheque et

Archives Canada

Direction du

Patrimoine de l'édition

395, rue Wellington

Ottawa ON K1A 0N4

Canada
Your file Votre reférence

ISBN: 978-0-494-58440-8

Our file Notre reference

ISBN: $978-0-494-58440-8$
NOTICE:

The author has granted a nonexclusive license allowing Library and Archives Canada to reproduce, publish, archive, preserve, conserve, communicate to the public by telecommunication or on the Internet, loan, distribute and sell theses worldwide, for commercial or noncommercial purposes, in microform, paper, electronic and/or any other formats.

The author retains copyright ownership and moral rights in this thesis. Neither the thesis nor substantial extracts from it may be printed or otherwise reproduced without the author's permission.
AVIS:

L'auteur a accordé une licence non exclusive permettant à la Bibliothèque et Archives Canada de reproduire, publier, archiver, sauvegarder, conserver, transmettre au public par télécommunication ou par l'Internet, prêter, distribuer et vendre des thèses partout dans le monde, à des fins commerciales ou autres, sur support microforme, papier, électronique et/ou autres formats.

L'auteur conserve la propriété du droit d'auteur et des droits moraux qui protège cette thèse. $\mathrm{Ni}$ la thèse ni des extraits substantiels de celle-ci ne doivent être imprimés ou autrement reproduits sans son autorisation.
In compliance with the Canadian Privacy Act some supporting forms may have been removed from this thesis.

While these forms may be included in the document page count, their removal does not represent any loss of content from the thesis.
Conformément à la loi canadienne sur la protection de la vie privée, quelques formulaires secondaires ont été enlevés de cette thèse.

Bien que ces formulaires aient inclus dans la pagination, il n'y aura aucun contenu manquant.

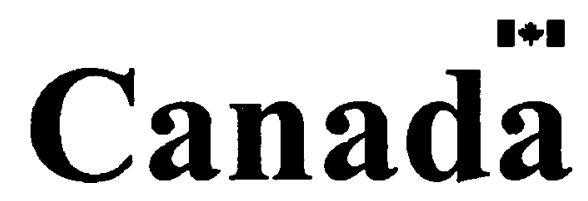




\begin{abstract}
\end{abstract}
From a human resource development perspective, it is evident that the future economic progress of any country relies profoundly on the level of education opportunities it provides for its citizens (Mandi, 1981). Even though The Bahamas boasts an adult literacy rate of more than 95 percent, there is increasing concern over academic standards and the quality of the education with which students are graduating from high school. This thesis examines the potential of Geographic Information technology to improve the quality of education in Bahamian schools in both academic and technical terms, once focus is placed on using the technology as an educational tool rather than on the technology itself.

This thesis provides an overview of educational challenges and development in The Bahamas and argues that although much progress has been made over the 35 years since independence in 1973, many problems of educational quality still exist. Education officials, teachers and students were key participants in the development of this study. The research instruments used to qualitatively collect data from the participants were interviews, focus groups and the distribution of surveys, which adequately produced the data required to support this research. 


\section{ACKNOWLEDGEMENTS}

It is difficult to calculate the debts owed to so many individuals for the position that one reaches. These must be acknowledged in some way. But I would first like to give thanks to God for guiding me and ensuring that I maintained a level of good health to complete this thesis. I would like to acknowledge Dr. Fraser Taylor's motivation, guidance, advice, wisdom, and knowledge on GIS and education, which certainly made the completion of this research possible. To Dr. David Bennett, a special thank you for the tremendous guidance and directions.

I extend a sincere thank you to the Organization of American States for affording me the opportunity to pursue graduate studies at Carleton University. The Ministry of Education is also to be thanked for the study leave provided in 2007. Mrs. Delores Ingraham, thank you for your continued encouragement, guidance and support. It also goes without saying that I would like to thank all those people who contributed to the development of this thesis, in particular the principals and teachers of the participating schools.

The thought of going to a new country, with no familiar faces around could be frightening. But knowing that you are surrounded by individuals who fully support you can make the experience much easier. It is for this reason that I wish to express profound gratitude and appreciation to my family and friends. Elwood and Elizabeth Simms, words cannot express how grateful I am for your constant support and encouragement over the years. To my siblings, in particular Samantha, Omara and Daniel thank you for the emails and telephone calls. I thank aunt Paula for the calls, and words of encouragement. Reverend Meread Burrows, Reverend Samuel and Shirley Green, thanks for the unwavering support. To my dear friends: Patricia Hamilton, Carolyn Rolle, Clifton Walker, Patricia Fowler, Mrs. Gharbharan, Rashimah, Shikara, Erica, Anshanique, Jannell, LerDon, Triver, Damone, Reverend Jarred and Val Gardiner and the entire Zion Yamacraw Baptist Church family, a heartfelt thanks for the prayers, inspiring words, emails and phone calls. Shenika, besides the many calls, thank you very much for being a source of strength in my life. Bethsheba Williams-Clarke, to whom I owe a debt of gratitude, thanks for the many telephone calls, emails, constant encouragement and being that angel in disguise in my life.

I would of course like to extend my sincere thanks to Milen Milanov, whose unending encouragement; motivation, love, presence and constructive feedback have truly helped me over the past two years, especially with the writing of this research. Over the years a number of other people have both added to and enriched my knowledge and enthusiasm to always excel. These include: my mom, the late Melvise Miah (to whom this thesis is in memory of), Gloria Gomez, Sharon Poitier, Dr. Marlene Jackson, David Anderson and the staff of BNGIS center. To the many friends that I have made at Carleton, a special thank you. It is because of all of you that my time here has been an enjoyable and memorable experience. 


\section{TABLE OF CONTENTS}

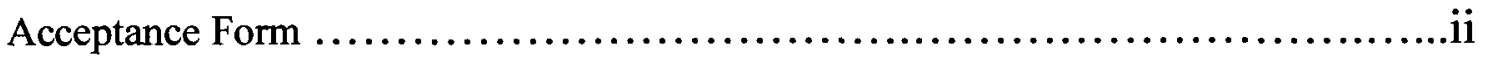

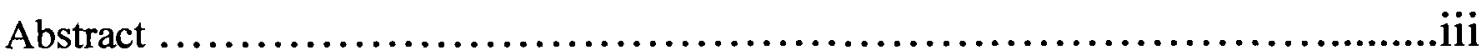

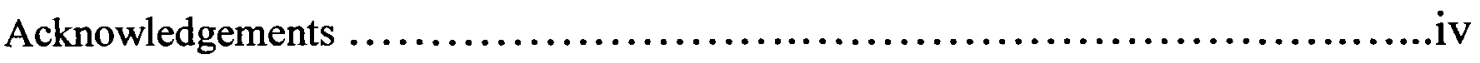

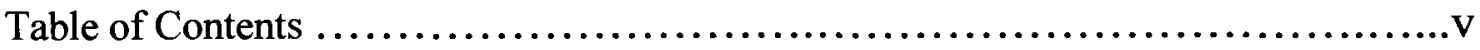

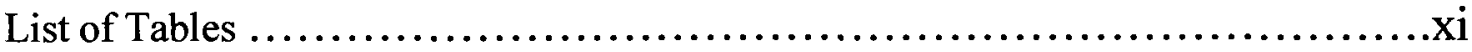

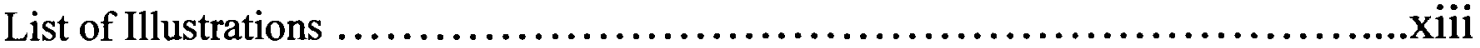

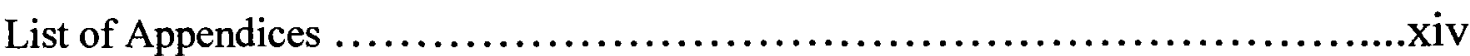

CHAPTER ONE: INTRODUCTION TO THE RESEARCH $\ldots \ldots \ldots \ldots \ldots \ldots .1-12$

Introduction to the Research Problem and Central Argument ....................1

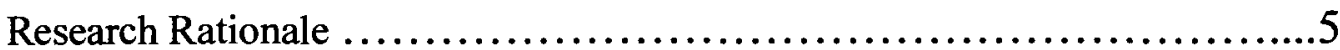

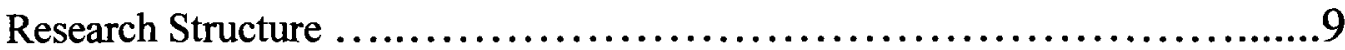

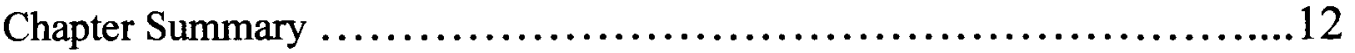


Introduction .....................................................13

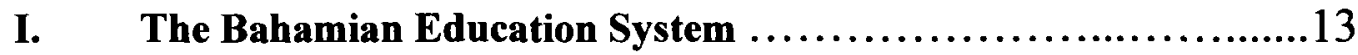

Developments and Challenges of the Bahamian

Education System ..........................................15

Are Educational Standards an Issue in The Bahamas?

An Educator's Perspective ...................................33

The Importance of Future Educational Developments ..............41

Educational Priorities and Improvements in The Bahamas ...........42

The Linkage between Education, Training and Economic

Performance: In the case of The Bahamas ........................44

II. GIS and Education ......................................47

Pedagogical Benefits that GIS can potentially provide for

Educational Improvements in Bahamian Schools when compared to Traditional Methods

A Traditional Education System

An Education System that utilizes GIS and related

Technologies as a Pedagogical Tool

The Challenge with GIS Advancement in Education: How can GIS be accessible and useable for Teachers?

Chapter Summary .65 


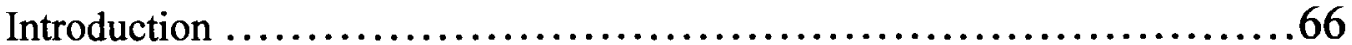

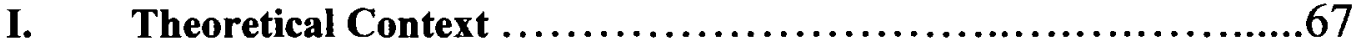

Theoretical Support for GIS and related Technologies as

Pedagogical Tools ..........................................76

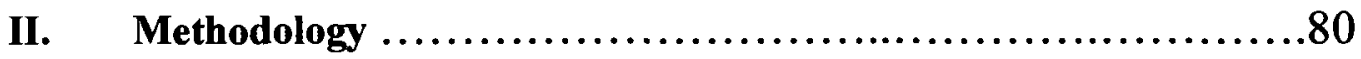

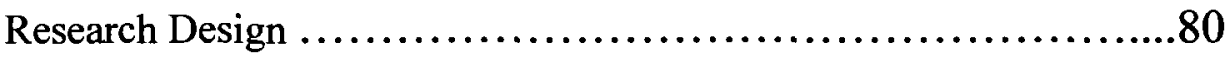

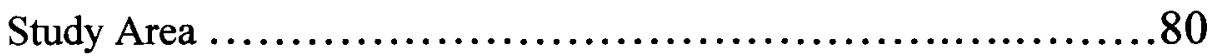

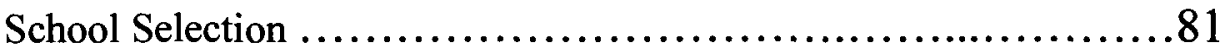

Data Collection Instruments $\ldots \ldots \ldots \ldots \ldots \ldots \ldots \ldots \ldots \ldots \ldots \ldots . \ldots . \ldots \ldots 2$

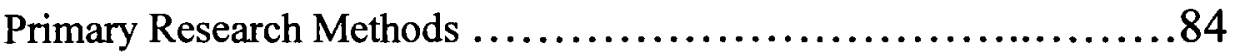

Research Analysis Employed ...............................91

Ethical Considerations ....................................93

Chapter Summary ..............................................94 
Introduction .96

I. Making GIS Available in Bahamian School to Improve

Pedagogical Standards ......................................97

Results on Educational Standards and Challenges:

Teachers' Perspective .98

II. Results on Educators and Students Attitudes towards some form of Technology in the Classroom ..................... 106

Discussion and Findings on Educators' Attitude towards Technology use in the Classroom ...

Discussion and Findings on Students' Attitude towards Technology use in the Classroom

Students Demographics and Attitudes toward the Use of Technology

Results and Discussion on the Importance of Future

Educational Developments

III. GIS as a Pedagogical Tool: A Sample Module

Module Rationale 132

Module Description 134

Web-based GIS Software Description 134

Design Considerations 136 
Motivation .................................................136

Infrastructure: Technical and resource aspects .................137

Curriculum Requirements and Students' needs:

Content and learning abilities ..............................138

IV. Discussion of Sample Module ............................. 139

Educators' Reasons for educating students about

Tourism in The Bahamas ...................................140

V. Sample Module Planning Guide .......................... 143

Module Overview ......................................143

Module Instructions ........................................ 144

Module Objectives ...................................... 146

Teacher Notes ......................................... 148

Student Activities ...................................... 152

Student Question Sheet ................................158

Icons Reference Guide Sheet ..............................159

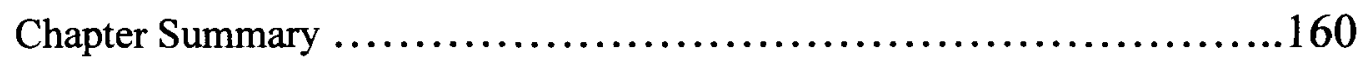




\section{CHAPTER FIVE: SOME CONCLUSIONS, OBSERVATIONS AND}

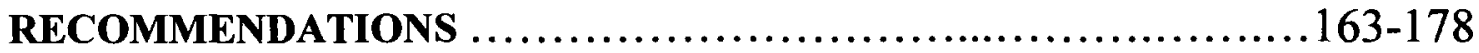

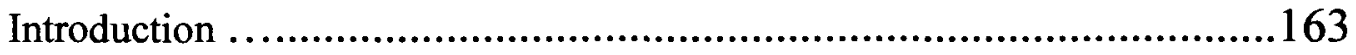

Strengths, Limitations and Challenges of Methods Employed ..............165

Limitations of the Thesis ....................................... 168

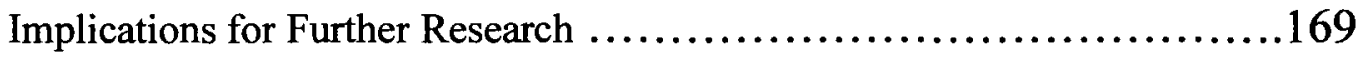

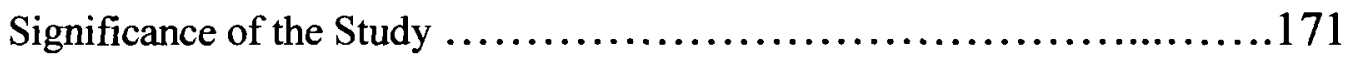

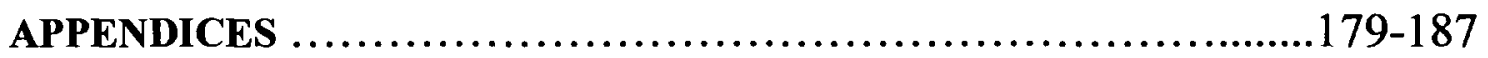

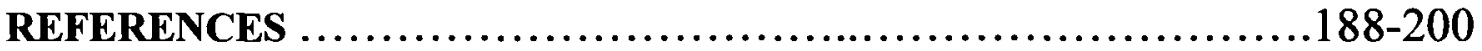




\section{LIST OF TABLES}

Table 1 The BGCSE Eight Point Grading Scale and National Average for the Examination over a five year period

Table 2 Teachers Perspective on Current Educational Challenges

Table 3 Teachers Rating of High School Graduates Academic Standard

Table 4 Reasons for Teachers Dissatisfaction with the Standard of Education in The Bahamas

Table 5 Common Themes and Total Number of Responses for Teachers Dissatisfaction with the Standard of Education ...........................104

Table 6 Total Number of Participants by Status ..................... 105

Table 7 Common Themes for Technology Use as a Pedagogical Tool: Educators' Perspective 108

Table 8 Educators Reasons for Technology Application ..................109

Table 9 Teachers Reasons for the Usefulness of GIS ...................110

Table 10 Total Number for the Age Range of Participants Surveyed ...........113

Table 11 Students Reasons for Technology Application by Gender .118

Table 12 Students Perceptions of the current Learning Environment .119 
Table 13 Students Satisfaction and Dissatisfaction with Traditional

Teaching Methods used ................................. 120

Table 14 Total Number of Responses for Technology Usefulness

Rating by Students ....................................122

Table 15 Priority Rating for Education Development and Total Number of

Teacher Responses for each one ............................126

Table 16 Common Themes provided by Teachers for the Importance of Educational Improvements .............................127

Table 17 Educators Reasons for the Importance of Educational

Improvements ....................................... 128 


\section{LIST OF ILLUSTRATIONS}

Figure 1 The New and Old Version of Benjamin Bloom's Taxonomy ........................................49

Figure 2 Characteristics of Geographic Information Systems

Figure 3 Howard Gardiner's Nine Multiple Intelligences ...................75

Figure $4 \quad$ A Map of The Bahamas $\ldots \ldots \ldots \ldots \ldots \ldots \ldots \ldots \ldots \ldots \ldots \ldots \ldots \ldots . . . . \ldots 0$

Figure 5 The Academic Standard Rating of Public High

School Graduates by Teachers Surveyed 101

Figure 6 Age Range of Teachers Surveyed and Level of Positive Response for Technology use

Figure 7 Percentage of Students and Rating Given for Technology Usefulness

Figure 8 Education Priority Rating given by Teachers Surveyed .............125 


\section{APPENDICES}

Appendix A Interview Questions and Inform Consent Document ...............179

Appendix B Cover Letter and Questionnaire ............................181

Appendix C Parental Consent Form .................................. 185 


\section{CHAPTER ONE}

\section{INTRODUCTION TO THE RESEARCH}

\section{INTRODUCTION TO THE RESEARCH PROBLEM AND CENTRAL ARGUMENT}

In the fall of 2003 the author began a long-time-dream career as a geography teacher in a government high school in Nassau, Bahamas, the nation's capital. The author was imbued with great enthusiasm and commitment to the profession and the drive to make a difference in the country's education system. Little did she know at the time that her entrance into teaching would coincide with a national teachers' protest and an education system that faces numerous challenges in terms of students' performance. The particular source of the country's education maladies and the best prescription to remedy them, however, engendered enormous disagreement among educators, citizens, and politicians. The issue of educational reform continues to receive a tremendous amount of attention and the Ministry of Education (MOE) continues to debate the implementation of appropriate measures that will refocus and re-energize teachers' efforts to improve student achievement; methods to increase students' interest in their education and to get parents more actively involved. The lack of students' interest and motivation to learn remain a critical concern for all major stakeholders involved in education. Students' lack of engagement in 
their education and lack of motivation to obtain an education are probably two of the major reasons why alternatives to education delivery should be made available.

The author's four year teaching experience left her with a profound sense of the enormous possibilities and challenges of education and an intense desire to better understand the factors that shaped the way political and policymaking institutions confronted the issue of educational improvement. As the author thought about this issue she realized that the major barriers to educational improvement are 1) an educational curriculum that is generally traditionally focused and fails to meet the learning styles of students; 2) a large number of students who are not motivated to learn; 3) parents who fail to play a role in their child's academic life and some who just do not know how to; and 4) teachers, who are major stakeholders when it comes to promoting student achievement who feel that their contributions toward educational reform are too often over-looked. These thoughts were an important basis for this research and motivated the author to present an alternative approach that will help improve teaching and learning in Bahamian public schools, using a methodology which included direct input from teachers as part of the research process.

While every country tends to bemoan its educational system, and many will say standards are falling universally, there is no reason to feel that improvements are out of reach. In fact many countries do better and it is quite possible to rapidly and effectively overhaul and improve the educational system in The Bahamas. The continued discussion of the problem and possible solutions are in themselves not enough: action is required in an attempt to address this national education issue, for eradication of the problems will take time to accomplish. 
From the outset of this research it was obvious who the major stakeholders in educational improvement were. Educators, Students and parents are the major stakeholders who must be involved in improving educational standards and in modifying the curriculum so that it caters to the needs of students and meets the demands of the twenty first century. Any approach that does not involve these stakeholders is likely to fail. The term educators are used to refer to education policy makers, principals and teachers. If one of the stakeholders in this educational relationship fails to play their part, then educational challenges that The Bahamas now experience is what will happen. Many parents neglect to play an active role in their children's education, and according to teachers and principals, the present education system fails to adjust its educational strategies and curriculum (Focus group discussions and interviews, 2008). As a result, there continue to be student-dropouts every year, students who are unable to meet graduation standards, and are ill-equipped to perform practically in the employment sector, and educational standards remain an issue of concern. There is no doubt that in order for any educational approach to be effective it is important that all stakeholders work in a cooperative manner.

For the purpose of this thesis a GIS can be described as a system which uses computers and software to develop, organize, store and communicate geographic knowledge. In simple terms, GIS takes the numbers and words from the rows and columns in databases and spreadsheets and puts them on a map. It is a computer system capable of integrating, editing, analyzing and displaying geographically referenced information (Malone et al., 2005 and Bernhardsen, 2002). The benefits that GIS can potentially bring to education are numerous: enhancing curriculum development with spatial reasoning, problem solving, data analysis, critical thinking, community involvement, teamwork and interdisciplinary real-world subject matter (Audet and Paris, 1997; Kerski, 2003; Meyer et al., 1999; Yen, 2003; Yuda and Itoh, 
2006). GIS technology and methods have transformed decision-making in society including in areas such as government, academia, and industry. Some educators consider GIS to be one of the most promising means for implementing educational reform, in terms of improving teaching and learning methods.

The Bahamas possess an adequate basic educational system by both national and international standards. The problem lies with the effectiveness of the education system in accommodating the learning needs of students in the twenty first century. If one were to generalize about the basic instructional model of traditional public education, it could best be summarized as a factory-style model where children are turned out much like a factory product of the 1920s (Callahan, 1964). The ideas of a teacher as the principal source and disseminator of knowledge and students as passive receptors of information with eager young minds fully attending are relics of a by-gone past. Today, with the rate at which information advances, the power of telecommunications, and the ubiquitous nature of computers (not to forget their low cost and ease of use), traditional instruction has been found to be more inefficient and ineffective than ever before. This is not to say that traditional methods are irrelevant, however, teaching and learning with computer technologies rather than about them can perhaps bridge the gap between traditional teaching and experiential learning. That is, it may provide a vehicle for a more practical and engaging learning experience for students.

Educators, specifically in the sciences, have been progressing gradually toward a model of instruction that emphasizes a hands-on, research-based learning experience in the classroom, typically referred to as inquiry (Greening, 2000 and Moffet and Wagner, 1992). Since 1962, with the development of the world's first operational GIS in Ottawa, Ontario, Canada (Briney, 2008, 
April 6), GIS has proven capable of providing this type of inquiry learning experience. There continues to be a debate among educators, policy makers in education and government and GIS specialists about the benefits that GIS presents for educational development and eventually economic prosperity. Richard Groot and John McLaughlin (2000) question why the field of education has yet to harness GIS as an analytical and teaching tool for research in the same ways as other fields. However, Joseph J. Kerski (2003) claims that the issue with GIS and education has primarily been one of curricular decision making, the prime hurdles being attainment of knowledge about the software by teachers and students, and how to manipulate it in ways that will promote better teaching and learning.

\section{RESEARCH RATIONALE}

The past several years have seen a rising concern over The Bahamas' 'failing' educational system. This includes both private and public sectors. This deterioration in educational standards and students achievement is being referred to as a national "crisis" with the potential to undermine our prosperity and our children's future. The underlying reasons for conducting this study have to do with the author having experience in the education system in The Bahamas, specifically high school (grades 10-12); and seeing the poor academic performance of many students, and their lack of interest and motivation to actively participate in the learning process, as well as the essentially passive nature of the Bahamian education system. The motivation for seeking to propose an alternative means of using GIS in the education system in The Bahamas was created by the Bahamas National GIS Center (BNGIS) initiatives to introduce the technology in the school system. This was therefore perhaps an opportune moment 
to develop a study on how The Bahamas' education system can potentially benefit from harnessing this technology as an educational tool, with the hope that more teachers will soon begin to recognize the growing importance of GIS in the world outside the classroom.

GIS was selected as the technology to be used in Bahamian high schools as a teaching and learning tool because 1) teachers from a few schools throughout The Bahamas have already been introduced to the technology; 2) the BGNIS has developed collaboration with the MOE in terms of advancing the use of GIS in schools, a proposal supported by the ministry because they have seen "skills improvement in students who have just been taught how to use the technology" (Personal Interview, 2008); and 3) initiatives have been taken to implement the technology in the government sector and other agencies. This may make the process of applying the approach proposed by this thesis much easier because teachers are gradually becoming familiar with GIS and the use of it is being promoted.

\section{The Purpose of the Study}

In industry, business and government the use of GIS is rapidly expanding. In education, despite the apparent potentials for student learning, the fact that GIS is not growing as quickly as expected is another concern. But how easy is it for non-GIS specialists to utilize this technology in education when at present the focus is not on using it to teach with, but rather teaching about it? How can barriers to the use of GIS by Bahamian teachers such as the lack of time, lack of GIS knowledge and inadequate availability of software and hardware be overcome? How can teachers without GIS training use the technology to teach their subjects (history, geography, mathematics), as well as create GIS-based lessons to teach, and execute all of their other 
responsibilities? It is these aspects that will guide the main theme of this thesis, which is to explore how using GIS as a mechanism to teach and learn with has the potential to help improve pedagogical standards by being a change agent, to complement and improve traditional educational methods. This includes the GIS technology capacity to actively engage students in and outside the classroom. "GIS is an enabling technology so that it is possible to teach both with it and about it" (Unwin, 1991, p. 82). It is the former mode which this study adopts.

The aim here is to explore whether using a hybrid approach will make GIS use easier and more useable for both teachers and students, without having to worry about the many barriers that presently prevent this type of teaching and learning with the technology to take place. The purpose is to emphasize the benefits that GIS can provide for the Bahamian education system. It is hypothesized that teachers, and students' age and gender, and students' grade levels and academic standing will affect their attitudes toward technology in general and GIS specifically. The fact that many of the teachers involved in this study are also parents was considered in terms of hypothesizing that this would make a difference with their responses on education standards in public schools. The design of this research is focused on the following questions:

The central question is: How can GIS help Bahamian high schools improve the ways in which teaching and learning presently take place when the technology is used as a pedagogical tool? There are three specific subsidiary research questions: 1) what are some of the major challenges of the Bahamian education system? This is supplemented by the question: what are some of the major concerns of educators and parents regarding the educational standards with which public high school students are graduating, 2) Why are improvements of educational standards important and necessary for The Bahamas?), and 3) What are some of the main 
challenges experienced by the Bahamian education system that teaching and learning with GIS can help improve when compared to traditional methods? The third research question also includes a sub-question about teachers and students attitudes toward technology use.

\section{The Extent of the Educational Problems and Central Argument}

In discussing the need for educational improvements in The Bahamas, one must have a full understanding of the extent of the major educational problems and concerns. Following local newspaper articles, news reports, debates, television and radio talk shows on the state of Bahamian education are not encouraging. The Bahamas General Certificate of Secondary Education (BGCSE) results from the high schools on students' achievement for 2007 and 2008 are now available, another $\mathrm{D}$ and $\mathrm{D}+$ national average (Assessment and evaluation division, 2007, August). Although it is argued that using GIS in the curriculum will help improve these results, this argument cannot be fully validated until the action proposed is taken, which is beyond the time frame for the completion of this study.

Many parents are not pleased with the academic achievement of their children and the measures taken to help them. There continues to be a major concern among teachers, education officials and parents regarding the alarming rate at which students are failing academically and the low number of students meeting the criteria to graduate. Many teachers are frustrated by students' lack of interest and motivation to participate in their learning. There continues to be a problem of students not being able to practically apply the knowledge gained in school in the employment sector. As a result, the MOE in The Bahamas is seeking ways in which they can address this national educational issue. In The Bahamas' existing education system, there is 
currently little or no use of GIS. The central argument here is that the use of GIS as a pedagogical tool can provide enrichment for The Bahamas' education system by presenting an effective approach to complement and improve the ways in which teaching and learning presently take place.

\section{RESEARCH STRUCTURE}

The thesis is organized as follows:

\section{Chapter One}

"Introduction to the Research" provides the central argument and research question to be answered, as well as three supplementary questions. It introduces the research topic in terms of why GIS was the technology of choice to be proposed in this thesis, what was the motivation behind conducting this type of research, its purpose and possible outcomes.

\section{Chapter Two}

"The Bahamian Education System and GIS and Education" provides the context of this research with a review of the importance of future educational developments for the country. This section presents a history of the educational developments and challenges over specified time periods, thus identifying some of the educational problems that the use of GIS as a pedagogical tool can help improve. It also addresses the question of whether the overall educational standard is an issue of concern for the country. It further discusses the importance of addressing educational challenges in order to improve standards and maintain economic progress. The first section of 
this chapter therefore gives a clear understanding as to how the challenges being experienced by the system can threaten the future educational and economic stability of the country by exploring the links between education and training, and economic development. The second section of chapter two explores how this thesis fits into the literature on GIS and education. It will also investigate the type of learning using GIS and related technology can offer when compared to traditional methods.

\section{Chapter Three}

"The Theory and Methodology" chapter examines the theories that support the general approach proposed by this thesis. The theoretical context provides educators with ideas and guidelines to better educate students. The methodology section provides a description of the study area, as well as gives reasons for the schools selected to participate in the study. This chapter provides an overview of the primary methods and secondary methods that were utilized for the data collection process.

\section{Chapter Four}

"Making GIS available in Bahamian High Schools to Improve Pedagogical Standards" presents the results and findings of the data collected. It discusses the findings and analyzes if the data collected support the arguments, hypothesis and objectives of this study. This chapter includes a sample module called: GIS as an Educational Tool, which demonstrates a practical example of using GIS as a pedagogical tool. This examines whether adapting this approach would make the use of GIS in education easier and more accessible for teachers and students. The sample module 
described was created using Microsoft Word 2007, ArcGIS Desktop Edition or ArcMap 9X, Mapping our World Website, and the Paint art program.

\section{Chapter Five}

"Some Conclusions, Observations and Recommendations" provides an overall assessment of the research. It reviews each chapter and discusses if they validate the arguments of this study. It evaluates whether the thesis objectives were accomplished and if the study's proposed approach was adequately supported by the main stakeholders involved in educational improvements. This chapter highlights some of the strengths, limitations and challenges experienced while collecting the data for this research and the steps taken to address them. It further discusses the overall limitations of this thesis; identifies implications for further research and this study's significance for the Bahamian education system and in the literature on GIS and education. Finally, chapter five provides specific and general conclusions. It also offers some suggestion as to how some issues can be addressed. 


\section{CHAPTER SUMMARY}

Chapter one provides a clear description of the overall objectives of the research. It gives the reasons for the author's motivation to conduct this type of research, as well as the arguments to be validated. This chapter briefly describes the goals it intends to achieve in regards to helping to improve students' performance and the overall standard of education in The Bahamas.

To initiate any change is an enormous task, but it is a task that must be undertaken because while the risk of failure is there, the consequences of not trying are worse. This research presents an alternative educational method that can potentially help address the educational issues The Bahamas presently experience. It explores the ideas, suggestions and feedback from the major stakeholders directly involved in the process of pedagogical improvements, in order to find out if they are receptive to toward this educational approach. 


\section{CHAPTER TWO}

\section{RESEARCH CONTEXT}

\section{INTRODUCTION}

A description of The Bahamas' education system is necessary to have an understanding of the developments and challenges it faces. Once there is an indication that educational standards are a concern for the country, it would be appropriate to discuss why educational improvements are necessary for ensuring a diverse and stable workforce for the future advancement of the Bahamian economy, and how the approach proposed by this research can help in this regard. This chapter examines the contextual frameworks within which this thesis is situated, that is, the Bahamian education system and the literature on GIS and education. The discussion in this chapter reviews the relevant literatures to illuminate the arguments and objectives of this study.

\section{THE BAHAMIAN EDUCATION SYSTEM}

Education plays a significant role in the development process of countries all over the world. This "progress requires the cooperation of people with different abilities, different experiences and specialized training, working together to produce a dynamic system which could be improved upon over a period of time" (Personalities in Bahamian education, 1992, p. ii). For a 
long time there has been an awareness of the defects of the inherited tradition and systems of education which have been implanted on Bahamian soil. Every ex-colonial country faces the inherent educational drawbacks and impediments of an alien system, in addition to coping with the problems of a developing country (White Paper on education, 1973 and Ministry of Education, 2004, August). The system introduced under colonialism was narrow, meager, illsuited and irrelevant to the needs of most Bahamians. With increased responsibility for its own education system and the steps taken to move to eventual nationhood, it was imperative that The Bahamas make a concerted effort to work towards a system of education which represented its own situation.

The standard of education which now exists in The Bahamas was a result of the "rising aspirations for economic, social and political progress and it is based upon the optimistic conviction that man, in this century of science, can move forward by leaps instead of steps" (White Paper on education, 1973, p. 1). However, a number of the same educational problems that existed under colonialism are still prevalent in The Bahamas' education system. The nature and extent of these current problems emerged during focus group discussions that were held with a total of 15 history and geography teachers at three public high schools in New Providence and a survey conducted among approximately 130 teachers from these same schools in August and December, 2008. One of the teachers' major concerns was the many educational challenges they are experiencing, especially at the high school level. These challenges include the lack of resources and preparing students for an examination that academically many of them are incapable of successfully writing. 
The development of these challenges are discussed by reviewing the history of education in The Bahamas divided into the periods 1950-1973, 1973-1993 and 1993 to the present, along with discussing some feedback gained from current educators, which will appear in the results section of this thesis. This chapter briefly touches on post-colonial theory to show how this sheds some light on this study in terms of The Bahamas's education system during colonial rule. During these periods, especially those prior to independence, Bahamian society underwent profound social and political changes which, in turn, had a major impact upon the development of education in the country. These time periods are significant because they signify some major developments and challenges that The Bahamas' education system experienced. The changes in education during these periods substantially impacted the quality and standard of education Bahamians received. The events that occurred during the periods 1950-1979 and 1973-1993 transformed many Bahamians' attitude towards education and its importance for the country's future advancement and stability.

The Bahamas' educational history and future improvements are important in order to understand the progress that has been made, and to examine the adjustments required for the further success of the educational system. It is hoped that knowledge of the Bahamian educational history will help avoid the repetition of educational mistakes made in the past.

\section{Developments and Challenges of Education in The Bahamas}

During the period 1950 to 1973 , the educating of black Bahamians was almost nonexistent. This was an era in Bahamian history where only a very few people, such as Lynden Oscar Pindling (first Prime Minister, 1967-1992), Paul Adderley, Cecil Wallace-Whitfield, 
Orville Turnquest (former Governor General) and Arthur D. Hanna (Governor General) had the opportunity to obtain an education at the Government High School (GHS), which had been established in 1925. It was these same GHS scholars who led the journey toward independence achieved on July 10, 1973. As the name implies, the government of The Bahamas owned one high School during the early 1950 's to the mid 1960 's. Student placements were extremely limited, so entrance into GHS was by way of an examination known as the Common Entrance Exam (CEE). In some cases, provision had to be made to accommodate the children whose parents were considered to be among the elite. However, the percentage of white and black individuals who were among the elite class is not available, but based on history it can be assumed that the elite status was highly dominated by whites. This further reduced the number of students who gained entrance as consequence of passing the entrance examination. Therefore, a total number of twenty students were accepted by open examination into GHS each year. This was the only black school at this time and was referred to as the 'black elite school.' Educational improvements in The Bahamas during the first two decades of the post World War II era, were slow and haphazard (Trainor, 1989). The educational changes that took place lacked direction and an underlying philosophical foundation.

The problems in education were also due to the absence of the sense of urgency and commitment by legislators and educational leaders. Additionally, colonial authorities such as professional educators from Great Britain, and members of The Bahamian House of Assembly, dominated by the white elites, all contributed significantly to the educational failures and must bear responsibility for vacillation, lack of commitment to programs, and perceptible arrogance (Trainor, 1989). British educators failed to develop a coherent education policy aimed at the Bahamian people and displayed a conceited and paternalistic attitude toward those individuals. 
They failed to identify or come to grips with the educational needs of the nation. Access to meaningful education was denied to the Bahamian masses for decades. This resulted in them being immobilized in their own country.

To satisfy the educational aspirations of the people and to see quality education become reality, adequate funding was required. In the early 1950s, The House of Assembly knew that their refusal to provide an adequate financial commitment for education would continue the second class status for the black population and would aggravate the ill will that grew among those long denied participation, and who were emerging from generations of relative vulnerability (Trainor, 1989). In The Bahamas, the acquisition of education for the general population did not become a high government priority until the late $1950 \mathrm{~s}$, and by this time it was evident that colonial rule was in decline and that Bahamian involvement in self-rule was inevitable. "The Bahamian educational system as it existed in the post-war period had its roots in the nineteenth century and had evolved, since the formation of the first Board of Education in 1836, into a government system serving a predominantly black student population" (Trainor, 1989, p. 173). The Board of Education was responsible for teacher training and for all primary schools. GHS, the only public high school, was not under the Board's supervision, but directly under the government and controlled by a board of governors. Private schools also existed at this time and those receiving government aid were subject to certain rules of the Board. GHS during the 1950 s was the only school that promoted the organization of a growing black elite which soon dominated education, politics and the professions.

Bahamian educators such as Carlton Francis and Rodney Bain who were trained abroad were a force to reckon with because of their incessant initiatives, suggestions and criticisms 
concerning the state of the education system in The Bahamas (Personalities in Bahamian education, 1992). As a result, Francis was "accused of insubordination and denied promotion" (Trainor, 1989, p. 175). Francis and Bain were prime examples of qualified black Bahamians employed in the lower levels of educational institutions, while white expatriate educators from the United Kingdom held the superior positions in education (Trainor, 1989 and Personalities in Bahamian education, 1992). Black leaders were deeply concerned as the recruitment of educators from Canada and the United Kingdom continued during the early 1950s. In 1955 recruitment was extended to include teachers from the West Indies. Prospective Bahamian teachers were offered bonded scholarships, which required them to serve in government schools for the same specified time as their scholarship. In addition to this, there were a few black Bahamians sent to foreign schools on government scholarships. A positive step was taken to improve teacher training in 1950 with the opening of a Teachers' Training College (TTC). However, this was short lived and the college closed its doors in 1957. Teachers were then sent to the United Kingdom for training.

In spite of the efforts being made to upgrade education, a large number of untrained teachers still existed in Bahamian schools. The advancement of education in the rural areas, better known as the Family Islands, differed in many respects from the two most populated islands, New Providence and Grand Bahama. The number of unqualified teachers on the Family Islands, was extremely high, which did little to improve the standard of education in the schools there. The two urban centers or nation's cities Nassau, New Providence and Freeport, Grand Bahama were given first priority when it came to educational development, one reason being because they accounted for more than fifty percent of the total population. Education officials 
were and still are faced with the task of providing education for a school population scattered over wide areas, which can be a challenge.

Many individuals used teaching as a stepping stone because it was not considered as a prestigious profession, especially when lucrative positions in other employment sectors gradually became available to black Bahamians during the late 1950s and early 1960s. Unfortunately, this led to the rapid turnover of teaching staff. However, statistics regarding the turnover percentage are not available. The resignation of teachers became a norm with 15 being recorded in 1952 and 1957 respectively (Trainor, 1989). Statistics indicating the total number of teachers and the number who resigned during this period are not available. In the 1950 s, the education system was characterized by the existence of poorly equipped teachers and the lack of any system for upgrading teaching skills (Ministry of Education, 2008). Overall the educational system in terms of morale and quality was probably at its lowest point in 1957. But black Bahamians saw a ray of hope with the emergence of the Progressive Liberal Party (PLP) in 1953 that held the view that a campaign for change was one that provided a voice for the black population.

There are many aspects of the history of education in The Bahamas that statistics do not disclose. These include the growing racial polarization, the dissatisfaction over low pay, the lack of opportunity for training, the large number of untrained teachers, the high resignation rates and the liability of teachers to dismissal if they were deemed troublemakers, or the poor quality of all but the most privileged schools (Trainor, 1989). In addition there was the slow growth in the percentage of school age population enrolled in schools and the amount of revenue allotted for education. Even though from 1955 to 1960 there were gradual increases in the expenditures on education, these were not adequate to meet educational demands. Nevertheless, there were a few 
reports that acknowledged the challenges of the education system between 1950 and 1960: The Hutchinson Report of 1952 and the Houghton Report of 1958. Although these reports were: "limited in scope, outlook and effect, they demonstrated a degree of concern for the failures of the system and recognized the need for change" (Trainor, 1989, p. 176).

The Hutchinson's Report of 1952 highlighted the intellect and attainments of Bahamian children. Hutchinson in his report defended the backwardness of a people. He argued that the low expectations held by British teachers for Bahamian students were due in part to a population so young from slavery (Trainor, 1989). Furthermore, Hutchinson in his report made it obvious that it was in the interest of the colonial system to maintain the subjugation of the black population in bondage by denying them the benefits of an education. Hutchinson noted that Bahamians lacked aspiration for higher education; they rejected vocational education and preferred literary education so that they could let others "know that they were educated." On the other hand, the most significant of all reports was the Houghton Report of 1958; it set the context for legislation that formed the basis of the Education Act of 1962, which has since been revised in 1996 (Ministry of Education, 2008).

According to Houghton's Report, there was a lack of genuine enthusiasm and demand for education among Bahamians (Trainor, 1989), an attitude that is still all too common. He stated that the feeling of resentment and frustration held among the poorer and darker skinned Bahamians was due to the belief that politically, socially and economically the odds were against them. Houghton mentioned that politics was becoming obtrusive in the field of education and strongly cautioned against the risks of partisan decision making concerning educational matters (Trainor, 1989). He also suggested the establishment of an affiliation with the University of the 
West Indies (UWI). The report also noted the issue of unqualified teachers and their training, the lack of a sense of continuity between primary and secondary schools, and the preoccupation with examination results. Houghton recommended the development of a more centralized education system, so that all educational laws could be brought under one Act. He recommended that all government endeavors should be controlled by a centralized board, and that grant-in-aid schools should be eradicated and that private schools should cooperate in achieving common educational goals (Trainor, 1989). In his report he further suggested that more emphasis be placed on practical subjects, better training of teachers, provision for inspection of schools, the revival of radio classes, and emergency training of teachers already in the classrooms (Trainor, 1989).

A new teachers' college was established in 1961. The establishment of the TTC was one of the many recommendations of Houghton Report which also led to the passing of the 1962 Education Act (Ministry of Education, 2008). Around the period of 1962-1963, the Family Islands remained at a disadvantage because emphasis was on consolidation and improvement in quality and not on expansion. "Indeed Houghton said that the construction of high schools in the Family Islands would be an extravagance" (Trainor, 1989, p. 178).

The Education Act of 1962 made provisions for: expansion of schooling, school committees, teacher training, and governance of the high schools. From this point on, it was distinctively clear that the "color bar" was excluded in public education. These educational changes were made precisely to allow Bahamian children to understand their rights and responsibilities as citizens, to actively contribute to the progress and welfare of the nation by the full development of their natural abilities and to earn an adequate livelihood as adults (Trainor, 1989 and White Paper on education, 1973). Progress in education in The Bahamas was explicitly 
tied to the needs of the economy. Houghton's report made a significant impact on changes that took place in the Bahamian education system; however information relating to where he was educated and trained is not available. This could be attributed to the poor documentation of the history of education in The Bahamas.

The Board of Education minutes and annual reports which were available until 1962 provided a clear idea of the difficulties, discontent and deteriorating nature of the educational system at the time. During the last years of the Board, vocational training, evening classes, summer school and radio broadcast classes were introduced with varying measures of success. Nevertheless, a number of these innovations were discontinued after a few years (Trainor, 1989). The topic of teacher training was a constant issue in these reports with the main point of contention being whether to train teachers locally or to provide financial support for training abroad. Although the local teacher training college was open, some training abroad still took place. Another question of concern was whether to continue to employ foreign teachers for positions as training masters or important headships positions at the preferential schools. Few Bahamians were able to gain positions as teachers or administrators. Only a limited number of Bahamians were trained and progress was sporadic at best, especially with the closing of the teacher's college in 1957 for four years.

In the mid-sixties, the social and political context in which educational development took place was one of discontent and progressively vocal antagonism to the state of affairs that existed at that time. These affairs were epitomized by socioeconomic and racial stratification, segregation, inadequate job opportunities for black Bahamians, especially those employed in the civil service, banking and business (Trainor, 1989). This painted an unpleasant picture under 
colonialism because blacks were treated as second class citizens by the colonial power, Britain. The Bahamas was not seen as a country owned by Bahamians. Independence gave Bahamians ownership of their country, one that a colony by definition, can never have.

Additionally, the founding of The Bahamas Union of Teachers (BUT) carried the political campaign into the realm of education, demanding a voice for teachers in their own destinies. However, for a number of years after its formation the union was not recognized by the Board of Education or Director of Education as a bargaining agent for teachers, but the BUT remained active. The union presented petitions and, in the early 1960s, took to the streets with posters to demonstrate against the deficiencies of the education system (Trainor, 1989). There were many individuals, including Gerald Cash, a Board of Education Member until 1962 who strongly opposed the hiring of white teachers in predominantly white residential areas reluctant to accept black teachers. Prominent black leaders such as Cash saw educational progress as critical to The Bahamas' further development. Despite the fact that they were accused of supporting quantity over quality, their major demand at the time was for the rapid expansion of education especially in the Family Islands, which had previously been over-looked by educational authorities. They also argued for the need to Bahamianize the teaching profession (Trainor, 1989 and Personalities in Bahamian education, 1992), a situation that continues even today.

In 1964, after internal self-government was achieved, all education laws were combined into one Act and government education was controlled by the Board of Education. In 1964, "with the establishment of a cabinet form of government, much power was vested in the Minister of Education, and the Board ceased to exist" (Trainor, 1989, p. 178 and Ministry of Education, 
2004, August). The year 1964 also saw the beginning of a transitional phase in the educational system of The Bahamas. This lasted for three years, and led to positive changes, even though many of the old problems lingered (Ministry of Education, 2008). The education system became affiliated with UWI, and more public service students and prospective Bahamian teachers were able to study abroad as the availability of scholarships increased.

The changes that occurred on the educational map provided hope and a sense of prosperity for Bahamians who had been outsiders under a system that was racially driven. Bahamians developed a new outlook when it came to education as the number of schools between 1962 and 1966 increased by thirty and the student population rose from 19,314 in 1960 to 29,762 in 1966 (Trainor, 1989). Nonetheless, the number of untrained teachers-they accounted for about $60 \%$ of the total teaching population during the 1960 s-still remained high.

It was shortly prior to The Bahamas' election on January 10,1967 , that many Bahamians realized that it was only a matter of time before the nation achieved Majority Rule which would grant black Bahamians full political power. "When that time came with the election of 1967 and the further consolidation of PLP power in 1968 it became equally obvious to most that independence could not be delayed many more years" (Trainor, 1989, p. 179). Majority Rule ushered in the opportunity for all Bahamians to have constitutional, political, social, cultural, educational and economic rights, rights that were not readily available before 1967 (The government commemorates majority rule, 2007). This marked the first time that the country would be led by an individual of African descent.

The political change in 1967 had far reaching effects on the development of education in The Bahamas. The government embarked upon a determined course of assessment and 
reassessment of its educational system by requesting the expertise and assistance of both local and foreign experts (Ministry of Education, 2008). So with great enthusiasm and support from the majority of Bahamians the government proposed to carry out many changes. Education benefited immensely from the plans that emerged. Improvement of the education system became a top priority for the government with an increase in educational expenditures from 12.47 percent of the Gross Domestic Product (GDP) in 1960 to 20 percent in 1970, an increase in the number of schools and a corresponding increase in the student population from 19,314 in 1960 to 48,000 in 1976 (Trainor, 1989).

Another significant event in The Bahamas that contributed to continued educational improvements was the country's Independence in 1973. Throughout the period 1973-1993, efforts were made to formulate educational policies and to chart the course that future educational development would take. One of the most important of these educational developments was increased support for The Bahamas Teachers College and the San Salvador College which contributed to a remarkable increase in the quantity of trained teachers (Ministry of Education, 2008). The number of trained teachers increased from 1187 in 1974 to 2126 in 1979 (Trainor, 1989). Also in 1973, the College of The Bahamas was established, which would later become the premier institution of higher learning in the country. The government's attempt to Bahamianize the education system started to come to fruition at the primary school level in the mid-seventies and further materialized with the consolidation of higher education in the College of The Bahamas (COB), which was responsible for technical education, teacher training, instruction for A-level examinations and conducting Associate degree courses (Trainor, 1989). 
Along with the practical accomplishments of the new state, efforts were made to devise educational policies and to plan the future course of educational development for the country. The White Paper of 1973, the Maraj Report of 1974 along with speeches by Pindling, the Prime Minister at this time and various ministers of education all outlined significant plans and policy changes for education. The White Paper guaranteed equal opportunity for all Bahamians, foreshadowed $\mathrm{COB}$ as the premier institution of higher learning, and outlined the policy of Bahamianization to be accomplished by 1976-1977 (Trainor, 1989). The colonial system of education was discarded and a system that promoted Bahamian values, ideals and culture was put in its place. The Maraj Report was comprehensive and included recommendations on all phases of Bahamian education, the most important one, being the need to develop an overall philosophy for educational development. The report further proposed a national development plan for education and the diversification of the economy through promoting sectors such as agriculture and fishing. From this point on Bahamians were now educated to meet the needs of their own society, rather than to serve the needs of a colonial system.

During the 1980 s, educational contributions and recommendations provided by the Prime Minister and the Minister of Education often took an explicitly partisan approach, generally praising the present government and condemning the past. One disadvantage of this approach was that specific educational policy proposals were frequently forsaken, in favour of party political action. Pindling encouraged self-help and community action, endeavors that can be seen in retrospect to have placed the Family Islands at a disadvantage by compelling them to pay for improvements that were regularly provided without direct cost to their New Providence counterparts (Trainor, 1989). Here it can be seen that the unequal distribution of educational resources and developments under the colonial system was perpetuated. 
Furthermore, Pindling stressed the necessity to alter the aspirations and priorities relative to manpower and occupational needs in order to provide a realistic base for economic diversification. Pindling asserted the view that trained teachers were an absolute necessity and that the support of parents was required if children were to make the most of their education. There was no doubt that the educational efforts implemented after independence were a remarkable success. But in order to continue to move forward, a thorough examination of both the strong and weak points of the education system was required. This also included new ideas on how to address pre-existing problems.

Education under the Colonial system excluded Bahamians from the country's decision making processes. The PLP, the governing party during the 1980s made a major contribution to liberating The Bahamas from this educational bondage. A view that is widely held by all political affiliations is that this government "deserves immense credit for its successes in the field of education during the early years of majority rule and independence" (Trainor, 1989, p. 182). The effort to accommodate the increasing student population was one of its most worthy achievements, along with the consolidation and decentralization of education locally. Other accomplishments of the PLP government included its endeavor to Bahamianize the system, establishing $\mathrm{COB}$ as the premiere institution for higher education and the launching of high schools in the Family islands, which ended the exclusion of those islands from educational benefits that they had so long been denied (Trainor, 1989). These benefits included resources, trained teachers and the construction of schools.

One of these noted accomplishments of the PLP government that attracted criticism was the attempt to Bahamianize the education system. Some education officials did not view 
Bahamianization as an unrealistic goal, but criticized its implementation in terms of preparation and selection of teachers. They claimed that teaching qualifications had been lowered in order to achieve Bahamianization. This belief was held by some education and political officials because during the late 1960 s and early 1970 s there were not sufficient trained Bahamian teachers available; therefore, hundreds of teachers were imported from the United Kingdom (Trainor, 1989). It was not until the 1980 s that two teacher training colleges gradually began to meet the need for teachers at the primary level. It was argued that Bahamianization of the system should not have been focused at the primary school level because it created deterioration in writing skills among other problems (Trainor, 1989). One approach suggested in terms of Bahamianization was to strive to implement it at all levels of the education system as a long-term goal. Other weaknesses in the system were the failure to develop a philosophy of education, the perpetuation of attitudes that have a negative effect on educational development, and the politicization of education.

Education in The Bahamas became the prime vehicle for promoting the development of individuals and the nation as a whole. The period 1970-1989 saw profound change and significant activity (Trainor, 1989). In the education system, remarkable growth has been made in the areas of enhancing access by the general population to schooling, the gradual increase in financial provisions made for improvements, the enhanced efforts for teacher training and the notable upgrading in the student-teacher ratio. John M. Trainor (1989), referred to this progress as "generations of lost time that have been reclaimed overnight" (p. 172). Regardless of these advances in the Bahamian education system, major problems, still remain, even in areas that have undergone transformation, and new setbacks have surfaced which place constraints on continued educational development. For example, Trainor (1989) argued that the attitudes of 
both parents and educational policy makers placed obstacles in the path of educational improvement. Trainor (1989) stated that between the years of 1981-1989 the education system "has seen a loss of momentum, a diminishing of the enthusiasm and activity of the years of euphoria that accompanied black majority rule and independence ..." (p. 172). The dynamism has vanished, and in order for progress in the education system to be restored and genuine improvements made, a new direction for the educational system was required.

The educational system between 1993 and 2008 has had its share of successes and challenges. The highlight of this period was the introduction of The Bahamas General Certificate of Secondary Education (BGCSE) in May, 1993. This was the first time that Bahamian students could write a national examination whose development had the direct input of local educators. Until 1993, all national assessments were developed in the United Kingdom by specialists in Cambridge and London and administered by examiners from Cambridge and school Inspectors of the Board of Education. Before 1993, students who were viewed as ambitious from selective high schools were registered for the Cambridge General Certificate of Secondary Education (GCE) Ordinary Level (O’levels) Examinations (Sumner, 1995). Only a small percentage of students graduating from high school wrote these examinations, as the curriculum on which they were based was not available in all high schools. A major argument to support the introduction of the BGCSE was that it created more equal opportunities in education by enabling a wide cross-section of high school students to obtain some national or international achievement certification upon completion (Sumner, 1995). The introduction of an examination of this magnitude was a necessary step in the continued growth and development of The Bahamas as a nation and to gain greater autonomy over all matters relating to education. The introduction of 
this examination marked a significant advancement in testing and evaluation strategies in The Bahamas (Sumner, 1995).

The education system experienced many changes and challenges from 1993 to 2008 . As government's changed in 1992, in 2002 and then again in 2007, this also meant changes in the Minister of Education, Director of Education and other education policy makers. Each new government brought their own plans for education, and existing educational developments were adjusted or removed. Does this pose a setback for educational improvements? Opinions on this topic vary, but according to some current teachers, "it does because when you think education is moving one step ahead, when the government changes, a hold is placed on many developments, which puts improvements of the system at a standstill" (Survey, 2008).

By 2004-2005, there were 245 schools in The Bahamas, which included public and private schools and public preschools (Ministry of Education annual report, 2004 and 2005). This total does not include private preschools, post secondary and tertiary institutions. Although specific figures are unavailable the number of public schools has increased since 2005. Of the reported 245 schools, sixty five percent or 159 were public schools, fully maintained by The Bahamas government (Ministry of Education annual report, 2004 and 2005). The educational system also made improvements in terms of catering to special needs students, including those with severe cognitive and physical disabilities, behavioural challenges as well as pregnant teens (Ministry of Education annual report, 2004 and 2005). In 2004-2005, there were ten schools for this specific purpose (Ministry of Education annual report, 2004 and 2005). According to the Ministry of Education 2004-2005 annual report, there were approximately 3234 teachers and administrators employed in public schools. Ninety eight percent of these teachers possessed a 
degree and a teaching certificate or diploma in education. This was the largest number of trained teachers recorded in the educational history of The Bahamas. The education system sought to employ only teachers who are certified. All expatriate teachers must possess a minimum of a Bachelor's Degree and a Teaching Certificate (Ministry of Education annual report, 2004 and 2005).

In 2005-2006, the Ministry of education was faced with a major industrial action by teachers nationwide. This industrial action was to demand better conditions for teachers in terms of: increasing the beginning and maximum scale salaries of teachers, reviewing the current curriculum and modifying it as necessary, sabbatical leave for teachers, and adjustments of maternity and paternity leave. As a result, a collective bargaining agreement was signed on July 7,2006 . The process to achieve a collective agreement for teachers was referred to by teachers as an historic juncture, one that was arduous and long, but worth it in the end.

\section{Colonialism}

One cannot underestimate the impact that colonialism had on the educational history of The Bahamas, as well as many other countries. The problems that The Bahamas' education system now experience in terms of content delivery and curriculum structure seem to be a hangover from the colonial period. In this respect, what is most distinctive about postcolonial theory is its particular conception of power. "Terms such as 'representation', 'discourse', and 'textuality' all converge around a shared sense that knowledge is a critical resource in the exercise and contestation of political authority" (Barnett et al., 2006, p. 155). Colonial rulers realized that knowledge or education was an ideal means for them to maintain this type of power over the Bahamian people. 
From a social perspective of postcolonial theory, it is obvious that colonialism had a great influence on the mindset of Bahamians during colonial-rule. They used education as a means to politically and psychologically oppress mainly black Bahamians. This is why Franz Fanon in his writings said that he strongly understood the struggles that countries under colonialism experienced and the psychological dimensions of colonialism on the people of these countries (Barnett et al., 2006). He further states that the wealth, culture, and civilization of the West were built, due to the exploitation of non-European countries (Barnett et al., 2006), like The Bahamas.

Countries like The Bahamas have had a colonial-form of educational system and cultural system imposed upon them some decades ago, and according to this theory many of these patterns persist. For example, the education system in The Bahamas generally focuses on teaching information and history many students cannot relate to, which leaves students ignorant about the rich history surrounding the development of their own country. From the author's experience of teaching geography in Bahamian schools, many students ask, "Why is it important that I know this information after I leave high school?" This is because the curriculum for geography barely focuses on the geography of The Bahamas, and the same can be said for so many other disciplines within the Bahamian education system. It generally places emphasis on content and not the application process of learning. This is one reason why many students are uninterested in learning because they do not see the relevance of the information they are being taught. There are a number of other challenges that current educators experience with the Bahamian education system, but this will later be discussed in chapter four.

Postcolonial theory suggests that even though The Bahamas is not now under colonialrule, the ideologies, identity, political and cultural power of this system are still reflected in many 
aspects of this country (Barnett, et al., 2006). The effects of this system can still be seen in many of the parents that experienced colonialism because many of them never saw the importance of completing a basic education; therefore, they now struggle with instilling the value of education in their children. Education is a powerful vehicle that not only has the potential to transform educational development, but also the mindset of the Bahamian people, especially students towards the importance of obtaining a meaningful and useful education. The country needs to design an education system that can be called their own, one that is a representation of the culture and history of the Bahamian people. To validate the central arguments presented in this research, it is necessary to discuss that educational standards in terms of the curriculum, student achievement and methods of instruction used are concerns for The Bahamas.

Are Educational Standards an Issue in The Bahamas? An Educator's Perspective

Words such as 'inefficient', 'ill-equipped', 'poorly-skilled' and 'inadequate sham' are used by the public and businesses to describe the students and the educational standards with which they are graduating from high school. The general public, business owners and other stakeholders continue to complain about the training and capabilities of the majority of students who leave high school. According to the Prime Minister of The Bahamas, Hubert Ingraham, The Bahamas government will ensure the expansion of technical and vocational education in schools due to the "direct response to the uniform complaint from the private sector that the majority of high school graduates are not adequately prepared to assume entry level positions in their organizations" (The Tribune Newspaper, 2008, January 17, p. 10). The national average of the BGCSE examinations continues to be at a ' $D$ ' average, which is totally unacceptable (Table 1). 
Table 1: Shows the BGCSE Eight Point Grading Scale and National Average for the Examination over a five year period (The government of The Bahamas official website)

\begin{tabular}{|c|c|c|c|}
\hline LETTER GRADE & LETTER STANDARD & NATIONAL AVERAGE & YEAR \\
\hline A & \multirow{3}{*}{$\begin{array}{l}\text { Denotes an } \\
\text { "above } \\
\text { average" } \\
\text { Score }\end{array}$} & D & 2004 \\
\hline B & & $\mathrm{D}+$ & 2005 \\
\hline C & & $\mathrm{D+}$ & 2006 \\
\hline D & $\begin{array}{l}\text { Average/fairly good grasp } \\
\text { of subject }\end{array}$ & D & 2007 \\
\hline$E$ & \multirow{3}{*}{$\begin{array}{l}\text { Reflects a } \\
\text { "below } \\
\text { average" } \\
\text { score }\end{array}$} & $\mathrm{D}+$ & 2008 \\
\hline$F$ & & & \\
\hline $\mathbf{G}$ & & & \\
\hline $\mathrm{U}$ & $\begin{array}{l}\text { Unclassified/lacks a basic } \\
\text { understanding of the subject }\end{array}$ & & \\
\hline
\end{tabular}

Source: BGCSE final report, Examination and Assessment Division, Ministry of Education

The BGCSE examination is taken by every public school student regardless of ability, so it is only natural for the nationwide results to reflect a low grade average on an eight point scale. Another point to consider is that this examination does not "pass" or "fail" students. It generally tests students for what they know and in a few cases for what they can do in areas such as: geography, history, carpentry, technical drawing and biology where coursework is a requirement. The BGCSE examination generally caters to the academically inclined students. Many teachers and citizens question the structure and effectiveness of this examination and claim that it does not cater to varied abilities and learning styles of all students. Former President of The Bahamas Union of Teachers (BUT), Ida Poitier-Turnquest, stated "the basis of education is the curriculum and we can put many things in place, but if the curriculum is not meeting the needs of our 
children, nothing will happen" (The Journal Newspaper, 2008, August 21, p. 1). Therefore, no matter how many resources are invested for educational developments, it will be useless until the main causes are addressed: the structure of the curriculum and the BGCSE examination.

Another area of concern is the low percentage of students who meet the criteria to graduate at the end of each academic year. There are less than fifty percent of students at the twelfth grade level nationally, who achieve the 2.0 grade point average (GPA) standard to graduate (The Nassau Guardian Newspaper, 2008, June 20). However, data on high school graduates by the Ministry of Education (MOE) were not retrievable, but concerns shown by Education Minister, Carl Bethel in this regard indicate that the number of twelfth grade students meeting the graduation criteria is not acceptable (The Freeport News, 2009, June 10). According to top educational officials, this number is falling. For example, in June, 2008, principals from three government schools in New Providence released their graduation figures to the media. From school A, of the 240 students in grade twelve, only 40 percent or 96 achieved the standard to graduate (The Nassau Guardian Newspaper, 2008, June 20). School B recorded that 38 percent of high school seniors received diplomas, 23 percent received certificates of attendance and the remaining 39 percent left high school without anything to show for it (The Nassau Guardian Newspaper, 2008, June 20).

Then there is school C, which reported that of the 219 twelfth grade students enrolled in the traditional curriculum, 141 or 64 percent received diplomas, while 78 or 36 percent got certificate of attendances (The Nassau Guardian Newspaper, 2008, June 20). The vice principal of school $\mathbf{C}$ added that 11 students in the school's work-based learning program also received diplomas. The implementation of this program was an initiative that this school introduced in 
order to cater to those students who were less academically inclined. Students were required to work at various businesses for three days each week, and attend school on Mondays and Fridays. According to a senior education official, due to the positive results other selected schools will replicate this program in the up-coming 2008-2009 school year (Personal Interview, 2008, August).

For many of the jobs in the skilled and technical areas, companies are forced to employ foreign labour, due to the inability of Bahamians to meet the demands of the workforce. The demand for sufficiently prepared job candidates in The Bahamas simply exceeds the supply. The present Minister of Education, Carl Bethel stated, "this is a sad reality that the country's education system has faced for years, however, his ministry will endeavour to do all it can to improve the situation" (The Nassau Guardian Newspaper, 2008, June 20, p. 1). He added that this is a long-standing problem that has been around from the very inception of education in The Bahamas (The Nassau Guardian Newspaper, 2008, June, 20).

In the Education Minister's budget communication in June, 2009, he stated that high school students at government institutions nationwide will soon be required to satisfy a new criterion proposed by the MOE before they receive their high school diploma (The Freeport News, 2009, June 10). Bethel said that for the 2009-2010 academic school year the Department of Education (DOE) plans to introduce the High School Diploma program (HSDP) for all students who would have successfully completed 12 years of schooling. He said the purpose of this new initiative is to help establish benchmarks in academic achievement, social development and preparedness for work or college and encourage students to attain at least the minimum standards of education (The Freeport News, 2009, June 10). This indicates that the MOE realizes 
that the structure of the current system and standards used to evaluate the performance of all students is not effective and adequate in examining students' full potential. It further supports the arguments of this thesis as to why changes in educational approaches need to be adjusted in order to adequately prepare those students who will not or do not intend to attend an institution of higher learning. It is evident, that more than $50 \%$ of Bahamian students who leave high school go directly into the workforce (Personal Interview, 2008 and Focus group discussions, 2008). Therefore, the graduation criterion for students can be the same, but it has to consider those students who are technically and vocationally gifted and not just the academically inclined. In doing so, it provides students with the basic qualifications to obtain employment.

Bethel added it is hoped that this new policy will provide students with a credential that provides meaningful information to a prospective employer or for college entrance and recognize their personal academic achievements. He further stated that his Ministry is cognizant of the need to ensure the delivery of quality education and by establishing higher standards for graduation; students will be adequately prepared to face the challenges before leaving high school (The Freeport News, 2009, June 10).

Are educational standards an issue in The Bahamas? To obtain a comprehensive and accurate response to this question, the views of educators are important. For years in The Bahamas, the general public has blamed teachers for the poor academic standards with which students were leaving school. It is now the twenty first century and The Bahamas possess one of the most highly trained teaching services in the Caribbean. Yet educational standards are still a critical concern among parents, key stakeholders, and most particularly teachers. According to the two principals and vice principals from the three schools mentioned earlier, education 
standards are declining because the school system is now faced with students who are not applying themselves and preparing themselves for life after high school and beyond the borders of The Bahamas (The Nassau Guardian Newspaper, 2008, June 20). Teachers added that "even though student attitudes play a major role in explaining poor levels of achievement and standards, the structure of the curriculum and the lack of parental involvement significantly contributes to this educational dilemma" (Focus group discussions, 2008 and Survey, 2008).

The lack of parental involvement in their children's education is a problem that has plagued The Bahamas for decades, especially within the last ten years. There is substantial research which supports the view that when parents are involved in their children's education, children tend to succeed better both in academic and behavioural terms (McGuinn, 2006, Omrod, 2005 and Bloom, 1981). However, when parents fail to play an active role in the educational development of their children, then a country's educational system suffers in terms of quality. Teachers continue to complain about parents neglecting to pick up their children's report cards, not attending PTA (Parents, Teachers Association) meetings and their refusal to purchase a $\$ 15$ or $\$ 20$ textbook (Survey, 2008 and focus group discussions, 2008). Hence, they view the increased lack of parental involvement in education as one of the critical contributors to students' poor educational achievements.

It is indisputable that Bahamian parents need to be accountable too for the educational standard of their children. But then again one must consider the fact that many of the parents of these children have been educated under the colonial system, therefore, they may not see a need to question the effectiveness of the current education system. How do you engage parents in the 
educational process of their children when the social and economic backgrounds from which many of them come are deprived?

A major factor that contributes to students receiving a quality and well-rounded education is the structure of the curriculum. The BGCSE as a national means of evaluating the educational standards of students is in the author's view, inadequate. Howard Gardiner (1983) firmly states that by understanding each student's strengths and weaknesses in each intelligence, we can help students become more successful. The BGCSE curriculum does not cater to the diverse learning needs of students and the examination is an inadequate measure of students' potential. If the curriculum does not meet the needs of students and the needs of the country, then the same problems will resurface, no matter what initiatives are implemented.

The structure of the curriculum needs to be re-evaluated and modified in order to accommodate the diverse learning preferences of students and to allow them to display their full potential, academically or technically. According to both education officials interviewed, more than 50 percent of Bahamian students are technically inclined; therefore the education system should cater to these students. Otherwise, how will Bahamians be able to cope with the competitive pressures of globalization when more than 50 percent of students graduating lack the basic skills of reading, writing and arithmetic? (Smith, 2008). In the workforce of the twenty first century, basic literacy and numeracy are two critical skills to possess.

A leading contributor to breakdown in educational standards starts with the curriculum structure at the pre-school and primary school levels. Educational psychologists such as Jean Piaget have shown that this is the most critical educational stage for students in terms of cognitive development and skills (William, 1974). This includes providing students with all the 
available possibilities to reach their potential in an environment that is conducive for this to take place. Til V. William (1974) refers to Jean Piaget who says, "the principal goal of education is to create men and women who can "do more than" simply reflect on what other generations have done, men and women who are creative ... and who are discoverers" (p. 417) [SIG]. High school is also an important stage in the education of students as it prepares them for life or further studies (Hall et al., 2002). It is at this stage of education where students should be given wider options that would enable them to discover their abilities and interests and to direct them in appropriate ways to achieve their expectations.

But despite the drawbacks, Minister Bethel firmly stated that his ministry is on a mission to implement initiatives to help address the problems, and committed to improving the quality of education in the country. Some of these educational initiatives include the implementation of reform initiatives to address core subjects (Mathematics, English, and the sciences), on the job training, after school programs and a standardized assessment (Smith, 2008). A more academicskilled and not solely academic approach to education will give all students the opportunity to maximize their potential. A well-rounded education system is one that caters to the diverse academic levels of students, whether those levels are more academic oriented or skilled oriented. The ministry of education, principals and teachers cannot address or solve the educational challenges and educational standard of students alone. This will take a concerted effort at a national level, which includes parents, the religious community, cooperative organizations and the general public. The qualitative evidence presented in this chapter confirms that tremendous problems in the Bahamian education do exist, therefore, supporting the argument of proposing an alternative means to help address some of these challenges. 


\section{The Importance of Future Educational Developments}

The quality of the human resources of a nation is often judged by the proportion of

literate population it possesses. It can be argued that educational improvements are a necessity if a nation aspires to achieve growth and development and more importantly sustain it. But what benefit is it to a nation to maintain a highly literate population, if many of these individuals are unable to effectively apply this literacy in practical and meaningful situations? This is why the rich and developed countries of the world have started imparting selective training and education programs in order to meet the technical demands of the twenty first century (Barro et al., 2002 and Raisian, 2002). These countries realize the importance of having a very high literacy rate and a productive human resource, but not one without the other. This is why it is necessary to examine the importance of future developments in education in order to demonstrate how using alternative educational methods like the one this thesis proposes can be beneficial in this regard.

The Bahamian education system has a well-trained and skilled teaching population, however, if they are not fully involved in decision making and policy formulation to develop education and improve standards, schools will continue to produce poorly-skilled students. This is not to say that students are not being provided with a standard education or schools are not producing literate students, but the fact that the present system has to be restructured and modified can no longer be ignored. There are clearly major structural problems with the educational system in The Bahamas and the introduction of GIS as a pedagogical tool cannot solve all of them. It can however make two major educational related contributions: 1) its use can lead to a better learning environment for students; and 2) the application of GIS to a number of sectors in both government and the private sector in The Bahamas can have a positive result in 
terms of planning and development. If GIS applications are adopted in the school system, then some of the skills that students learn can be practically applied when they enter the workforce. It is these aspects that this section of the thesis will focus on in exploring the argument as to why educational improvements are important and necessary for The Bahamas.

Education and training play a direct role in both an individual's progress and a country's advancement. An appropriate equation might read: education policy makers + teachers + an engaging education system + parents $=$ quality students. All of these individuals play a vital role in both educational improvement and the country's further development. Education policy makers and teachers must work as a cohesive unit and collaborate in order to design and achieve an education system that actively engages students, and accommodates their individual needs. In this equation, parents play a critical role in students' performance and standard, school attendance and instilling in them the importance of education, not just for oneself but also for the nation's economic well being.

\section{Educational Priorities and Improvements in The Bahamas}

"The world's most successful economies over the past two decades have given a high priority to education, skills and training as vital factors in their economic success" (Ashton and Green, 1996, p. 11 and Raisian, 2002). As much as 24 percent of the National Budget is allocated to education (The Bahamas Guide, 2008). The government has made a major effort to develop its education system, making education available to all Bahamians at no direct cost, regardless of their financial status. Nevertheless, the quality and standard of education remain a concern for many stakeholders involved in educational development. The quality of education includes the 
textbooks, teachers and curricula which are the major components of the school environment; they strongly influence the relevance of education to the needs of the society and the learner. Is the present education system in The Bahamas preparing students so that they can compete in the global economy? Looking at the structure of examinations, curriculum guides, students' performances both academically and technically and the diversity of the economy, suggest that this is not the case. Rote learning is the major characteristic of the education system, which does not sufficiently prepare students to perform in an extremely skill-focused era.

If one measures success in education by what children learn and what they can do with that knowledge and skills acquired, then public education in The Bahamas has been stalled in a long-standing educational malaise. It has been argued by many international economists and educators that cognitive skills and practical skills are basic skills that should characterize all learning and these are the ones required to generate prosperity in the twenty first century (Hall et al., 2002). Even though more priority needs to be placed on education, these improvements have to reflect what benefits they will provide for student achievement and motivation in the educational process. In this way the educational approach that this study recommends could help provide the Bahamian education system with the means to address some of the problems it is encountering. In educational improvement, an appropriate form of technology should be used to achieve the aims of education and to promote its quality and competency (Mungazi, 1991). This also involves devising new curricula and teaching methods.

Evidence collected in this study shows that teachers are concerned about student achievement and what they can do to get students more involved in the educational process (Focus group and survey, 2008). Many teachers state that they are aware that addressing these 
problems would mean restructuring the system. However, based on educators, students and concerned citizens' feedback on the state of education, it is important to reiterate that the approach proposed by this thesis can only help make a small educational contribution to the changes that are very much needed.

\section{The Linkage between Education, Training and Economic Performance: In the case of The Bahamas}

The thrust for educational development in The Bahamas must be seen in the context of the enormous social and economic problems that are inevitable when a country fails to adequately invest in educating its human capital. When it comes to educational reform and the level of priority that it is afforded, a natural starting point is to ask, 'why is education so important?' Gary S. Becker (2002) says that "human capital is the most important part of the economy, and human capital in a large part is produced by formal education" (p. xviii). Furthermore, the importance of education has grown in recent decades, so has new technology for delivering it because of its significant role in economic growth. Becker (2002) believes that considerable growth in the economy will come from increases in human capital, which in turn stimulates technological change. If improvements in education are made over time, then productivity might increase over time, resulting in economic growth. In this regard, it would be naïve for a nation not to recognize the important linkage between improvements in education and training and economic growth. According to Robert Barro (2002), both quantity and quality have an effect on growth. He further states that the quality of the outcome variables is a reflection of educational quality, which most notably has effects on economic activity. It is essential that 
students be provided with an education leading to economic growth and eventually to increased diversity in the economy.

The modern economic environment places more of a premium on education, training, and other sources of knowledge than was true fifty years ago (Becker et al., 2002). No economy can succeed without substantial investment in human capital. Of course, machines, and other physical capital are important. However, alone they are far from sufficient to produce growth because skilled workers and managers, and innovative entrepreneurs, are needed to operate complicated machinery, to produce efficiently, and to develop new products and processes. Economic success in life comes mainly by achieving success in education. This is why educational development must include elements that are critical to developing a viable economic system (Mungazi, 1991 and Raisian, 2002). Human capital, which includes education, is of great importance in modern societies because it is a determinant for economic growth. The creation and maintenance of a more productive and diverse economy, makes higher demands for skilled manpower (Ashton and Green, 1996). This is why it would not be in the best interest of The Bahamas to place more priority on the economy than on education, because each is critical to the development of the other.

For years now, there has been a call for the reform of the Bahamian economy as it is widely agreed that the economy is too reliant on two sectors, namely Financial Services and the Tourism Industry that are externally based and extremely vulnerable to external conditions (Ministry of Education planning and research unit, 2008). The first Gulf War in 1991, the second Gulf War of 2003, the September 11, 2001 terrorist attacks and the current economic recession in the United States (U.S.) are incidents that have affected the economy of The Bahamas. It was 
during the Gulf Wars that many Bahamians feared the United States would reduce its exports of goods and resources. Then there were the nine-eleven terrorist attacks and the current economic recession of the U.S. that impacted The Bahamas's economy especially given its high reliance on the tourism industry as its major source of income. The Central Bank of The Bahamas gave warning about the economic situation (The Nassau Guardian Newspaper, 2008, September 30), "with the deepening and broadening of the financial sector crisis in recent weeks, the short to medium term uncertainty for the Bahamian economy increases with implications for employment, inflation and government revenue performance" (p. A9).

With persistent concerns about the future of the tourism industry, many economic analysts have been calling on the government to lead the way in the diversification of the economy (The Nassau Guardian Newspaper, 2008, November 7). However, Prime Minister Hubert Ingraham said, "while it sounds appealing, that is not a realistic option for the country right now. He further stated that the reality is there is no diversification that could prevent what is happening today". Ingraham added that "the government supports the sentiment to diversify the country's economy, but the reality is that right now the dominant factor in the economy is tourism" (The Nassau Guardian Newspaper, 2008, November 7, p. A10). 


\section{GIS AND EDUCATION}

\section{Pedagogical Benefits that GIS can potentially provide for Educational Improvements in Bahamian Schools when compared to Traditional Methods}

Technology has been the catalyst for change at numerous schools and continues to be, along with the increasing understanding about its teaching and learning contexts. However, for the past decade there has been a major push toward integrating some form of technological resource into public school classrooms because of the promise it offers such as: cheap, accessible and instantaneous information; enormous potential for interactivity and media-rich communication; and powerful educational tools it will put at the service of students. Mouza, (2002), Geisert and Futrell (2001) argued that if teachers were to revolutionize their classrooms with technology as a teaching and learning aid, ordinary students would make massive gains. Wherever illiteracy is a problem, it would gradually be dissolved, and students would have new vistas opened to them. Moreover, education policy makers hoping to improve the quality and quantity of student learning have become increasingly willing to make major investments of fiscal and human resources into hardware, software, and training (Kumar, et al., 2008). There have been several major comprehensive reviews of the literature on GIS and education and the benefits this technology presents for educational development (Kerski, 2001 and 2003; Linn, 1997; Audet and Paris, 1997; Unwin, 1991).

Incorporated into each of these studies is a component for rethinking the role that GIS and technology play in classroom environments. These studies (Kerski, 2001 and 2003; Linn, 1997; Audet and Paris, 1997; Unwin, 1991) suggest that providing a more practical approach that 
can complement present educational methods might change teachers views on using this technology as a tool with which to teach. With technology advancing at an increasing rate, it is necessary to understand how it shapes or influences the learning process. As an ever-present component in higher education pedagogy, more empirical evidence is needed to demonstrate the connections between students' preferences for learning and the use of GIS technology in high school settings. This section will explore GIS and related technologies and their role in the classroom.

\section{A Traditional Education System}

Traditional teaching is characterized by the teacher being the controller of the learning environment. Power and responsibility are held by the teacher who plays the role of instructor (in the form of lectures) and decision maker (in regards to curriculum content and specific outcomes). This type of learning environment regards students as having 'knowledge holes' that need to be filled with information. This is partly because the traditional ways of gathering knowledge provide not only a familiar way of looking at reality but also a comfortable foundation for learning information. Learning is chiefly associated within the classroom and is often competitive. The lesson's content and delivery are considered to be most important and students master knowledge through drill and practice (such as rote learning). Content need not be learned in context (Theroux, 2002; Johnson and Johnson, 1991). The most common seating arrangement used by the traditionalists is rows. In this type of classroom setting when do creativity, discovery, collaborative and student-centered learning come into play? 


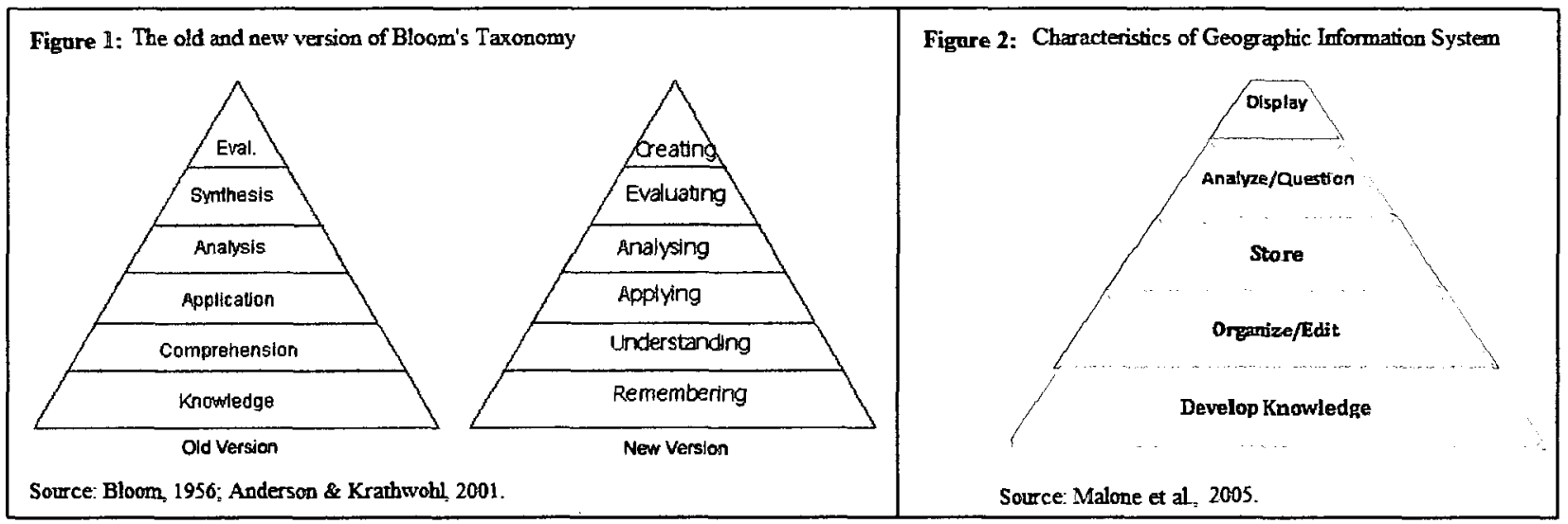

Education systems, including the one in The Bahamas, generally use Benjamin Bloom's taxonomy (Figure 1 and Figure 2) when writing instructional objectives. But how often do teaching and learning go beyond the first stage of Bloom's taxonomy? Many educators involved in this study stated, "not too often because it is becoming increasingly difficult to accommodate all of the diverse learning needs of students in one lesson" (Teachers' focus groups, 2008 and surveys, 2008). According to an education official, "many teachers are still focused on lecturing and too much teaching is at the recall level. Students learning need to focus more on cooperative learning, literacy and numeracy" (Personal Interview, 2008). When one considers Benjamin Bloom's (1956) taxonomy, traditional methods of teaching and learning predominantly use the first level (remembering) of this taxonomy and in few cases might attempt the second level (understanding) (Figure 1), which is not being disputed, but other levels in the taxonomy need to be used more often to cater to the learning needs of other students. Traditional methods to learning provide students with content information and generally require them to recall information learnt by answering questionings based on content given to them.

Also, from reports and feedback on the BGCSE results, school based exams and students' job performance it is known that students tend to perform poorly on questions and tasks that 
require them to think, analyze, synthesize, evaluate, critique and apply information learnt. Many students feel intimidated when they encounter tasks (academic or job-oriented) that require them to utilize higher level thinking skills (applying, analyzing or evaluating) (Bloom, 1956; and Anderson et al., 2001). Typically, teaching in The Bahamas' education system has focused on the passive learner where students are expected to learn and repeat back information.

There is no doubt that traditional emphasis on education will have to shift as young people steeped in the technological environments become impatient with less powerful and diverse tools and knowledge techniques (Jackson et al., 2009, April 6). But even with these types of students, there is a disconnection between traditional methods and new advancements in technologies that needs to be recognized and accommodated, and GIS as a pedagogical tool can help make this possible. There is no doubt that traditional teaching and learning methods are effective, but only to a certain extent. Advancement in technology continues to occur, therefore, educational institutions, especially high school education need to reflect these changes because traditional methods alone can no longer provide the standard of education that is necessary.

\section{An Education System that utilizes GIS and related Technologies as a Pedagogical Tool}

The first and foremost goal of any technology used in education, including GIS, should be to improve and complement the teaching and learning methods of teachers and students and not to assess the competent use of the technology. There are numerous reasons in terms of the benefits that GIS as an educational tool can provide for education, but the three most commonly cited are 1) spatial data analysis can provide students with new ways to understand and learn about phenomena through interaction with dynamic visual representations; 2) it can bring 
authentic inquiry activities into the classroom; and 3) it can provide students with the opportunity to develop fluency with visual representations of data, quantitative data analysis, and qualitative data unique to the various disciplines. This type of classroom provides more room for students to inquire about what they are learning, constructive and discovery learning, and caters to individual learning preferences.

Consider Figure 1: Bloom's Taxonomy and Figure 2: Characteristics of GIS, which show the stages of Bloom's taxonomy and characteristics of GIS. Both of them are headed in the same direction in terms of the level of student achievement. GIS by itself caters to diversity in learning because it provides students with a range of options to complete a task. Furthermore, even if it is a cooperative group activity, each student can select an aspect that meets their needs: researching the information, editing the data, writing a report, inquiring or critiquing, presenting the information, or developing a visual or graphic representation of information learnt. So if teachers were provided with the opportunity to use this technology as an instructional tool, they might be able to: 1) improve the traditional methods of teaching and learning, 2) accommodate the learning preference of students in one lesson and at the same time ensure that there is a thorough understanding of content information, and 3) achieve curriculum objectives with a more innovative approach.

In the influential document of the National Center for Geographic Information and Analysis (NCGLA) Core Curriculum, Goodchild and Kemp (1990) further rationalize that the use of GIS in education is beneficial because 1) it is a key tool to analyze the environment and solve problems, particularly at the local scale, 2) it enhances student interest in geography and related subjects, and 3) GIS is an attractive technology capable of motivating students in a variety of 
careers. Tourism and fishing are two major economic activities in The Bahamas, both of which depend on environmental maintenance to some extent for their continued growth. Teaching students with GIS allows students to practice applying skills learnt to make effective decisions in terms of planning and development whether for the environment, education or their local communities.

A GIS has a lot to offer education, particularly in more student-centered classes where students are active participants (Audet and Paris, 1997). One of the main objectives behind using technological resources in education should be to examine whether it brings change to teaching methods, students' performance, participation and motivation to learn. Does the use of technology in a classroom lesson change students' attitudes towards learning is a study conducted in the United States by Anthony Girasoli (2006). It involved thirty six, 15 and 16 year old students from tenth grade classrooms. Qualitative data from this study concluded that when technology is utilized effectively to support a lesson, it appears that it can increase students' selfefficacy. More importantly, there appears to be a link between students' technology self-efficacy and their academic self-efficacy.

It is possible that technology, situated in a classroom lesson to increase academic selfefficacy, may be able to increase students' academic performance and provide them with an authentic learning experience. Authentic, practically applied learning challenges students to take a more active role in their own education, as they assimilate a strong theoretical knowledge base within the context of material that they can work with in real life (Girasoli, 2006). The use of technology as an alternative approach in educational does not mean that traditional educational methods become outdated; rather, technology will complement such methods and maximize 
contact between teacher and student. Evolving teacher roles from lecturer to facilitator will support the shift towards authentic learning through using technology as an educational tool, a shift that will be neither easy, nor quick. In discussing the context in which this research is situated in terms of the Bahamian education system and GIS and education, it is important to also mention some of the challenges teachers face with using GIS and related technologies.

As a result of technological advances in society, the options for learning in and outside the classroom have broadened tremendously. There have been many of arguments about the advantages and disadvantages of the use of such technologies in the classroom. One major argument seems to be focused on the results from hybrid classrooms compared to just the traditional setting. Hybrid classrooms incorporate characteristics of both the traditional and online classroom settings. In an article titled Wiring the Classroom, Stannie Holt of InfoWorld claims, "along the way, computers are changing the typical classroom from a traditional factorylike model into something more open, flexible, and self-guided, with multiple sources of information and authority" (Okolo and Naidoo, 2005). With the combination of World Wide Web access and face-to-face interaction, hybrid classrooms give the student the best of both worlds (Okolo and Naidoo, 2005). It is not being inferred that this type of learning will guarantee excellence in student learning, but it gives the individual options on when and how they want to learn.

On the other hand, in terms of knowledge construction and application, traditional settings restrict the type of learning a student experiences. There are great differences in the ways in which people construct knowledge, and there are equally large differences in the ways in which knowledge is constructed in different domains (Okolo and Naidoo, 2005). Hybrid 
classrooms are the future and eventually these will prove to be more effective than traditional setting of learning. However, if hybrid classroom is found to be a hindering learning method in the future, then taking another look at this choice and conducting a more thorough investigation in what is being advocated would be necessary.

Overall, however, despite the potential benefits this technology presents, GIS has made only limited in-roads into schools. GIS technology has reached a state of maturity and accessibility that makes the prospects for its use in classrooms more promising than ever. The consensus of participants involved in GIS and education related studies was that GIS significantly enhanced their teaching and learning environments (Kerski, 2001 and 2003; Audet et al., 1997; and Meyer et al., 1999). The technology created myriad opportunities for students to participate in real world, spatial problem solving. From their examples it was learnt that introducing GIS into schools is likely to encounter unanticipated and formidable obstacles, which can spell the end unless teachers are determined and motivated. This is why teachers' attitude is a vital factor when it comes to technology use in the classroom (Tsitouridou and Vryzas, 2003).

\section{The Challenge with GIS Advancement in Education: How can GIS be accessible and useable for Teachers?}

Education today is faced with the challenge of adapting to an environment of ever increasing technological advances. The challenge for educators is to utilize this technology and related ones in ways that facilitate the highest level of learning outcomes. The educational community has growing concern about the effectiveness of technology such as GIS, CD-ROM, 
videotapes, multimedia presentation software, World Wide Web (WWW) discussion forums, and the Internet to meet the needs of students when utilized in the classroom (Lukow, 2002). Thus, it can be said that while technology use in the classroom is pervasive, improving learning through the application of any technology should be the goal.

According to some studies, powerful new technologies exist that can enhance instruction and learning, yet these new technologies are not being widely used by $\mathrm{K}-12$ public school teachers (Wiburg, 1997). Teachers are not readily choosing to incorporate technological resources into their teaching even though these new resources have been empirically shown to facilitate student interactivity (Hardin and Ziebarth, 1995; and Owston, 1997), increase mental functioning (Conlon, 1997), and promote social interaction (Kagan and Widaman, 1987; Sharan and Kussell, 1984; and Slavin, 1983). Why then, are teachers not readily using these resources in the classroom?

According to research conducted in 2004 by the Geographic Data in Education Initiative (GEODE), more teachers would like to utilize GIS in their classroom. However, their major request is that the technology be designed or made easier and more useable to get started. The introduction of any new technology can create problems for educators, especially if much attention has not been placed on how the technology can complement and improve the present ways in which instructional delivery is taken place.

Apparently, GIS has not been adopted in the K-12 classrooms in the United States (US) at a rate that the Environmental Systems Research Institute (ESRI) and geography educators had once hoped (ESRI, 1998 and Fitzpatrick, 2002). This is due to a number of impediments experienced when teaching and learning about GIS, which can be addressed if more emphasis is 
placed on using the technology as tool to teach and learn with, the approach which is being employed by this study. Fitzpatrick (2002) noted that ESRI's goal in 1992 was for K-12 educators to be the largest single group of users of GIS by 1996, a goal still not achieved. The key reason for this slow pace of GIS use in schools, according to Bednarz and Audet (1999), is that no exemplary models for using GIS in education exist.

The curricula in geography education focus on how individuals observe, conceptualize, analyze, and evaluate information from a spatial perspective (Fredrick and Fuller, 1997). Three types of technology that can provide this spatial dimension have been identified: exploratory systems such as Atlas CD-ROMS; database systems such as GIS; and simulation systems such as National Geographic's Weather Machine (Fitzpatrick, 1990). Of all these database systems, GIS has been recognized as critical for the use of computer-based technology in geography education (Bednarz and Audet, 1999; Keiper, 1999 and Kerski, 2001). Yet it is still not being harnessed in the field of education as expected.

After reviewing a number of academic studies written on GIS and education, it became obvious why the technology was not fully embraced in education, which was largely due to numerous hurdles experienced by teachers because the focus was on teaching about GIS. Cuban (1986) stated that less complex options need to be explored and developed in order for GIS to be more easily accessible to more teachers and students. Only then will the K-12 educational system see a significant increase in GIS use. It was only after reading GIS and education studies conducted by Kerski, 2001 and 2003; Myer et al., 1999; Unwin, 1991; Audet and Paris, 1997 to explore the barriers that hinder the pervasive and easy use of GIS in education, that it was evident there was a possibility to investigate an easier and useable way of using the technology. 
Furthermore, it is vital to mention that all of the following studies focused on teaching about GIS and not with it. Two qualitative case studies focusing on K-12 and middle school performed by Meyer et al. (1999) indicate that the critical barriers are access to appropriate hardware, and time (to learn the GIS software and time in the curriculum to incorporate GIS as a learning experience). On the other hand, research conducted by Kerski (2001 and 2003), which encompassed questionnaires for teachers, experiments and case studies that included three public schools in metropolitan Denver, Colorado, USA, specify that obstacles included lack of time to develop GIS-based lessons, inadequate training support, complexity of the software, limited hardware and software, and the pressure to teach a given amount of content during each term. Unwin (1991) further states that some of the chief challenges with GIS and education, which surface from the study he did included students struggling with learning the details of the software and providing and maintaining a sufficient number of hardware devices. Moreover, Audet and Paris (1999) in their study, which used questionnaires, field observations and interviews as the principal data sources, signify that software and hardware incompatibility, proficiency in GIS and lack of time and GIS training were cited as the major constraints.

The above commonalities among these studies identify the major hurdles experienced by teachers who taught or attempted to teach about GIS in their classrooms. All of the teachers involved in the above mentioned studies complained about lack of time for preparation and to develop GIS-based lessons, even though they had a week or more of support to develop GIS lessons. Clearly, GIS is not the type of tool that a teacher can implement into the curriculum as soon as it is obtained, nor can it be easily expanded in the curriculum. Results from a study conducted by Kerski (2003) showed that teachers felt that the lack of time to develop GIS-based lesson plans was the chief challenge to using it in the classroom. This suggests that alternative 
approaches to utilizing the technology in classrooms must be considered. One of the main reasons why many educators are of the view that GIS poses an educational challenge is because "almost all the reported educational effort has been directed to teaching about GIS with very little work reported in which it is used to assist learning in some other area" (Unwin, 1991, p. 82). David Unwin (1991) further stated that one of the main reasons behind the many challenges educators face with GIS has to do with the way the technology was introduce in education in the first place. There is no clear consensus of GIS place in the education system, the geography curriculum, its content or the appropriate pedagogic approach.

According to one study, many of the detailed issues of content, sequence and approach can be resolved through a clarification of GIS main purpose in education, particularly in choosing an appropriate balance between teaching the technology (learning about GIS) and application (learning to teach with GIS) (Kemp et al., 1992). Education will continue to experience the above mention problems with GIS until research that focuses on both the teacher and the student is undertaken. In other words, until studies examine the key factors on how K-12 teachers can use GIS to enhance instruction delivery and how learning with GIS can help improve student achievement and involvement, the technology will be under-utilized in the school system in the ways that it can be.

"GIS is a very rapidly expanding and changing technology, which also happens to be fairly expensive to deliver" (Unwin, 1991, p. 82). For the education system, this creates major problems of resource provision. However, there are a number of excellent low cost GIS available, including web-maps, online atlases with easy access and open source educational software where teachers do not have to pay a license fee. While some teachers have found 
desktop GIS programs and lessons to be useful in teaching and learning about GISs and geographic concepts, web-GISs provide a new and potentially easier opportunity for incorporating GISs in education. The technological changes taking place in web-based and 'cloud' computing are altering this situation. Until now teachers wanting to use a GIS in lessons have had to devote much class time to teaching the technology (Audet and Paris, 1997). While the fundamental educational objectives remain relatively consistent over time, the reality is that educational needs are constantly changing as well as the technology to support them (Mackaness, 1994). That is why it is important to focus on the needs of the students in order to meet educational standards, and find ways to expose students to new technologies while supporting those fundamental objectives. These new web-based technologies will help make the use of many of these resources in education viable.

The reality is that most teachers cannot take the time needed to adequately learn the software and create lessons on top of their regular teaching duties, which means an alternative approach to using GIS must be adopted. This thesis is arguing that teachers do not need to have detailed knowledge about GIS in order to learn how to use its tools to help improve teaching and learning. In the case of The Bahamas in its teacher education bachelor's degree program, teachers are required to complete at least two technology related courses, one that involves using technology in the content area. However, this program has been improved since 2004 because the College of The Bahamas (COB), the country's major institution of tertiary education is about to gain university status. So an approach to advancing technology use in the classroom can be achieved by making it mandatory for all education majors at $\mathrm{COB}$ to complete at least two courses in this regard. 
In this thesis, the importance and use of GIS and related technologies in education is not centered on the technology but on its ability to help students to better understand how to apply concepts taught in their subjects by using it as a tool with which to learn. For example, GIS technology uses querying tools to question and evaluate data, but students using GIS as a vehicle with which to learn, students can query content that is unique to the discipline being taught. They are learning how to become more active participants in their learning experiences, rather than passive recipients. Lessons are constructivist, reformist, and interdisciplinary in nature, emphasizing teaching with GIS in a content area, rather than teaching about GIS in a GIS course. In this regard, sole emphasis is being placed on using GIS concepts and techniques for students to learn with. The availability of web-based resources is making this a reality with a less challenging experience for both teachers and students.

Using free Web services despite having no GIS education, have permitted millions of people to perform operations that were very recently known and used only in the closed community of GIS, and this progress ushers in a new age of information integration and the harmonization of the wide variety of the world's diverse collections of geospatial information (Jackson et al., 2009, April 6). GIS and related technologies interoperability enables educators to think about data as a vast Web resource whose application components are easily discoverable, assessable and accessible. Web-based technologies have removed barriers such as incompatibilities between diverse systems and lack of software imposed on organizations, business and education systems from taking advantage of these resources. In cases where Bahamian teachers need data that are not readily available by The Bahamas National GIS Center (BNGIS), capabilities of improved web-based data are more available and efficient to assess. 
The movement toward open access of GIS-related information and data on the internet is supported because it provides ways to build a better connection between the real world and the digital world. The Geomatics and Cartographic Research Centre at Carleton University is contributing to the science of geospatial interoperability in a number of ways. This open source and open standards cybercartographic atlas framework are integrating geospatial information from a wide variety of online sources to produce a number of cybercartographic atlases on a variety of topics of interest to society (Jackson et al., 2009, April 6). A cybercartographic atlas is a metaphor for all kinds of qualitative and quantitative information linked through location (Jackson et al., 2009, April 6).

GIS and related technologies and application will experience a remarkable transformation due to the adoption of open standard geospatial Web service interfaces and encodings (Jackson et al., 2009, April 6). This approach holds great promise for the future of chained Web services, sensor webs, geospatial semantics, and online catalogs for data, "but there is no guarantee that this promise will be fulfilled" (sensor webs, geospatial semantics, and online catalogs for data). The question is, can the institutional will, in academia and government be found to make changes that enable societies around the world to make the most of these new tools? (Jackson et al., April 6, 2009).

The recent development of Arc Internet Map Server (ArcIMS) provides one potential solution to some of these challenges. An integration of GIS capabilities with internet technology, this web GIS provides an application with which standard GIS operations can be performed over the Internet without the need for local software (Longley et al., 2001; Xue et al., 2002). This new technology offers schools a way to incorporate GISs into curricula by providing some of the 
basic functionality of a full GIS, as well as the appropriate data sets, in a way that is accessible via the Internet without the need for GIS software or data on local computers (Green, 2001a). ArcIMS can be accessed from most Internet-accessible computers, allowing students and teachers the ability to access a GIS from inside and outside of the classroom. The interface of ArcIMS is less complex than the multiple windows and menus of a full GIS such as ArcView, thus making it easier for novices to use. It is hypothesized here that the user-friendly nature of ArcIMS potentially makes it simpler for both teachers and students to learn to use a GIS, and therefore is less intimidating and time consuming for educators to teach. This opens up the world of GISs to not just Bahamian teachers, but thousands of others, including their students, who otherwise would not have the time or resources to learn and teach using a full GIS such as ArcView, and thus has the potential to bring GIS one step closer to becoming an integral pedagogic tool used in secondary education.

To study and test the feasibility of ArcIMS as a pedagogic tool, the program was used to create The Tahoma Virtual Atlas, a model virtual physical geographic community atlas. The atlas was integrated into secondary science curriculum in the Tahoma School District in Washington. The use of this web-based GIS and others solve if not all, many of the problems that hinders the easy use of this technology by teachers. Currently ArcIMS offers limited capability compared to ArcView, but for some who just wish to use a GIS as an educational tool and not devote precious time to learning the technology of a GIS, the benefits of an easily accessible local atlas with a simple interface are more appealing.

A lot has changed in regards to GIS and how schools can get access use to the technology. Therefore, it is recognized that some of the studies on GIS and education cited 
throughout this study are dated, but are still relevant to the situation being discussed. The technological changes taking place in web-based sources are quickly modifying the situation of using technology in schools. The fact that this is taking place and will continue to cannot be ignored because it presents implications for educational development. Teachers can now access information through the web without possession of expensive software and hardware, which makes the technology easier and more useable. There is much that is not known about web-based GIS and other forms of web-technologies, especially in terms of how successful they would be in exploring the approach this thesis is proposing, but it must be recognized that web-based materials are available, which increases the possibility of using GIS in schools.

The overall goal of education should be to generate and lead development, whether it is social or cultural (D'Oyley et al., 1994; Bloom, 1981). However, when an education system does not view each child as an individual who learns distinctively, then it has already failed in its pursuit for academic success. This means that alternative educational approaches should be used if educators' focus is to develop knowledge and skills in students (Bloom, 1981). The notion of knowing that new educational technology is seductive, and using it in many cases shows no enhancement in learning or transformation of the education system (Bednarz, 2000), formed the context to address the questions of: In what ways can using the techniques of GIS help improve teaching and learning? How can the use of GIS enrich The Bahamas' education system? Some studies question the type of teaching and learning that take place with the use of GIS, when compared to conventional methods. G. L. Salinger (1995) asks, "what insights does GIS allow that the other ways of learning do not? What is GIS going to allow in education that we cannot do in other ways?" (p. 24). Yet others investigate the potential and actual role of GIS in education and generally in educational development (Bednarz, 2000). 
Students using technologies with which to learn presents a new way of making them understand and appreciate the ways of spatial thinking. For geographic educators the most important and powerful arguments for incorporating GIS into the curriculum is its purported ability to enhance spatial thinking and application skills, and the ability to have students actively engage in learning, not only in geography but a variety of other disciplines. On academic grounds, GIS should not be perceived as a technology for geographers, since potential benefits exist for virtually every science that that has a spatial or graphic content (Unwin, 1991). GIS as a pedagogic tool has the ability to help improve and develop the diverse learning skills of a larger student population, when compared to just teaching the technology. It would allow teachers to start with GIS software that is less demanding of memory and speed (Meyer, et al., 1999); and help address the frequent lack of appropriate software. This is an approach to educating students that is supported by Gardiner's MI theory because it recognizes that students do possess different learning styles. The fact is GIS in education has to complement existing teaching priorities of teachers, and not be a separate entity if it is to be successfully used for students learning. The important thing is that students are passionate about technology, so education systems should use this as a vehicle to motivate them and get students more involved in their learning. 


\section{CHAPTER SUMMARY}

To justify the purposes of the research, this chapter described and collected relevant knowledge and information from literature in the areas of: 1) the Bahamian education system, and 2) GIS and education. The chapter started with an historical description of the developments and challenges of education in The Bahamas from 1950 to the present. It also looked at the influence that technologies like GIS can have on economic development. To provide more focus on the role that GIS can potentially play in student achievement and helping to improve standards, the chapter included details to show where this research fits into the literature on GIS and education, the educational benefits it provides, as well as the challenges that have been experienced with the use of the technology.

The Bahamas has journeyed a long way and has achieved considerable success when it comes to the development of education, but it still has a long way to go. Classrooms continue to be over-crowded, and too many novice teachers continue to resign. Teachers' on-going struggle to obtain study leave to upgrade themselves, or to transfer to other departments in the government sector is a major concern. Teacher shortages continue in critical areas such as Mathematics, English Language and the Sciences, and lack of parental involvement is a continuing problem. Trainor (1989) warned educators about the possible consequences arising from the high interest placed on examination results. With a country so fixated on examination results, so many students are left at a grave disadvantage because the education system does not cater to the large percentage of the student population that is generally technically and vocationally inclined. The following chapter describes the research's theoretical context and how it was designed and carried out. 


\section{CHAPTER THREE}

\section{RESEARCH THEORETICAL BACKGROUND AND METHODOLGY}

\section{INTRODUCTION}

It is argued here that technologies such as GIS have the potential to help improve practical and theoretical skills in students because the technology provides an alternative teaching approach for teachers to use. There are a number of theoretical and empirical concepts that support the use of methods that would provide a more engaging learning experience for students. From these, four major theories have been selected from which to develop a theoretical and conceptual base. These are: Constructivist learning theory, Discovery learning, Inquirybased learning theory and Howard Gardiner's (1983) multiple intelligences. This chapter therefore begins with an examination of these four theoretical perspectives and how they support the use of technologies like GIS. It is followed by a review of the research design which includes: the data collection techniques and analysis process utilized for the study. This chapter also discusses the analysis process and ethical considerations included during the course of the research. 


\section{THEORETICAL CONTEXT}

Constructivist learning theory or constructivism, in its most reduced form, is interpreted in the field of education as a class of learning methods, where students construct their own knowledge, with the aid of a teacher-mentor and resource rich environment (Greening, 2000; Aulls and Shore, 2008). When considering the passive nature of The Bahamas' education system where students are taught large amounts of information in preparation for examinations or other forms of assessment, constructivism recommends that students be more active participants in their learning. In this case, the theory suggests that students will develop lifelong learning abilities; a learning experience that will remain with them beyond the examination process, one that would provide them with skills that can be applicable to their everyday lives (Greening, 2000; Aulls and Shore, 2008). "Learning is an activity we have to carry out ourselves ... it is the process that allows us to build up skills in acting and thinking as a result of our own experiences ..." (Von, 1997, pgs. 397-398). The central concept of the constructivist view of education is that greater emphasis needs to be placed on the broadening and development of problem solving and critical thinking skills, rather than simply on the memorization of lessons (Greening, 2000). It holds the position that teaching methods should be focused on understanding and application of subject content, and not just place emphasis on the memorization of information (Aulls and Shore, 2008).

Constructivism is a theory of learning that supports student involvement and encourages them to learn subject content through participation in an environment that promotes inquiry. It argues that knowledge is meaningful and lasting when it is constructed by the learner alone from his or her own experiences. This theory supports any educational approach where the learner is 
highly active in knowledge construction because when knowledge is actively constructed and interpreted it is remembered longer (Aulls and Shore, 2008). But then that leaves the question: What is conceptualized as knowledge? Knowledge includes but is more than the result of information processing efforts; it has the purpose of helping the individual cope in the world of experience, rather than being limited to a goal of furnishing a representation of a world as it might exist apart from us and our experience (Von, 1995a). Many well-known educators and psychologists such as John Dewey, Jean Piaget and Lev Vygotsky support inquiry on constructivism due to its effectiveness in educational practices, particularly in the areas of mathematics, English language and the sciences (Aulls and Shore, 2008).

Discovery learning theory argues that students should discover their own learning experiences, rather than be passive recipients. This connects with constructivism because through discovery learning, students are better able to construct knowledge that is unique to their ways of understanding. When students are provided with opportunities to construct their own knowledge, the learner's depth of understanding of that knowledge becomes greater (Aulls and Shore, 2008). The theory promotes the idea that students learn best by discovery and the learner is a problem-solver who interacts with the environment (Bruner, 1967). Research suggests that when students are engage in learning that reflects familiar aspects of their cultural surroundings, learning becomes a meaningful and everlasting experience for them (Bruner, 1986). Jerome Bruner (1986) was interested in both learning and instruction, and strongly supported discovery learning as useful to individualized instruction in the 1960s. However, by 1986, his thinking had evolved beyond discovery learning. In his book, Actual minds, possible worlds (1986), he said:

My model of the child in those days was very much in the tradition of the solo child mastering the world by representing it to himself in his own terms. In the intervening 
years I have come increasingly to recognize that most learning in most settings is a communal activity, a sharing of the culture. It is not just that the child must make his knowledge his own, but that he must make it his own in a community of those who share the sense of belonging to a culture (p. 127).

This is why it is necessary that students not only construct their own knowledge, but that knowledge provides them with a sense of ownership, belonging and is knowledge they can relate to and find useful. Educators need to recognize that how students perceive their learning experience is influenced by how meaningful they interpret that instruction to be (Aulls and Shore, 2008). With using the discovery method for teaching and learning, students who are not knowledgeable about the relevant content to complete a problem will experience some difficulty carrying out the task alone through discovery. This is why educational approaches that encourage small group activities should be adopted, especially during discovery learning (Aulls and Shore, 2008).

Inquiry-based learning theory describes a range of philosophical, curricular and pedagogical approaches to teaching (Educational Broadcasting Corporation, 2004). Its core premises include the requirement that learning should be based around students' questions. With this approach, pedagogy and curriculum require students to work together to solve problems rather than receiving direct instructions on what to do from the teacher. The teacher's job in an inquiry learning environment is therefore not to provide knowledge, but instead to help students with the process of discovering knowledge themselves. Inquiry theory requires that teaching be student-centered and students do the inquiry. For "students to become more active learners, they must take on more responsibility for what and how to learn" (Aulls and Shore, 2008, p. 9). This approach to learning allows students to utilize the means by which they learn best. 
Even though this theory has gained great popularity over the past decade, there is considerable debate about the effectiveness of this form of instruction (Educational Broadcasting Corporation, 2004). This could be due, in-part, to the complex, ambiguous, and highly challenging nature of the inquiry instruction process which makes understanding and participation difficult for both teachers and students alike (Aulls and Shore, 2008). Inquiry learning is an instructional method developed during the discovery learning movement of the 1960s. It was developed in response to a perceived failure of more traditional forms of instruction, where students were required simply to memorize fact laden instructional materials (Bruner, 1961). This is referred to as a passive approach to learning, a major characteristic of the Bahamian education system.

Educators in The Bahamas are realizing that alternative methods need to be implemented if education is to be an active and engaging process for both teachers and students (Personal Interview, 2008). Inquiry learning is a form of active learning where progress is assessed by how well students develop experimental and analytical skills rather than how much factual knowledge they possess. Just like discovery learning, inquiry is the engine for independent, curiosity and interest driven, lifelong learning (Aulls and Shore, 2008). Inquiry provides both a general and specific learning experience to accommodate the needs of the learner. Mark W. Aulls and Bruce M. Shore (2008) indicate that inquiry is not just another pedagogical technique; it is an approach that can transform the education system and immensely improve educational standards across the curriculum. Aulls and Shore (2008) are of the view that the inquiry learning theory "should be regarded as an imperative curriculum dimension in all schools" (p. 2). 
Bruner (1996), argued that some form of inquiry can be made available to all students, and all students can succeed at being an inquirer on some level, despite their learning capabilities. "Any form of inquiry approach to education must cultivate and honor the child's struggle to become an individual who is more independent at learning, as well as successful as a learner, in the real world of work and in all disciplines of academia" (Aulls and Shore, 2008, p. 2). When it comes to learning information and concepts, some students prefer to construct their own ways of learning subject material such as reading, writing, singing, researching, questioning and analyzing or through some form of graphic and application display of subject content learnt. The present structure of The Bahamas' education system does not permit this diversity in learning to take place due to the constraints placed on teachers to have students prepared for school-based and national assessments. In this type of learning environment students are expected to be "passive more than active learners who acquire factual and conceptual knowledge by hearing it or seeing it, rather than thinking and doing" (Aulls and Shore, 2008, p. 16). Inquiry theory maintains the belief that if learning is to be a lifelong experience, it must meet the goals of: discovery, being inquisitive, a problem finder and problem solver, a thinker, and doing what you can to create meaning on your own (Aulls and Shore, 2008).

One of the most widely distributed educational learning theories that questions the typical uniform style of teaching is Howard Gardiner's Multiple Intelligence (MI) theory (Gardiner, 1993). From the author's own experience as a geography teacher at the high school level in The Bahamas, the curriculum generally focus on Gardiner's first MI: verbal-linguistic intelligence, which involves generating spoken and written language and the capacity to use this language to achieve certain goals (Gardiner, 1983). In Gardiner's book, Frames of Mind (1983), he argues that people exhibit each of the seven intelligences (Figure 3); but they possess strengths and 
weaknesses in different ones. However, because the understanding of the brain and human behavior are constantly changing, the number of intelligences is expanding. Therefore, two new intelligences have recently been added: naturalistic and existential (Figure 3).

The conventional teaching methods mainly focus on the first two intelligences: verballinguistic intelligence and logical-mathematical intelligence as shown in Figure 3, thus neglecting students who demonstrate the other forms. It is for this reason that this study uses Gardiner's MIs to support using an approach that engages the diversity associated with students' learning, when compared to traditional methods that fails to recognize and meet these differences. Originally, Gardiner (1983) developed the list of intelligences as a theoretical model about the psychology of the mind, rather than a practical way to address individual differences. However, by understanding a student's strengths and weaknesses in each intelligence, educators can help students become more successful (Johnson and Lamb, 2007). Gardiner (1999), states that integrating MIs into the classroom involves changing ideas about teaching and learning. It requires addressing individual differences and providing a range of activities and experiences to facilitate learning. He suggests that technology can be used as a pedagogical tool to facilitate learning in each intelligence area. There is no "right way" to integrate intelligences or technology in the classroom. The key is to provide the most effective and meaningful learning environment for students.

Nevertheless, there are various criticisms of, and problems around, Gardiner's conceptualization of multiple intelligences. The way in which his theory of multiple intelligences has been translated into policy and practice has been very varied. Gardner did not, initially, spell out the implications of his theory for educators in any detail. Subsequently, he has looked more 
closely at what the theory might mean for schooling practice in: The Unschooled Mind, Intelligence Reframed, and The Disciplined Mind. Indeed, Gardner himself has listed some of the main issues and his responses (1993, p. xxiii-xxvii; 1999, p. 79-114). He has also admitted that there is subjective judgment involved. Here, the author will focus on three key questions that have been raised in debates. There are plenty of other questions around, but these would seem to be the most persistent:

Are the criteria Howard Gardner employs adequate? John White (1998) has argued that there are significant issues around the criteria that Gardner employs. There are questions around the individual criteria, for example, do all intelligences involve symbol systems; how are the criteria to be applied; and why these particular criteria are relevant. In respect of the last and fundamental question, White states that he has not been able to find any answer in Gardner's writings.

\section{Does Howard Gardner's conceptualization of intelligence hold together? For those} researchers and scholars who have traditionally viewed intelligence as, effectively, what is measured by intelligence tests, Gardner's work will always be problematic. They can still point to a substantial tradition of research that demonstrates correlation between different abilities and argue for the existence of a general intelligence factor. Gardiner (1993, p. xxiv) disputes much of the evidence and argues that it is not possible, as yet, to know how far intelligences actually correlate. More recent developments in thinking around intelligence such as Robert Sternberg's $(1985,1996)$ advancement of a 'triarchic model' have shared Gardner's dislike of such standard intelligence theory. However, in contrast to Gardner, Sternberg does not look strongly at the particular material that the person is processing. Instead he looks to what he calls the 
componential, experiential and contextual facets of intelligence. A further set of criticisms centre on the specific intelligences that Gardner identified. For example, it can be argued that musical intelligence and bodily-kinesthetic intelligence are better approached as talents, they do not normally need to adapt to life demands.

\section{Is there sufficient empirical evidence to support Howard Gardner's conceptualization? A} common criticism made of Gardner's work is that his theories derive rather more strongly from his own intuitions and reasoning than from a comprehensive and full grounding in empirical research. For the moment, there is not a properly worked through set of tests to identify and measure the different intelligences. But Gardiner (1999) himself has not pursued this approach because of a more general worry with such testing, that it leads to labeling and stigmatization. It is under this same aspect that Gardiner's MI theory has been disputed by some cognitive psychologists, who claim that there is inadequate support to show whether or not MIs and learning styles are related; and evidence for such intelligences is not very strong. Regardless, the fact that existence of different learning styles exist is indisputable. Gardiner sees MI theory as a basis of education reform that will encourage educators to adapt teaching techniques to reach these other intelligences (Gardiner, 1983 and 1999). Hence, it is important to identify the nine main MIs (Figure 3) that Gardiner (1993) proposes need to be in education, which starts from verbal-linguistic intelligence. 


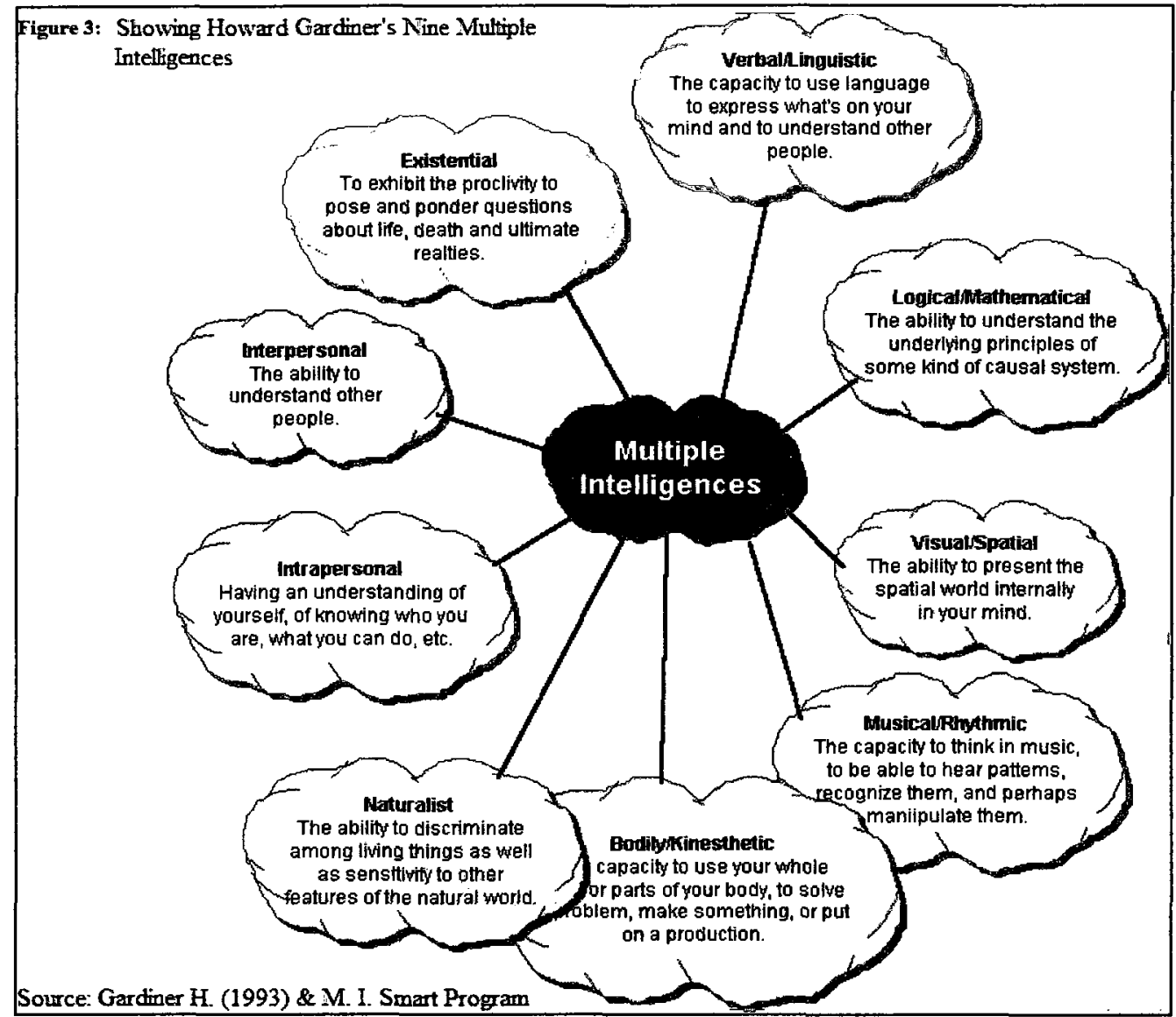

Verbal-linguistic learning is the most common of Gardiner's intelligence used in education systems. Although MI theory has its share of criticisms, the theory provides a basis for the injection of new life into teaching and learning experiences, whereby both teachers and students benefit (Gardiner, 1999; Johnson and Lamb, 2007). According to Samantha Baulch et al. (2005), MI theory helps to explain why some students do not learn well under traditional logical or linguistic teaching methods. She further states that this allows "teachers to recognize that students may have different means of exhibiting intelligence, making the classroom far more egalitarian" (Baulch et al., 2005, p. 499). With an understanding of Gardiner's theory of MIs, teachers, school administrators, and parents can better understand the learners in their midst. They can allow students to safely explore and learn in many ways, and they can help students 
direct their learning. The concept of this theory helps to explain and support the focus of this study as to why it is important that educational experiences replicate students' learning diversity.

While there may be some significant questions and issues around Gardner's notion of multiple intelligences, it still has had utility in education. It has helped a significant number of educators to question their work and to encourage them to look beyond the narrow confines of the dominant discourses of skilling, curriculum, and testing. Gardiner's MI theory allows for hope, and an alternative way of thinking, for those educators who feel out of step with the current, dominant product orientation to curriculum and educational policy. To the extent that Gardner's multiple intelligences theory has helped educators to reflect on their practice, and given them a basis to broaden their focus and to attend to what might assist students but people in general to live their lives well, then it has to be judged a useful addition (Johnson and Lamb, 2007).

\section{Theoretical Support for GIS and related Technologies as Pedagogical Tools}

In educational philosophical terms the use of GIS and related technologies transform the passivity of teaching and learning because they actively engage students. Constructivist learning theory, discovery learning, inquiry-based learning theory and Gardiner's (1983) multiple intelligences encourage and support the active involvement of students during the learning process. They support the central argument and hypothesis of this thesis because GIS technology can help provide the type of learning environment these theories advocate. Therefore, in this regard, GIS in the classroom is an affirmation of pedagogic theory. However, even though the four theories discussed, all support the learning experience that GIS can provide, inquiry-based 
learning theory seems to be the one that best captures the overall objective of this technology in a classroom setting. Both this theory and the technology offer a problem-based learning environment for students.

Constructivist learning theory, as a method of instruction, GIS inquiry draws upon an epistemological learning theory referred to as constructivism (Kerski, 2003 and Zerger et al., 2002). This research adopted this theory because GIS has a constructivist approach to teaching and learning and the ability to actively involve students in knowledge construction. The method proposed by this thesis encourages students to develop this type of knowledge by making a direct input to knowledge construction. Constructivist learning theory is important conceptually to this study because it provides theoretical support to the central arguments stated in chapter one and how GIS can provide a learning experience that is hands-on, student-centered and inquiry based, when compared to traditional methods.

Discovery learning suggests that teaching and learning with GIS allows students to engage in learning experiences in and outside of the classroom, which provides them with the opportunity to interact with their immediate surroundings and discover a new learning experience on their own. Discovery learning techniques like GIS allow students to discover their learning in ways that best meet their needs. This theory supports the idea of developing alternative approaches to using technologies in education, especially if it makes the technology easier and more accessible for teachers and students to utilize in discovery education. Discovery learning theory supports the view that GIS use will help in producing independent learners and thinkers (students who are in control of how they learn) when compared to traditional methods, rather than learners who are highly dependent upon the teacher to direct them through the entire 
learning process (Omrod, 1995). "The fact, however, that every learner and every teacher might well be unable to engage in discovery learning on a given day does not detract from the fact that discovery learning has been proposed, done well, done poorly, and even critiqued with a view to its encouragement, not its demise" (Aulls and Shore, 2008, p. 137).

Inquiry-based learning theory, with this form of instruction, it is proposed that teachers should be viewed as facilitators of learning rather than vessels of knowledge. In the traditional classroom setting, teachers are generally seen as disseminators of knowledge, whereas in a classroom environment that uses the approach proposed by this thesis would not only encourage students to create their own knowledge, but also to analyze and question the accuracy and validity of the knowledge created (Aulls and Shore, 2008). This theory states that despite the academic capability of students, all of them can achieve a level of inquiry. GIS and its diverse tools provide students with the opportunity to manipulate any tool, until a level of mastery based on their abilities is obtained. By using this technology as a tool to better understand and apply subject content, it provides students with skills that are in great demand in the workplace. Additionally, it provides students with a sense of ownership and success because they possess control over how they learn.

Consultation with Bahamian teachers revealed that one of their main challenges is students' lack of interest during the learning process (Focus group discussions and survey, 2008). GIS involves an inquiry approach to teaching and learning and has demonstrated its ability to increase students motivation and involvement during teaching (Unwin, 1991 and Kerski, 2000). But what is so relevant about using GIS as a means to an end is that the technology by itself is already an inquiry approach to teaching and learning because it involves the major aspects of an 
inquiry learning experience. For example, research, data collection or creation, analyzing, displaying information and questioning that information are all characteristics of both GIS and inquiry-based learning. The approach proposed by this thesis has the potential to provide students with a dynamic and engaging educational experience, which indirectly helps improve educational standards. The use of this technology allows students to create projects, develop experiments, collect and analyze data, and make judgments about that data. Aspects of learning that many students currently struggle with. It has therefore demonstrated the ability to provide this type of inquiry learning for students (Unwin, 1991).

Howard Gardiner's (1983) multiple intelligences theory, provide ideas and methods to accommodate students' varied learning styles. The approach hypothesized by this thesis takes into consideration the diverse learning preferences that students possess and realizes how vital it is to accommodate these learning needs in order for education to be a successful process for both teachers and students. It provides students with the opportunity to retrieve and manipulate realworld data that are also relevant (Audet and Paris, 1997). Students who are engaged in this type of learning, can progress in varied ways, in a style and at a pace appropriate for their individual interests, strengths and needs (Environmental Systems Research Institute, 1995). MI and GIS are means to foster high quality work. Using MI as a tool to promote high quality student work rather than using the theory as an end in and of itself has proven to be effective, the same approach proposed by this thesis with the use of GIS as a tool and not just a technology. Gardiner states that approaches to teaching and learning must be altered in order to use the intelligences in education. This is the same with using any form of technology in education, changes to using them has to take place in order to adopt an approach that effectively facilitates their use. But in order to investigate whether Bahamian teachers and students were dissatisfied 
with the current education system and wanted changes to be made, data had to be collected and the following section will provide a detail description of how the research was designed and conducted to assist in this regard.

\section{METHODOLOGY}

\section{RESEARCH DESIGN}

\section{Study Area}

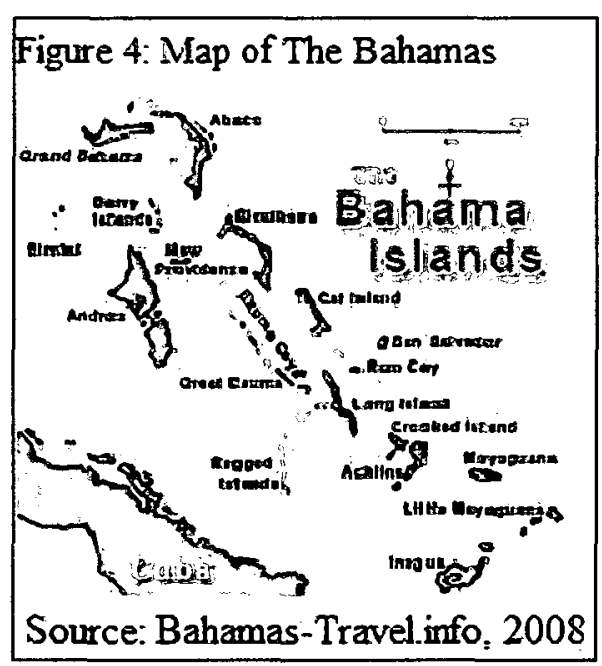

The Commonwealth of The Bahamas is an archipelago of predominantly narrow, low-lying islands, spread over some 100,000 square miles in the western Atlantic Ocean just south of Florida. The total land area is approximately 5,350 square miles. The country is comprised of some 700 Islands (any piece of land that is surrounded by water) and Cays (a small, low-elevation, sandy island formed on the surface of coral reefs). However, there are only twenty-two (22) inhabited islands. Transportation between the islands is often by air, although frequent use is also made of the inter-island mail boat services. The Department of Education (DOE) in The Bahamas is, therefore, faced with the task of providing education for a school population scattered over wide areas. Nassau, New Providence is selected as the study location because two-thirds of The Bahamas' total population resides in the city, the majority of the public schools are 
located in Nassau and the largest student population resides there as well. Additional reasons for the selected study site have to do with accessibility in terms of: transportation, living accommodation, participants for focus group discussions, interviews and surveys and being able to involve a larger number of teachers and students in the data collection process (Bradshaw and Stratford, 2005 and Holliday, 1994).

\section{School Selection}

Education in The Bahamas is highly centralized so if new approaches to teaching and learning are introduced, all teachers will be informed, either via professional workshops or curriculum guides. The schools selected to participate in this study included three out of the six public high schools located in Nassau at the time. Since the initial fieldwork was conducted for this study (August-September, 2008) an additional school has been built, but has not fully taken on the status as a high school. The Ministry of Education (MOE) has established these three schools as pilot or magnet schools to focus on technical and vocational skills, business studies, and academic studies.

The number of schools chosen is based on previous research conducted on public high schools in the United States by H. R. Audet and L. G. Abegg, 1996; J. J. Kerski, 2003; and J. W. Myers et al., 1999. These authors conducted research related to the use of GIS in the K-12 and middle school classrooms, where three public schools were chosen to participate. This was done to explore the benefits and challenges teachers experienced with using GIS. More than fifty percent of students in The Bahamas attend public school, these schools are the ones mostly funded by tax payers' dollars, and 
according to educators the performance of many students who attend public schools are below average (Survey, 2008).

\section{Data Collection Instruments}

The data collection process employed primary and secondary methods. The primary methods included six focus group discussions, five interviews and surveys that were used for collecting data from the main stakeholders (education policy makers, principals, teachers, and students) in this study. The participants for the focus groups and interviews were not selected randomly, but were chosen because rapport and trust had already been established, which made it easier to obtain their approval to participate. The subjects involved in the survey and focus group discussions were certified $\mathrm{K}-12$ public schools teachers. The study was conducted between August, 2008 and December, 2008. All participants for the data collection process will be kept anonymous throughout the thesis. All focus group discussions and interviews were digitally recorded to ensure and maintain accuracy and validity in terms of participants' responses.

In the case of this study and the time frame allotted for its completion, focus group discussions only included teachers and students from the History-Geography Department of the three schools selected. One major reason why the History-Geography Department was directly selected to participate is because the author was a member of this department while teaching at a public school, which made it more feasible to obtain assistance and approval from participants. The focus group discussions consisted of individual sessions held at each school, one for the teachers and one for students. Participants were informed that they were not obligated to participate in the research 
study and they could withdraw their agreement to do so at any point during the study. The teachers' focus group, interviews and survey (not completed during this time) took place between August and September, 2008. The students' focus group and survey completion took place in December, 2008. A description of the primary methods employed will follow.

\section{Secondary Sources}

The secondary sources included a review of selected documents and texts on education in The Bahamas. These included local newspaper articles, MOE annual reports, textbooks (which are limited) and consultation with senior education personnel. This allowed the author to provide a comprehensive history of the development of education in The Bahamas and describe some of the current major challenges being experienced by the Bahamian education system (see chapter two). Some information for this section was also obtained from consultation with senior education officials, as well as educators who were around during colonial rule and The Bahamas' independence in 1973. 


\section{PRIMARY RESEARCH METHODS}

To supplement and add depth to the results of the survey, focus group discussions for teachers and students were also utilized. The two forms of focus groups (teachers and students) consisted of four to ten individuals. All of the sessions were held for a duration of 60-70 minutes on a date specified by the Head of Departments (HODs) and teachers. All focus group discussions, interviews and survey distribution were facilitated by the author.

\section{Surveys}

The survey method contains a description of the four following sections: respondents, survey selection process, questionnaire design, and procedure.

\section{Respondents}

The author intended to obtain a response rate of fifty-plus percent or a total of thirty completed surveys from the three public schools (school A, B, and C) selected to participate in the study, and a fourth school was included in the survey process as an additional support in case the target percentage or amount was not obtained from the three schools. More than ninety percent of participants possess a Bachelor's Degree in education. The age of surveyed participants is in a range from 20 to 65 years, coming from diverse ethnic backgrounds (Bahamians, Jamaicans, Guyanese, Indians, Africans, Americans and Canadians). Many of these teachers are also parents who had or have children who attend public schools. 


\section{Survey Selection Process}

The initial target number was ninety teachers, but 130 questionnaires were distributed among the three schools involved in this research. Each of these schools has a teaching population of approximately sixty-plus teachers. Developing an effective participant selection strategy for a research study can be a complex task. The teacher participants in the survey were selected based on their agreement to participate, so those who were skeptical about being involved had the choice to decline. Teachers were not randomly selected for the survey; they were involved in this data collection method because they taught at the three schools involved in this study. In carrying out this research method, the author considered the major aspects and purpose of this study which are: educational standards, educational development, educational challenges and what can be done to address each of them. In this respect, the author viewed education officials, principals, teachers, and students as the main population of interest that should be targeted in this survey process. The major reasons behind selecting the participants for the survey were based on their knowledge of the topic under investigation, the extent of their contribution in terms of achieving the study's objectives, and their importance as a target group.

The frame for survey participants selected was based on the sign-in register for teachers. This provided all teachers with an equal opportunity to be included in the survey, because even though there was a specified target to be achieved, all teachers were included in the process. It was not only important to achieve the target number, but to ensure that the results included a fifty percent or more representation of teachers at the three schools. For example, 30 from school $\mathbf{A}$, 30 from school $\mathbf{B}$, and 30 from school $\mathbf{C}$. 


\section{Survey Design}

A closed and open-ended questionnaire method was used in designing questions. A copy of the questionnaire can be found in Appendix A of this thesis. Just using openended questions is harder to analyze quantitatively, without some form of content analysis, whereby utilizing that particular design allows data to easily be analyzed, especially with a computer-based quantitative analysis (Kitchin and Tate, 2000). The survey consisted of four closed questions and six open-ended questions for a total of ten questions (Appendix B), and also contained a cover letter with instructions about how to return the completed survey and a preamble of the study. In a number of cases, the author was told to wait for the survey. There were cases where some questions included aspects of both the closed and open-ended method. This was done to provide a brief explanation for the response given and a more thorough support for research questions during the analysis (McGuirk and O'Neil, 2005; Fowler, 1995 and Holliday, 1994). The purposes of open-ended questions in the questionnaire were to allow the participants to freely address their comments regarding challenges faced by the education system, the current standard of education in The Bahamas and how the use of a technological resource in all disciplines could contribute to improving achievement in students.

A pretesting of the survey was carried out with fifteen teachers from school $\mathbf{A}$. This allowed the author to revise and reword some questions. It was obvious that some questions were not clearly written or understood. Pretesting of the questionnaire was important because it helped avoid the use of biased language, provided an opportunity to identify any problems participants encountered while answering the survey, such as 
terms and phrases they found confusing and questions difficult to answer (Fowler, 1995). The piloting of the survey was also important in determining "whether the questions work well and produce the data that was required for the research" (Kitchin and Tate, 2000, p. 51). Some of the teachers who participated in the pretesting also pointed out some errors in the questions.

\section{Survey Procedure}

The face to face survey method was used during the implementation and distribution process. The survey was administered in September, 2008 and December, 2008. The dates show that a repeat visit was done in order to achieve the target amount. The face to face survey method was time consuming, but very useful and effective because it provided an atmosphere for direct communication to take place (Kitchin and Tate, 2000; Franfort-Nachmias and Nachmias, 1996). It was intended to get a response rate of fifty percent or thirty completed surveys from each of the three schools. One hundred and five completed surveys were obtained, surpassing the response rate targeted. There were 105 out of 130 distributed surveys returned, an $81 \%$ response. Overall, participants were supportive and willing to participate in the study.

\section{Student Focus Groups}

The focus group for students consisted of a total of eight geography and history students between the ages of 15 to 17 from grades ten through twelve. The students who participated were selected by their individual teachers. The group sessions included mixed-ability students in terms of academics: above average, average and below 
average. All participants will be referred to as student(s) throughout the study. At the beginning of each session, the author did a self-introduction and presented a brief PowerPoint presentation to explain the purpose of the study, to provide students with an understanding of what GIS is and show each question to which they would be asked to respond (Cameron, 2005). This approach maintained students attention and interest throughout the discussions. The purpose of this session was to obtain an understanding of students' reflections on their learning experiences, gain feedback on how they would prefer this experience to be. This allowed the author explore the attitudes of students on technology use. During the discussion, students were also questioned on their parents' involvement in their education. This method was useful for understanding and gaining knowledge on how students feel about their educational experiences (Bedford and Burgess, 2001; Cameron, 2005).

The author led all of the focus group sessions, without the teachers' presence so as to avoid intimidation on the students' behalf when answering questions. Bedford and Burgess (2001) state that focus groups usually consist of four to eight individuals who are brought together to discuss a particular topic chosen by the researcher who moderates or structures the discussion. This approach also ties in with the constructivist theory on students participating in decisions that affect their learning (Greening, 2000).

\section{Teachers' Focus Groups}

The teachers' focus group sessions consisted of between four and six participants. The number of teachers in the history-geography department varied at each school. Two out of the three focus groups were male dominated, which was a surprise 
when considering that female teachers account for approximately fifty percent or more of the total teaching population in The Bahamas (White Paper on education, 1973). Throughout this study, all participants will be referred to as teachers, educators or male and female teacher if a particular point is to be highlighted.

The goals of these sessions were to gain direct and conflicting view points on educational issues, inquire as to whether a form of technology would make a difference in education, and find out what teachers think are the major factors affecting educational standards among high school students, and why educational improvements are important for The Bahamas. Focus group discussions were also used to explain to participants the use of GIS as a pedagogical tool. The objective of this was for teachers to clearly understand how the use of GIS as a teaching vehicle will help remove focus of only teaching about the technology. This method was selected for teachers' participation because focus groups are flexible, multidimensional and promote a continuous dialogue among members, which can give the researcher insights into the social, cultural, political, economic and personal dimensions of an issue (Bedford and Burgess, 2001; Hoggart etal., 2002; and Cameron, 2005).

\section{Interviews}

There were a total of five individuals selected for an interview: the three principals of the participating schools, and two senior education officials from the MOE. Throughout the study these interviewees will be referred to as respondent A, B, and C or in terms of their respective occupational status (principal or senior education official). Participants for the interviews were selected based on their positions in education, the 
years ( 20 plus) they have contributed to educational development in The Bahamas and the in-depth knowledge they would be able to provide in terms of this nature. Also to understand their views on the present state of education in the country, as well as what procedures are being implemented to improved educational standards (Dunn, 2005). The purpose of these interviews was to explore the knowledge, opinions and beliefs (Punch, 1998; and Dunn, 2005) of each interviewee based on the above mentioned elements.

A more standardized open-ended interview method was used to gain information from all participants. This was an appropriate method to use as research suggests it allows you to ask the same questions to all interviewees, it is easy to analyze and compare, provided room for probing and there is freedom for opinions (Dunn, 2005; Kitchin and Tate, 2000). The items developed to guide the structure of the interviews were based on the research questions (Appendix A) to ensure that the questions worked well and produce the data that the research requires (Dunn, 2005; McGuirk and O'Neil, 2005; Kitchin and Tate, 2000).

Five questions were designed for the interviews, but these questions led into subquestions being asked. This allowed more probing to take place and more in-depth information to be retrieved. All interviewees requested to have a copy of the interview questions in advance, which was attached to the consent letters that were hand delivered to each interviewee. One observation that was made from all the interview sessions is the passion and enthusiasm exhibited by interviewees, especially while discussing educational standards and the present structure of the education system and its appropriateness for meeting students' learning needs. 


\section{Research Analysis Employed}

In the analysis quantitative methods were used. Two qualitative methods that were used are focus groups and one-on-one in-depth interview with selected respondents. These approaches were directed towards gaining an in-depth understanding of participants' perception of GIS and on the state of the education system in The Bahamas and to gain feedback on what measures they think should be implemented to help improve educational standards. These methods were primarily utilized in testing the research arguments and questions mentioned earlier. With using these qualitative methods, participants were provided with an understanding of the purpose of the research, extensive probing took place, and observation of participant behavior. Both qualitative methods were analyzed by using the "hermeneutic method" (Punch, 1998). This involved the author looking at how all the statements made by the interviewees and the various focus groups participants are inter-related, also for contradictions and consistencies.

The survey was used to collect qualitative data; however, some of the information collected was quantitatively analyzed. The purpose of the collected data was to qualitatively test the argument of this study and provide tables and graphs to illustrate important findings. The data collected from the survey were mostly utilized in chapter four and chapter five of this study, which discuss the concerns of the main stakeholders in education concerns about educational improvements, their views on whether some form of technology will help improve pedagogical standards, when compared to traditional methods and discussing the use of GIS as a pedagogic tool. The author identified major themes from the survey that are important in supporting the thesis objectives, these themes were related to variables (age, gender, education precedence and 
student academic standard) (Howitt and Cramer, 2005). Microsoft Excel 2007 was used to help analyze and create graphs and tables with the data obtained.

These are the research questions that were analyzed using the data collected: 1) what are some of the major challenges of the Bahamian education system? This is supplemented by the question: what are some of the major concerns of educators and parents regarding the educational standards with which public high school students are graduating? Question 1 was answered by using selected documents and texts on public education to provide a description of the development and challenges experienced by The Bahamas' education system. Data obtained from education officials, teachers and students, as well as secondary sources were used to analyze their attitudes toward technology. Why are improvements of educational standards important and necessary for The Bahamas? The second question was assessed by drawing from literature on educational development, specifically in developing countries, as well as using feedback gained from surveys and interviews on the importance of improved educational standards for the future development of The Bahamas.

What are some of the main challenges experienced by the Bahamian education system that teaching and learning with GIS can help improve when compared to traditional methods? The third research question also includes a sub-question about teachers and students attitudes toward technology use. Question 3 was explored by using feedback and suggestions gained from educators via questionnaires, interviews and focus groups discussions on the delivery and standard of public education in The Bahamas. This question was further supported by reviewing current literature on GIS and education and devising a sample module: 'GIS as an Educational Tool', that demonstrates how the use of GIS as pedagogical tool can actively engage students in 
learning when compared to traditional methods. The methods employed and analysis of the data assisted in testing the arguments put forth earlier in this thesis.

\section{Ethical Considerations}

Every research study undertaken has associated ethical issues. In this case, prior to collecting data for this study, it was mandatory that ethics clearance be obtained from Carleton University's Ethics Committee. This is particularly the case when people are involved directly but also when certain secondary sources are used. Research ethics are concerned with the extent to which the researcher is ethically and morally responsible to his or her participants (Kitchin and Tate, 2000). Permission had to also be obtained from the principals of the schools selected to participate. In submitting an ethics application, a letter of information that thoroughly described the research to be undertaken, as well as the methods that would be employed had to accompany the application. This application process also included copies of consent letters and forms for participants to complete before participating in the research. These letters explained that the sole

purpose of the data collected is to provide support for the research study being conducted and a copy of the final thesis document will be made available for participants to view.

The letters also mentioned that there was no obligation to participate, anyone could withdraw from participating in the study at anytime and all participants would be kept anonymous in the final thesis document. Special ethical considerations were taken into account for student participants. For all student participants, it was mandatory that a parental consent form was filled out and returned to the researcher before they could participate. Since children are a vulnerable group because they are a group with few rights and subject to the power of all adult peers, in this case parents and teachers, 
consent letters were also provided for students to sign. Therefore, students had the right to decline from participating even if their parent or guardian provided permission for them to participate.

\section{CHAPTER SUMMARY}

This chapter provided a discussion of the theoretical concepts adopted to support the study's empirical basis; and a description of the methods employed to collect data for the study. Collectively, constructivist theory, discovery learning, inquiry theory, and multiple intelligences theory, all support the belief that education is more practical, when learning experience is an engaging process that facilitates the needs of the learner. It is not being suggested that all theories be used in all classroom settings, but requiring that it be used or only from time to time in situations where the learning conditions support this sort of instruction and learning relative to each theory. All of these theories, just like using GIS as a tool, can help educators educate their students in new and better ways. It can help them to better understand and observe the ways in which their students learn best. The use of GIS provides educators with adequate time to observe students while they work because this approach is more student-oriented, meaning that students are more in engaged in their learning. This approach to teaching and learning is intuitive to the differences that each student possesses when it comes to education.

The methods employed were selected based on the study's arguments, hypotheses, objectives and research questions. This ensured that these were the best possible methods to use and they would provide the data required. Like conducting any research, strengths, limitations and challenges are expected and experience. However, 
these experiences were beneficial because they allowed adjustments to be made when methods were repeated and to avoid repetition of previous mistakes. Nevertheless, the goals of this chapter of the study were successfully achieved.

The chapter started with the introduction of the study's theoretical framework, which focused on theories associated with supporting the arguments and purposes of this thesis. A detailed description of how the research was designed and carried out in order to receive the required data has been provided. However, one of the most significant components of this thesis is to explore: 1) whether the data obtained support GIS being used as a vehicle with which students can learn and if this approach will make the technology available to more teachers; 2) will the technology help improve current educational methods and student achievement. This will be discussed in detail in chapter four. 


\section{CHAPTER FOUR}

\section{RESULTS}

\section{INTRODUCTION}

GIS is often claimed as a unique field of interest and expertise; the educational challenge lies in establishing a unique learning environment that would make the technology available and more easy to use by a larger number of schools. It has already been demonstrated that GIS and related technologies can help improve students' learning and how teachers disseminate knowledge to them. The major question posed here is: How can the educational benefits of GIS help Bahamian high schools improve the ways in which teaching and learning presently takes place when the technology is used as a pedagogical tool?

A major focus of this study is to investigate the use of GIS in enhancing educational methods in Bahamian high schools where the primary learning objective is to improve students' achievement and educational standards in various disciplines, rather than focus on learning about the technology itself. This study is specifically interested in fostering conceptual understanding through more practical applications of information learnt and in having students develop data analysis skills for the purposes of understanding the real life contexts of the various subjects studied. In this regard, this research is not particularly concerned with teaching GIS skills for career preparation. In other words, it is interested in students' learning with GIS, rather than 
about GIS. This chapter provides an analysis and results from the data obtained, as well as what can be done at the practical level. The following findings and illustrations show whether the arguments and objectives of this thesis were supported and to what extent.

\section{MAKING GIS AVAILABLE IN BAHAMIAN HIGH SCHOOLS TO IMPROVE PEDAGOGICAL STANDARDS}

Two major arguments put forth earlier were: 1) there are many problems experienced by the Bahamian education system and the use of GIS as a pedagogical tool can help address some of them, and 2) educational standards are a concern for The Bahamas and this can be improved once progress in students' achievement is evident. But educators and education decision makers need to have a clear idea of the impact that future educational developments can have on The Bahamas, especially the ones that take advantage of modern technologies. The educational approach recommended by this research is more than just another method to impose on teachers, but one that will potentially assist in enriching The Bahamas' education system and its economy by helping to provide high school students with the necessary skills demanded by the workplace and how to apply them in the appropriate settings. This chapter answers the research questions and hypotheses listed below.

1) Are educational standards a concern for The Bahamas?

a. What are some of the major challenges faced by the Bahamian education system?

b. What are the perceptions of teachers and students toward technology use in the classroom? 
2) Why are the improvements of educational standards important and necessary for The Bahamas?

3) What are some of the main challenges experienced by the Bahamian education system that teaching and learning with GIS can help improve when compared to traditional methods?

Hypotheses:

1) Using GIS as a mechanism to teach and learn with has the potential to help improve pedagogical standards by being a change agent, to complement and improve traditional educational methods.

2) Teachers and student age and gender, and students' grade levels and academic standing will affect their attitudes toward technology.

\section{Results on Educational Standards and Challenges: Teachers' Perspective}

Results from the data collected indicated that there was a great level of support from participants because of their strong belief that substantial changes need to be made in education and the use of some form of technological resource in all disciplines can help transform how students are learning. Table 2 provides a synopsis of some of the major challenges identified by teachers involved in this study. In addition to the challenges mentioned in Table 2, teachers and education officials claimed that a major educational challenge in Bahamian schools has to do with student achievement, which eventually affects educational standards. They further stated that a significant factor in students' lack of interest in education has to do with the lack of parental involvement (Teachers' Focus groups, 2008 and Personal Interviews, 2008). Some teachers added that it has to do with the relevancy and mode of content delivery. Additional findings showed that teachers are not pleased with the level with which students are graduating 
(Table 3 and Figure 5) because in many cases more than 50 to 60 percent of twelfth graders fail to achieve the standard to graduate. Table 3 and Figure 5 display the results on the academic standard rating of students obtained from teacher participants in this study.

TABLE 2: Teachers Perspective on Current Educational Challenges

\begin{tabular}{|l|}
\hline \multicolumn{1}{|c|}{ CURRENT EDUCATIONAL CHALLENGES } \\
\hline $\begin{array}{l}\text { I think that our challenge may not be so much in terms of the curriculum, but more in regards to } \\
\text { resources and structure. When we say resources, we refer to having the appropriate materials to } \\
\text { work with, the technology and tools for instruction, and having up to date materials. }\end{array}$ \\
\hline $\begin{array}{l}\text { There is a lack of scholarship in The Bahamas, because there are few if any books that are } \\
\text { produced by Bahamian focusing on most of the subject areas. So we need to have a greater } \\
\text { emphasis on research and writing as educators. }\end{array}$ \\
\hline $\begin{array}{l}\text { When I think about structure, I think we have to implement certain things to change and } \\
\text { improve our schools and education system as a whole to produce better results in learning. For } \\
\text { example, it may be in the way the timetable is structured }\end{array}$ \\
\hline $\begin{array}{l}\text { One of the main challenges that I think about is the lack of training for educators in terms of } \\
\text { applying for in-service study awards. }\end{array}$ \\
\hline $\begin{array}{l}\text { Technology implementation in education is another challenge because if you want teachers to } \\
\text { get away from the chalk and talk, then you need to provide another possibility for them to use. }\end{array}$ \\
\hline $\begin{array}{l}\text { My opinion is that more emphasis should be place on a greater use of technology as a means to } \\
\text { help in improving reading levels. }\end{array}$ \\
\hline $\begin{array}{l}\text { Class sizes: There are not sufficient schools to cater to a growing population and the increasing } \\
\text { influx of migrants }\end{array}$ \\
\hline $\begin{array}{l}\text { There needs to be more and better trained teachers in the area of geography. For the most part in } \\
\text { the social sciences in the education system in The Bahamas you would find more history } \\
\text { teachers. Geography is not provided with the necessary resources, which is tremendously } \\
\text { needed because it is a hands-on subject. }\end{array}$ \\
\hline $\begin{array}{l}\text { Some of the immediate challenges that I see is discipline, literacy and some teachers being } \\
\text { afraid and not interested in change }\end{array}$ \\
example, after 3 to 5 years teachers decide to leave the system \\
\hline
\end{tabular}


Table 2 documents a summary of the many challenges that teachers experience with the education system in The Bahamas. However, they believe that GIS technology can make a difference with problems related to improving their teaching and the ways with which students learn. During an interview process, an interviewee concluded that "many of the challenges teachers experience with the current education system contribute to a low morale among teachers and students. It was added that a good teacher can get a job anywhere, and many teachers remain in education because they really want to contribute to nation building" (Personal Interview, 2008). The lack of parental involvement was cited as a single major contributor to poor educational standards among students. This is what a senior education official and principal had to say when asked to comment on this issue:

I am hopeful that our parents will get onboard, not just those in the private schools who pay for their children's education but all parents. It is also hoped that the MOE understanding that some parents are daunted by this whole business of education will reach out to assist parents. Additionally, that our schools will become learning communities where parents feel comfortable in coming to the school not only to see what their children are doing, but so that schools can provide assistance for parents. This too generates parental involvement if parents see that it is not them against educators, but that we are all in this thing together. And that they are providing us with some assistance as well, therefore, I see good things for education (Personal Interview, 2008).

Adding to the issue of parental involvement a principal said:

It is time we stop finding excuses for the lack of parental involvement, and let them know if a parent or a guardian of the child do not attend PTA meeting or collect your child's report card, then your child would not be permitted to attend school until otherwise. There needs to be some type of legislation implemented that will hold parents accountable for their children. In a private school if there is no parental involvement, they put the child out of the school. This is not an option in public schools. The problem is that education like many other sectors has no strategic plan and rules. Look at the public and private schools besides private schools choosing which students attend their institution and the quality of teachers, the key factor is parental involvement and that should speak volume. If you have lack of parental involvement as the overriding factor between the successes of a private school versus a public school student, then it should stand to reason that you should target parental support. The lack of parental involvement will definitely lead to deterioration in students' performance (Personal Interview, 2008). 
Table 3 collectively shows how teachers rate the standard with which high school students are leaving school. It shows that many teacher-participants feel that by the time students get into twelfth grade at least $58 \%$ of them are not prepared with the basics to go into the workplace or to attend some higher institution of learning. This is a sentiment held by Prime Minister Hubert Ingraham and Minister of Education, Carl Bethel. Out of the 105 surveys returned by teachers, a total of 60 or $58 \%$ rate the standard of high school students as "below average" or "poor" (Table 3 and Figure 5), which indicates that educational standards are a problem. Even though these results cannot be generalized to reflect the views of the entire teacher population in The Bahamas, they still present a need for concern.

Table 3: Teachers Rating of High School Graduates Academic Standard

\begin{tabular}{|l|c|}
\hline \multicolumn{1}{|c|}{ STANDARD RATING } & TOTAL NUMBER \\
\hline Above Average & 4 \\
\hline Average & 41 \\
\hline Below Average & 50 \\
\hline Poor & 10 \\
\hline
\end{tabular}

Figure 5: Shows the Academic Standard Rating of Public High School Graduates by Teachers Surveyed

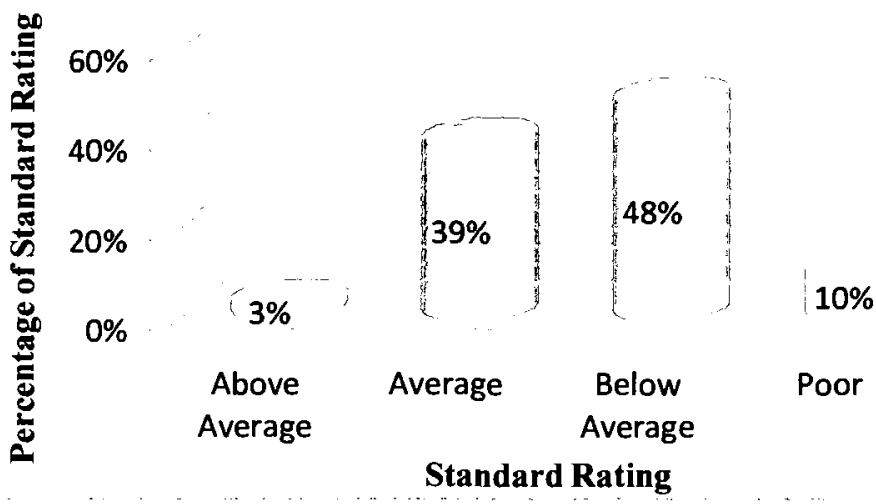

Rating Scale

Above Average

Average

Below Average 
In regards to the level with which students are graduating, a senior education official stated, "we are not getting the best out of our students and that is for a number of reasons, not only in terms of classroom instruction but also parental involvement. I think that plays a major role in the overall success of any student, that is, the degree to which parents are involved in their children's education" (Personal Interview, 2008).

There is no doubt that "a technology-driven curriculum is ultimately a narrow and limited curriculum" (Miller, 2007, p. 9). When the utilization of any new approach in education is going to be considered, there has to be a balance between that new approach and the ones that already exist (Table 4). Teachers stated that they were not pleased with educational standards because there is a lack of balance (Table 4) between technological resources and traditional methods, and it does not provide a large number of educational opportunities for students (Survey, 2008). A holistic curriculum seeks a balance between all aspects of learning and the ways in which students' learn (Miller, 2007). Yet if GIS is not to become just another technology looking for an application, it is essential that its teaching includes education with GIS and not just about it.

Table 4 presents a summary of teachers' reasons for their dissatisfaction with educational standards. In Table 4 , many of the reasons that teachers provided as to why they are not satisfied with educational standards in The Bahamas are related to addressing the learning needs of students and their level of achievement, indicating that standards are a concern and need to be improved. Teachers are of the view that standards are not being improved because developments in education do not directly affect improving students' achievement and what can be done to assist those students who are failing. In response to this a principal stated that he is not pleased because: 
Educational standards have been down-played for a number of years and in this regard the country is still in the catch up mode. I think that there needs to be less saying and more doing when it comes to education. All of this talking is not getting the end results that we need in terms of students' performance in education. We need to look holistically at education, and see where we are at, and target where we want to be. We need a national plan for education that is a 5 or 10 year strategic plan, so that no matter which government is in power the policies and guidelines of that plan would be enforced. In my view, this would be the best educational plan for the Commonwealth of The Bahamas for this time (Personal Interview, 2008).

TABLE 4: Reasons for Teachers Dissatisfaction with the Standard of Education in The Bahamas

\begin{tabular}{|l|}
\hline \multicolumn{1}{|c|}{ REASONS FOR TEACHERS DISSATISFACATION } \\
\hline $\begin{array}{l}\text { Strategies need to be implemented to improve standards, too many persons are settling for } \\
\text { mediocre standards in education. }\end{array}$ \\
\hline $\begin{array}{l}\text { Parents need to become more involve in educational development by helping students to see the } \\
\text { value of education. }\end{array}$ \\
\hline $\begin{array}{l}\text { The education system caters to the child who is academic, while the child with great } \\
\text { psychomotor skills is left behind. Therefore, the system does not attempt to bring out individual } \\
\text { talents or thoughts. }\end{array}$ \\
$\begin{array}{l}\text { The current system fails to meet students' interest and future career goals and as a result it is not } \\
\text { preparing students to meet the demands of a practical workforce and life. }\end{array}$ \\
\hline $\begin{array}{l}\text { Too many students are allowed to leave school without achieving the basic standard to } \\
\text { graduate. }\end{array}$ \\
\hline $\begin{array}{l}\text { The same measuring standard is used for all students which is unfair because of their varied } \\
\text { learning preferences. If we were to truly cater to students according to their interest we will see } \\
\text { a change in educational standards. }\end{array}$ \\
\hline $\begin{array}{l}\text { There should be a connection between technology and the way content is transferred to students } \\
\text { because technology plays a major role in the job market and improving economic standards. }\end{array}$ \\
\hline Too many students are struggling with basic academics (reading, comprehension and math). \\
\hline $\begin{array}{l}\text { There can be visible improvements in education if there is more collaboration with all entities } \\
\text { directly involved. }\end{array}$ \\
\hline
\end{tabular}

The August, 2008 survey conducted by the author with 130 Bahamian teachers described in chapter three revealed that of the 105 returned questionnaires, $80 \%$ admitted that although educational improvements have been made over the past 10 to 15 years, they were not 
comfortable with the current situation. Table 4 and Table 5 provide a summary of teachers' reasons and common themes derived as to why educational standards in The Bahamas have become an issue of concern, especially in the last decade.

TABLE 5: Common Themes and Total Number of Responses for Teachers Dissatisfaction with the Standard of Education

\begin{tabular}{|l|c|}
\hline \multicolumn{1}{|c|}{ COMMON THEMES } & TOTAL NUMBER OF RESPONSES \\
\hline $\begin{array}{l}\text { Additional measures to improve standards } \\
\text { need to be implemented }\end{array}$ & 30 \\
\hline Lack of parental involvement & 22 \\
\hline A lack of balance exists in the curriculum & 21 \\
\hline Lack of resources & 17 \\
\hline Not career focused & 14 \\
\hline Poor graduation statistics & 6 \\
\hline
\end{tabular}

This table depicts common themes that were derived from data on teachers' views about the standard of education in The Bahamas. The total number of responses column shows in descending order the frequency of support for each theme. From the 105 returned surveys, a total number of 65 or $62 \%$ (Table 5) teachers agreed that in order for educational standards to be improved, changes in education must first be made with the curriculum structure because it directly affects how students learn and are taught. This involves implementing measures to improve the national curriculum, an existing lack of balance in school syllabus and it not being career focused (Table 5). All educators in this study concur that the use of some form of technological resource in education across the board will help in improving standards, thus supporting the arguments of this thesis. Teachers' and students' attitude toward technology use 
in the classroom will later be discussed. Therefore, once standards are improved, then there will be an increase in student achievement, which will result in enhanced and more skilled students.

To further investigate the argument that educational standards are a concern, the author conducted an analysis on teachers' status (Sadik, 2006) to compare responses of those teachers who were also parents with children attending or who would have attended a public or private school. In Table 6, "educator" represents those teachers who did not have any children in school and "both" denotes teachers who were parents with a child still in school.

TABLE 6: Total Number of Participants by Status

\begin{tabular}{|c|c|}
\hline STATUS & AMOUNT \\
\hline Educator & 57 \\
\hline Both (Educator and Parent) & 48 \\
\hline Total & 105 \\
\hline
\end{tabular}

Table 6 shows that out of the total 105 returned surveys, 48 or $46 \%$ of participants were both a teacher and a parent; and 57 or $54 \%$ were teachers without a child in school. The question on the status of participants surveyed was important to avoid response bias to questions dealing with the standard of education in The Bahamas in terms of a public or private school. This helped in providing a stronger support for the argument of educational standards being an issue of concern in The Bahamas. For example, even though the occupational status of all the participants surveyed was a teacher, 48 out of the 105 participants surveyed were also parents. In addition to this 40 or $38 \%$ of those participants have a child attending public school, 35 or $33 \%$ of participants have a child attending private school. Data was not specifically collected on 
teachers who were not parents, so the remaining 30 or $29 \%$ accounts for teachers who are not parents and do not have a child in school.

The significance of some of the participants being both a teacher and a parent with children in a private or public school were important in terms of providing an objective response and not just a subjective one based on their personal involvement with the question (Appendix B) on the standard of public school education. Findings from the survey, especially for question 1, 2, 3 and 4 (Appendix B) showed that this was appropriate for balance and accuracy and provided an accurate representation of views on educational standard in The Bahamas and what could be done to help improve standards.

\section{Results on Educators and Students Attitudes towards some form of Technology in the Classroom}

A major argument of this thesis is that having students use GIS as a vehicle with which to learn will help improve student achievement through content delivery and the process of application and skill building. However, in order for this approach to be successful it was necessary to examine education officials, teachers' and students' views on whether they think using GIS as a teaching and learning tool would bring change to the education system in The Bahamas. Their opinions are vital because these are the main individuals who must be involved in order for any form of educational reform to effectively take place (Koszalka, 2001, June). This is also important to ensure that all stakeholders directly involved in pedagogical developments will cooperate and are committed to making the new educational approach work. A key reason for studying teachers' and students' attitude towards technology use is that it is a major predictor 
for future use of GIS as a teaching and learning tool or any other form of technological resource in the classroom (Koszalka, 2001, June; Myers and Halpin, 2002).

\section{Discussion and Findings on Educators' Attitude towards Technology use in the Classroom}

The chapter also compiled data discussing educators' and students' attitudes toward technology use in the classroom. The objectives of this were to understand how teachers and students felt about technology use and what difference they thought it would make in teaching and learning. The questionnaire (Appendix B) included factors such as perceived usefulness, and behavioral intention to use some form of technology once provided with the opportunity (Sadik, 2006). The survey incorporated questions concerning teachers' attitudes toward technology usefulness in the classroom because their perceptions are critical to the successful use of any new innovation in education (Koszalka, 2001, June).

Results showed that there was a $100 \%$ response rate in favour of technology use. Teachers felt that using GIS for students to learn with can present improvements in educational standards through student achievement (Table 8 and Table 9). Table 7 provides the common themes that were derived from survey data collected from teacher participants on why they would use some form of technology for students to learn with. The total percentage of responses reflects the frequency of the same responses given by teachers, indicating that some reasons for technology use were given more support than others. 
TABLE 7: Common Themes for Technology Use as a Pedagogical Tool: Educators' perspective

\begin{tabular}{|l|c|}
\hline \multicolumn{1}{|c|}{ COMMON THEMES } & TOTAL PERCENTAGE OF RESPONSES \\
\hline Enhance teaching and learning & $66 \%$ \\
\hline Cater to diversity and students' interest & $64 \%$ \\
\hline Expand educational opportunities & $45 \%$ \\
\hline Advance skill development & $36 \%$ \\
\hline Effective means to retrieve data & $12 \%$ \\
\hline Improve communication in education & $7 \%$ \\
\hline Improve record keeping & $5 \%$ \\
\hline
\end{tabular}

Table 7 provides the direct responses given by teachers involved in the focus group discussions and survey. These findings also suggested that teachers are willing to use GIS and related technologies to the extent to which they can help enhance student learning. Teachers' level of positive response was also due to the fact that using the technology as proposed earlier would not prevent them from executing their daily required tasks such as providing students with relevant content for the various disciplines. This is also indicated by the first four common themes and total percentage of responses that supported each one. These results (Table 7 and Table 8) suggest that teachers believe that some form of technological resource can help improve teaching and learning approaches, which in turn supports an argument of this thesis that the use of GIS as a pedagogical tool will assist in educational improvements by being a change agent in the ways with which students learn. 
TABLE 8: Educators Reasons for Technology Application

\begin{tabular}{|l|}
\hline \multicolumn{1}{|c|}{ REASONS FOR TECHNOLOGY USE } \\
\hline $\begin{array}{l}\text { The technology will improve educational opportunities for students and develop skills such as } \\
\text { the ability to take content information and utilize it in practical applications. }\end{array}$ \\
\hline $\begin{array}{l}\text { Students today are extremely savvy when it comes to technology, therefore using some form } \\
\text { of it would help to motivate and encourage learning. }\end{array}$ \\
\hline Technology use will provide the ability to share new developments and strategies in education. \\
\hline $\begin{array}{l}\text { Technology will help improve communication in the classroom, for example, teacher-student } \\
\text { interaction. Students are very interested in technology so they tend to be motivated to share } \\
\text { how it assisted them in completing a learning task. }\end{array}$ \\
\hline It would provide teachers with a broader base to retrieve useful information from for teaching. \\
\hline $\begin{array}{l}\text { Technology must be used as a strategy or method to improve teaching and learning, otherwise } \\
\text { using it is pointless. }\end{array}$ \\
\hline It provides an effective means of imparting subject content to students. \\
\hline $\begin{array}{l}\text { If students are introduced to some form of technology it would develop skilled-based learning, } \\
\text { which is at a low level in public schools in The Bahamas. }\end{array}$ \\
\hline
\end{tabular}

Table 8 is a summary of teachers' responses and level of support to the question as to why they would use some form of technological resource in the classroom. Prior to this study, it was expected that teachers' main concern about the technology would be not knowing how to manipulate it because it is fairly new to most of them. The findings of this study in terms of educators' attitude toward technology use indicated that familiarity with GIS and having knowledge on how to use the technology were not major concerns among teachers. It revealed that teachers' major concerns had to do with resource availability and being able to use the technology to teach with so that the focus would not be on teaching the technology and it would not take away from providing students with relevant content information (Table 8). 
This approach to using the technology provides a greater diversity of learning experiences to engage students when compared to traditional methods. Teachers felt that a hybrid approach to education delivery could help complement and improve traditional methods of teaching and learning. Teachers involved in the focus group sessions were asked about why they would use a technology like GIS to teach with and their responses are shown in Table 9.

TABLE 9: Teachers Reasons for the Usefulness of GIS

\begin{tabular}{|l|}
\hline \multicolumn{1}{|c|}{ REASONS FOR GIS USEFULNESS } \\
\hline Stimulate greater interest and accommodate a wide variety of learning styles. \\
\hline $\begin{array}{l}\text { It provides more hands-on learning experiences, which tend to produce more positive outcomes } \\
\text { in students' performance and participation. }\end{array}$ \\
\hline Some lessons can be enhanced or better illustrated with the use of some form of technology. \\
\hline The use of some form of technology has the potential to increase students' involvement. \\
\hline $\begin{array}{l}\text { The whole focus is not to focus on teaching GIS but to use it as a strategy or teaching tool that } \\
\text { could be incorporated into the lesson. In this way, it does not take away from you teaching and } \\
\text { preparing students for school-based and national exams. }\end{array}$ \\
\hline $\begin{array}{l}\text { First of all it provides so many alternatives that students can do in and outside the classroom } \\
\text { instead of just listening. I think one of the most important things that you can get from a system } \\
\text { like this is developing skill levels of students. }\end{array}$ \\
$\begin{array}{l}\text { It provides an opportunity to develop more active rather than passive learners. You can have } \\
\text { students use a technology like GIS to better understand, view and develop a comparison of the } \\
\text { spatial change. }\end{array}$ \\
\hline
\end{tabular}

Table 9, therefore summarizes focus groups participants and teachers surveyed reasons for GIS and related technologies utility in education. The above responses (Table 9) were encouraging, especially in terms of advocating the approach proposed by this thesis. Teachers' feedback showed that they understood that this method to using the technology would not hinder them from teaching students relevant content, but only improve and complement present content 
delivery techniques. Teachers also understood that the interactive nature of GIS and related technologies are generally more interesting to students and has been shown to increase students' learning in comparison to traditional methods, especially among average and below-average students (Kerski, 2001 and Linn, 1997).

Even though results from the survey showed that there were $66 \%$ females and $34 \%$ males surveyed, this did not affect teachers' overall attitudes on technology use based on gender or age as assumed at the beginning of this study. In general, educators portrayed a positive attitude toward technology use in the classroom and are keen to use it, providing the technology enables them to improve education delivery, get students more actively involved, meet the varied learning needs of students and provide the opportunity for students to develop a variety of skills (Table 7; Table 8; Table 9; Teachers' focus groups, 2008; Personal Interviews, 2008; Myers and Halpin, 2002; Mungazi, 1991; Marshall, 1983 and Yildrim, 2000). This level of positive response from teachers supports the argument that once focus is placed on using the technology as a means to teach and learn with, it will help improve educational standards. All high school teachers involved in the data collection process of the study displayed a positive mental state of readiness to adopt this innovation or any other for that matter, once the resources were made available.

When all participants were asked whether they would consider using some form of technology if it involved improving the current level of pedagogical standards in Bahamian high school students, they provided a positive response. In addition to this male and female teachers stated that they would consider using some form of technology if it meant improving their teaching methods and better accommodating the needs of their students (Table 7). Table 8 
documents direct responses of teachers' reasons for their willingness to use some form of technological resource in the classroom. Discussions held with both teachers and students, data compiled from all interviewees and the 105 returned surveys, showed that all participants supported the arguments presented. This along with the information in Table 7 and Table 8 indicate that educators strongly support the approach proposed by this study. Using the technology in isolation does not provide a balanced education in terms of skill development and relevant content for students (Table 5, Table 7 and Table 8). When asked whether the use of some form of technology in education would help improve standards and equip students for employment, a principal responded with an emphatic "yes". In reference to the point on the need to have a balance in what the curriculum offers students, another principal stated:

The education system needs to offer a balance: we need to offer the academics to cater to those students in that area, and the same amount of technical and vocational subjects to students whose main interests are in this area. Research tells you that all students will not be academically inclined, so how do you cater to those students who are not. There has to be a balance in order to adequately accommodate students educationally. If this is done you would see an increase in students' performance and behavioral improvements because they would be directed into areas where they could achieve success (Personal Interview, 2008).

Another hypothesis was that the older and more senior teachers would hold a less positive attitude toward technology use. Teachers were asked whether they would use some form of technology in the classroom if given the opportunity, all of them gave a "yes" response. As far as age was concerned, this was not a factor in terms of teachers' attitude toward technology use to improve instruction delivery in the classroom. 


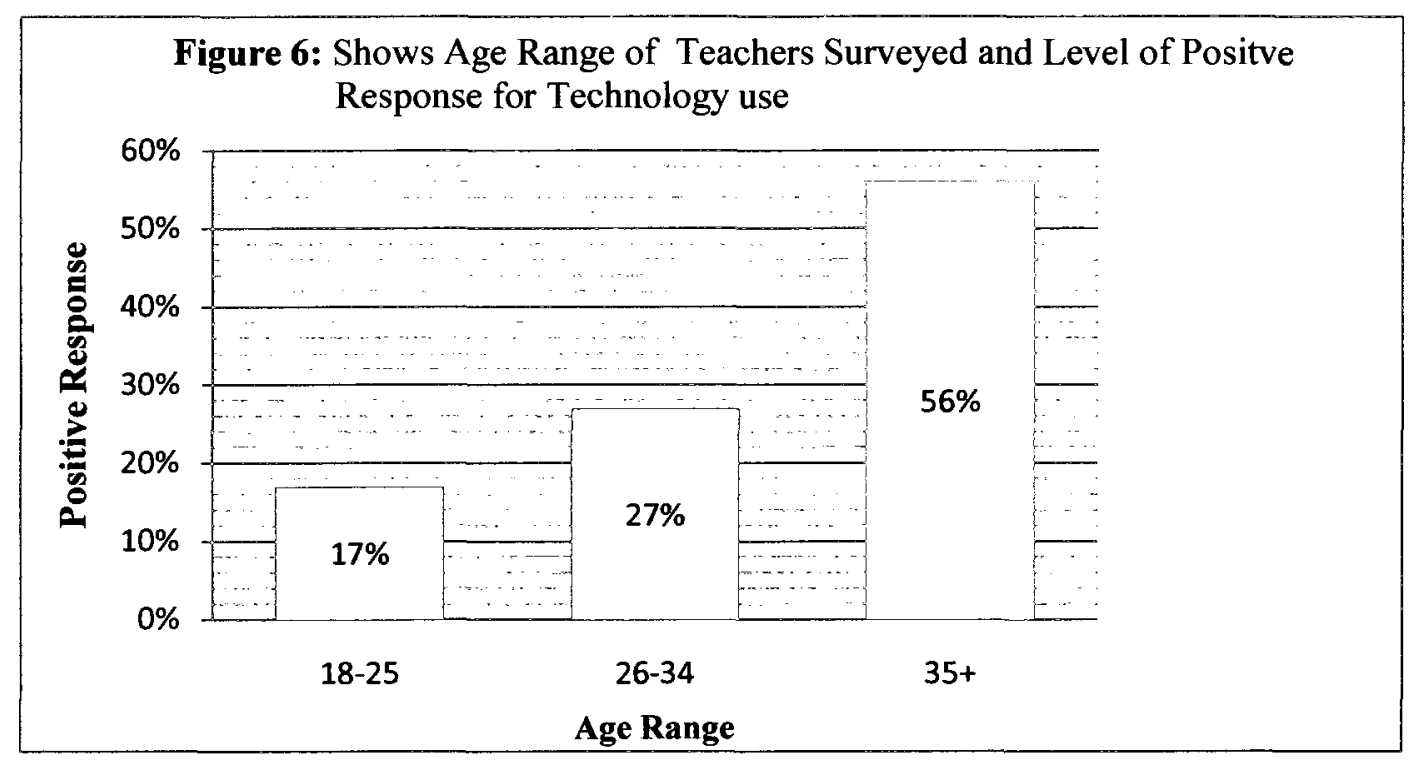

TABLE 10: The Total Number for the Age Range of Participants Surveyed

\begin{tabular}{|c|c|}
\hline AGE RANGE & TOTAL NUMBER \\
\hline $18-25$ & 18 \\
\hline $26-34$ & 28 \\
\hline $35+$ & 59 \\
\hline
\end{tabular}

The 35 plus age category accounted for 59 or $56 \%$ (Figure 6 and Table 10) of the total participants surveyed, which indicated that the senior teachers contributed the largest support for technology use. Based on these results the assumption made in chapter one about age affecting teachers attitude toward technology use was not supported. The 26-34 age range made up 28 or $27 \%$ and 18 to 25 accounted for 18 or $17 \%$ (Figure 6 and Table 10) of the positive response to technology use. All age groups held a positive attitude in this regard, which did not support the assumption held by the author that teachers' age would affect their interest in the approach proposed by this thesis. Nevertheless, this positive response rate from both sexes and all age group (Figure 6) came with certain conditions regarding their use of technology in the classroom 
(Table 8). It must be noted that the term 'educational tool' in reference to this study was explained to teachers during focus group discussions and once they realized that it would not take away from them achieving their teaching goals, but could help improve both teaching and learning they displayed a more supportive attitude towards the study being conducted. Teachers' responses also showed that when it comes to improving educational standards, they are more concerned about what is in it for the students and identify the best possible teaching practices to accommodate their learning variations (Miller, 2007; Myers and Halpin, 2002; and McGuinn, 2006).

Tables 7 and Table 8 also include some reasons behind principals and senior education officials' belief in making teachers and students, not only technology savvy, but also able to manipulate the technology in ways to transmit better and improved teaching and learning. The size of the discussion groups, small or large, had no effect on teachers' attitude toward technology use as the total number in each group varied. Further findings revealed that teachers who are involved in the developmental process and discussions of technology use in the classroom have stronger beliefs and feelings toward the use of these types of resources. These findings support the methods used in this thesis to involve teachers and demonstrate why their input was important. Teachers must play an important role in using new technology to enhance the learning of their students. In this way, teachers become an important element in the education of children in the use of technology as a learning element and not just a technological tool. GIS or any other educational related technology is not, and never will be, transformative on its own; it requires teachers who can integrate technology into curriculum and use it to improve student learning. 
Teachers firmly agreed that some form of technological innovation would definitely help motivate students in the learning process because this educational approach would maintain their interests and target those students who are not academically inclined (Survey, 2008). According to teachers this was based on their experience with using an overhead projector and PowerPoint as teaching aides. This view was confirmed by two senior educational officials, who were interviewed in August, 2008. They stated, "research has proven that some form of technology in the learning process of students is very beneficial because of the diverse learning opportunities it provides" (Personal Interview, 2008). In this respect, when asked the question during an interview: Do you think that a larger percentage of students in the public school system are more technically skilled than academically inclined? A senior education officer stated:

The numbers show that the majority of our students tend to have a more technical interest, and I suppose that is world-wide, you are only going to find a small percentage of students who are purely academic. So I think for a very long time we have been trying to make students who are technically inclined more academic. This might have been a cause of concern, but I think now we are beginning to recognize that perhaps we need to place a little more emphasis on the technical area while we do not want to throw away the academic. But you still have to prepare students in an area that they are going to feel some measure of success and that they can feel ownership. I think the emphasis particularly this school year when we look at the whole magnet school programs will be more on technical and vocational education (Personal Interview, 2008).

In response to the previous question, another senior educational official said:

Technology will have a great effect on improving the educational standards of students, especially in the areas of literacy and numeracy. If we do not want to be left behind globally, students need to be properly equipped. When we consider all of these international organizations that are promoting globalization of world economies and the free movement of trade and labour, then we must be competitive. Therefore, this can only be made possible through providing students with all the educational possibilities available (Personal Interview, 2008). 
When asked if the use of some form of technology is important to help improve educational standards, a senior education official responded:

There is no question about it and technology was one of the early recommendations of the committee in producing the 10 year plan for education. The recommendations were so strong that in September, 2008, there will be a division in the Ministry of Education geared specifically toward technology. This means that this division will be responsible for the procurement, distribution, training and maintenance of all technological media to the schools. We want to make sure that not only do the schools have the equipments, but they also know how to use them. So the emphasis is definitely going to be on technology (Personal Interview, 2008).

Each of the above responses and teachers overall attitude suggest that educators believe some form of technology use such as GIS can assist in improving educational standards.

\section{Discussion and Findings on Students' Attitude towards Technology use in the Classroom}

Although the learning environment continues to evolve, educators need to remember to adhere to sound pedagogical principles (Ahola-Sidaway and McKinnon, 1999; Grasha and Yangarber-Hicks, 2000). With the increased use of instructional technologies such as chalkboard, websites, PowerPoint, discussion forums, and other online and technological resources, educators may find themselves focusing more on the "bells and whistles" as opposed to the final goal of helping students learn. Over the years this has become a major concern among educators when it comes to a technology like GIS because generally the main focus is placed on students becoming competent in using the technology (Unwin, 1991 and Cuban, 1986). A concern for educators should be not to overwhelm students with technology; this could lead to the students becoming frustrated with the technology itself, hindering their efforts to learn the subject content. 
One way to ensure that teachers are positively influencing the learning environment with their use of new technologies is by asking the students what their opinions are with regard to technology use and how some use of it could help improve their learning, as well as finding out their perceptions of their schools' learning environments (Table 11 and Table 12). Based on the knowledge that students have different learning styles and may need course content presented in a variety of ways, finding out students' attitudes toward technology use is essential (Bostock, 1998). To accomplish this, individual focus group discussions were held with a total of 26 students from the three schools to gather their opinions on how they viewed their current learning experiences (Table 12) and whether they thought technology use in the classroom will help improve existing learning environments (Table 11).

In the selection process for student participants for the focus groups, teachers were instructed to include students of mixed-ability (academic, technical and vocational), both sexes and different age and grade levels $(10,11$ and 12) to examine whether these factors would affect their attitudes toward technology as hypothesized. At the beginning of the group discussions, students were asked which academic program (Business studies, tourism studies or technical and vocational studies) they were enrolled in to help determine their academic standing. In Bahamian schools, students who are more academically inclined are generally placed in the business studies program.

Based on the results, female students who accounted for $62 \%$ of the student-participants gave a higher level of support for technology use. The age range category was from "14 to 17" and grades "10 to 11 " which did not affect students' technology attitudes because all students provided a positive response. The reasons why grades 10 and 11 were selected were because if 1 ) 
a technological resource is to be used in the school systems, they are the ones who are more likely to benefit from it and; 2) it was more reasonable to get these grade levels involved, when compared to grade 12 who was being prepared for coursework and national examinations. Results indicate that a students' age, grade level and academic standing, did not affect their attitude toward the use of technology in the classroom (Table 11). However, there was a difference in the level of support provided for technology use by gender. Table 11 provides verbatim feedback by gender that students provided for supporting the use of some form of technological resource in the classroom.

TABLE 11: Students Reasons for Technology Application by Gender

\begin{tabular}{|l|l|}
\hline \multicolumn{1}{|c|}{ PARTICIPANTS' GENDER } & \multicolumn{1}{|c|}{ REASONS FOR TECHNOLOGY USE } \\
\hline Male & $\begin{array}{l}\text { I think that some form of technology would help } \\
\text { because instead of sitting down for an hour listening } \\
\text { to the teacher talk and writing notes, some form of } \\
\text { technology could be used to help you learn other } \\
\text { skills. }\end{array}$ \\
\hline Female & $\begin{array}{l}\text { Technology would provide activities where students } \\
\text { would be more involved }\end{array}$ \\
\hline Male & $\begin{array}{l}\text { There is more to learning than just writing and } \\
\text { technology has made this clear. }\end{array}$ \\
\hline Male & $\begin{array}{l}\text { Technology could help us to be more active and } \\
\text { motivated to do the work. }\end{array}$ \\
\hline Female & $\begin{array}{l}\text { Using some form of technology to learn with always } \\
\text { gives you a chance to learn something new. And if } \\
\text { you know that you are going to a class where the } \\
\text { lesson will be taught differently sometimes, then you } \\
\text { would be more motivated in going to that class. }\end{array}$ \\
\hline Female & $\begin{array}{l}\text { It would provide students with a more advanced way } \\
\text { of learning. }\end{array}$ \\
\hline
\end{tabular}


Distribution of the students' overall perceptions of the learning environment is shown in Table 12. A positive response was classified as students perceiving that the learning environment "facilitated" their needs and expectations; a negative response meant it "did not facilitate"; and a neutral response meant that even though they were not fully pleased, there were students who held an "impartial" perception about their learning environment. Students' perceptions of their learning environment (Table 12) correlated with their reasons for the use of some form of technology (Table 11).

TABLE 12: Students Perceptions of the current Learning Environment

\begin{tabular}{|c|c|}
\hline PERCEPTION & FREQUENCY \\
\hline Positive & 4 \\
\hline Negative & 17 \\
\hline Neutral & 6 \\
\hline
\end{tabular}

When students were asked whether some form of technology would make learning more interesting and keep them involved during class time, all of them gave a positive response. It appears that students felt the frequent use of some form of technology by their teachers would better help them achieve and participate in their classes (Table 11 and Table 13), thus supporting the arguments of this research. Many teachers use email, PowerPoint, and information from subject websites to help supplement classroom instruction, so this supports the continued use of these technologies for instructional purposes and not solely to teach the technology (Lukow, 2002).

Findings from this study show that to a considerable extent students are dissatisfied with traditional approaches to learning (Table 12 and Table 13) and suggest that this might contribute 
to poor pedagogical standards among students. Table 13 provides a documentation of verbatim responses given by students to the question of whether they are satisfied or dissatisfied with traditional methods used to teach them.

TABLE 13: Students Satisfaction and Dissatisfaction with Traditional Teaching Methods used

\begin{tabular}{|l|l|}
\hline \multicolumn{1}{|c|}{ SATISFACTION } & \multicolumn{1}{|c|}{ DISSATISFACTION } \\
\hline $\begin{array}{l}\text { There are some teachers who actually care } \\
\text { and try to explain the lesson thoroughly } \\
\text { and get students involved. }\end{array}$ & $\begin{array}{l}\text { Just writing information from the chalkboard or } \\
\text { textbook does not really show or help us with } \\
\text { how we can use this information in real life. So it } \\
\text { seems as if the GIS system would help us better } \\
\text { understand how we can use this information in } \\
\text { real life or for a job. }\end{array}$ \\
\hline $\begin{array}{l}\text { Some teachers will tell you to come to } \\
\text { them after class if you did not understand } \\
\text { something during class time. Also there are } \\
\text { others who would have afternoon classes to } \\
\text { further help students }\end{array}$ & $\begin{array}{l}\text { I am not fully pleased because I think that some } \\
\text { form of technology could improve teaching and } \\
\text { help students better understand some lessons } \\
\text { taught }\end{array}$ \\
\hline $\begin{array}{l}\text { I am pleased because if we are discussing a } \\
\text { topic in class and my response is wrong, } \\
\text { the teacher will explain to me why what I } \\
\text { said is incorrect and give me the correct } \\
\text { answer. }\end{array}$ & $\begin{array}{l}\text { Some teachers actually give you assignments to } \\
\text { do without even teaching it. }\end{array}$ \\
\hline & $\begin{array}{l}\text { I think that teachers are not applying their } \\
\text { knowledge with creativity. }\end{array}$ \\
\hline
\end{tabular}

Students' responses helped support the view that using traditional methods of teaching and learning alone cannot provide them with an engaging learning experience and do not meet all of their learning styles. Students agreed that using a technology like GIS as an educational tool would help provide a better learning experience, one that would motivate them to participate during class. But the student-oriented sessions also revealed that the problem with students' lack of participation could partly be due to them not wanting to participate. During discussion time 
when students shared how their teachers taught them, the MIs were taken into account to examine how many of the intelligences are actually utilized during teaching. The students' focus group discussions confirmed that Howard Gardiner's verbal-linguistic intelligence is most frequently used.

\section{Students' Demographics and Attitudes toward the Use of Technology}

The final section of the focus group discussions addressed students' attitudes regarding how they felt the specified technology or any other form of technology would facilitate or distract their learning. A rating legend was provided to guide their responses: the range of the scale extended from 1 , being the "lowest" to 5 , being the "highest" and with 0 representing students who were "undecided" (Figure 7). The "rating legend" represents the point ranking from 0 to 5 given by each student for technology usefulness. Figure 7, Table 12 and Table 13 below display how students felt about the use of some technological resource during classroom lessons. Figure 5 also shows the percentage distribution of students rating for technology usefulness in facilitating or distracting their learning; and Table 14 provides the total number of students' responses for each rating (on a scale of 0 to 5 ). 


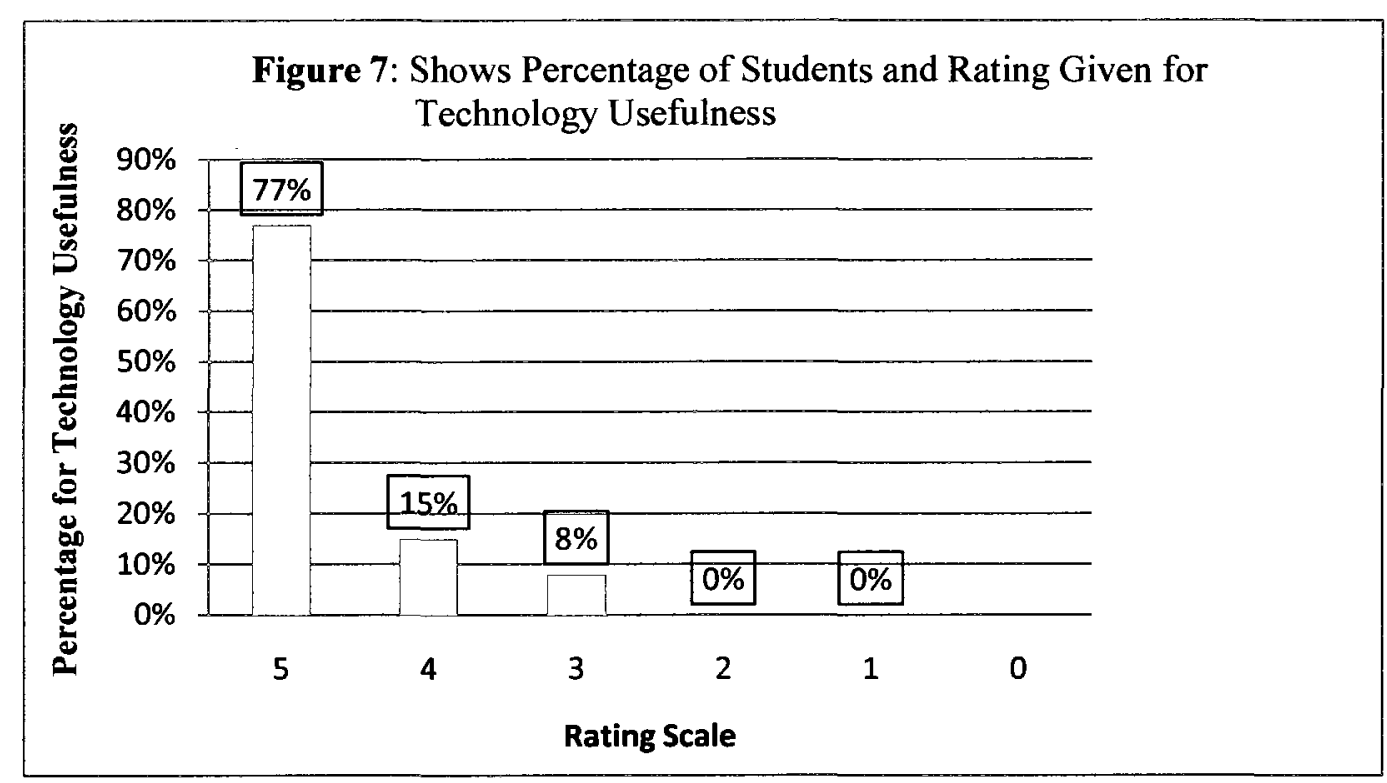

TABLE 14: Total Number of Responses for Technology Usefulness Rating by Students

\begin{tabular}{|c|c|}
\hline TECHNOLOGY USEFULNESS RATING SCALE & $\begin{array}{c}\text { TOTAL NUMBER OF } \\
\text { RESPONSES }\end{array}$ \\
\hline 5 & 20 \\
\hline 4 & 4 \\
\hline 3 & 2 \\
\hline 2 & 0 \\
\hline 1 & 0 \\
\hline 0 (Undecided) & 0 \\
\hline
\end{tabular}

A 5 point rating was given by 20 or $77 \%$ of the total 26 students for the usefulness of technology in facilitating their learning (Figure 7). In addition, there were 4 or $20 \%$ of students that provided a " 4 point" rating and 2 or $8 \%$ of the students who gave a rating of " 3 " for some form of technology being useful in facilitating learning (Figure 7 and Table 14). All the students involved provided a level of support for technology usefulness in the classroom (Figure 7 and Table 14), including the ones that said they did not have regular access to technology. Therefore, no student felt that technology use would distract them from learning but help them to have a 
better educational experience. As a result there were also no students who were undecided or gave a poor rating when it came to deciding on how and if they could benefit from the use of some form of technological resource.

The need for educational improvements or any new approach to be adopted in education, specifically relates to the benefits it provides for student development and achievement. This is why students' opinions on technology as a learning tool in the classroom were important to this study. Even though results from the study indicate that students have positive attitudes toward using technology as a learning tool, as indicated in Table 12 and Table 13 their perceptions of the current learning environment and traditional methods are not good. It goes back to the question of: What is the main goal of education? There is no question that enhancing education through the use of technological resources would help ensure that no child is left behind. But to achieve this means that teacher training and curriculum development must replicate research currently taking place in the field of instructional technology. In this way the current learning environment would be more than just a regular learning experience for students, but one that provides them with various educational opportunities to express themselves.

Results and Discussion on the Importance of Future Educational Developments

The importance of education is quite clear. Education creates the knowledge to allow individuals to put their potential to maximum use. Is The Bahamas' education system educating and training individuals to perform to the best of their ability? The evidence collected in this study from focus group discussions with educators and personal interviews with principals (2008) revealed that this was not the case. Teachers indicated that: 
Even though education is one of the top expenditures in the country's National Budget, it is not given the priority and recognition it deserves. Where much of this revenue is utilized remains a question of concern because many schools still lack the necessary and adequate resources that are conducive for learning. Teachers continue to provide ideas and methods that would potentially improve educational standards among students, but it seems as if no one is listening. Many students, in particular male students drop out of school by grade eleven; and those who remain complain of education boredom because the present education system fails to meet their needs.

The bottom line is that no matter how much funding is allocated for educational development, unless careful consideration is given to where funds are spent and the fundamental nature and origins of the problems are addressed, such spending will be unproductive. In this regard the author's research revealed some of the views of both educators and citizens on the current situation regarding education in The Bahamas.

The average grade for the BGCSE examination continues to fluctuate between D, D- and $\mathrm{D}+$, since its testing began in 1993. Social promotion (allowing students who have failed to meet performance standards to pass on to the next grade level) remains an issue of concern, but the reason given is the lack of classroom space. Teachers are undercompensated and not fully supported. The Department of Education (DOE) contributes to this situation because it fails to modify its existing system (this includes its structure, curriculum guides, and national examinations) to reflect the needs of the learner and demands of the workforce. Public schools, especially those on the Family Islands continue to be plagued with lack of resources and shortages of qualified teachers.

The above concerns shared by both educators and citizens are not unique to The Bahamas' education system. However, these individuals state that these issues have been experienced at the beginning of every school year over the past several years. In response to this a principal stated:

As a country we are not serious about educational developments. And until we have a National Plan for education, we will continue to waste money every year. If technology is one of the aspects we are targeting, with a 10 year strategic plan for education, it would provide effective ways to implement this approach from phase one to phase ten. And it would prevent spending money every year in the same areas and getting no results. When you pilot a program in year one, you would know what the drawbacks are so these same shortcomings should not be repeated in year two. Yes a lot of money is being spent, but in what direction? From my view a lot of money is being wasted (Personal Interview, 2008). 
This raises the question of the priority given by the government, and more specifically the MOE to education. When asked whether everything that could possibility be done to improve education is being done, on a rating scale of 1 to $10,70 \%$ or a total number of 67 teachers surveyed gave a 5 and below rating response (Figure 8 and Table 13). In addition the 15 teachers who participated in the focus group discussions concurred and added that there are problems and difference of opinions in communications between teachers and education policy makers (Focus group, 2008 and Survey, 2008). Teachers further stated that they are open to using new approaches that would potentially improve educational achievement in students and get parents more involved in this developmental process, but they do not have the power to do so. This lends support for the argument of why educational improvements are necessary for The Bahamas, and why the level of educational priority should be placed on measures that will provide a more enhanced learning environment for students.

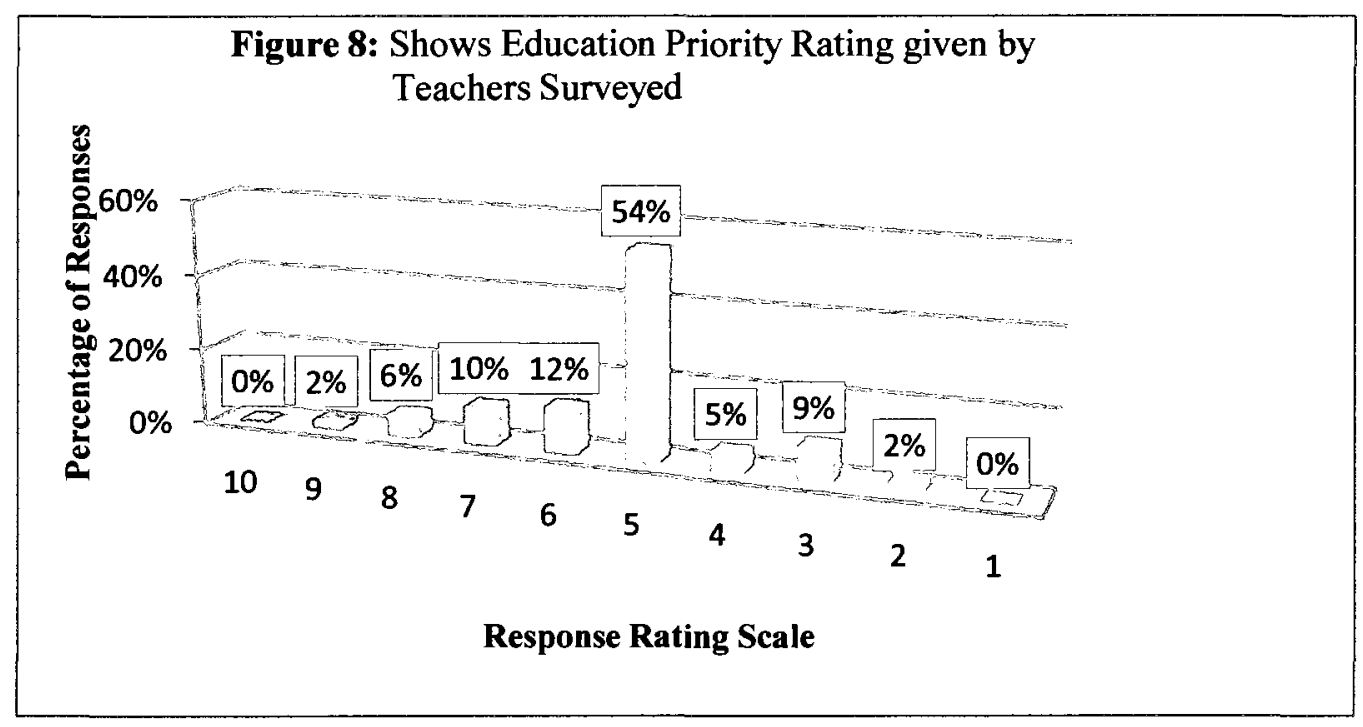


Using a scale from 1 to 10 , teachers were asked to identify what rating they would give for the government's priority on educational improvements. Figure 8 provides the results of their responses, and Table 15 shows the total number of responses for each rating (1-10).

TABLE 15: Priority Rating for Education Development and Total Number of Teacher Responses for each one

\begin{tabular}{|c|c|}
\hline EDUCATION PRIORITY RATING SCALE & TOTAL NUMBER OF RESPONSE \\
\hline 1 & 1 \\
\hline 2 & 2 \\
\hline 3 & 9 \\
\hline 4 & 5 \\
\hline 5 & 57 \\
\hline 6 & 13 \\
\hline 7 & 10 \\
\hline 8 & 6 \\
\hline 9 & 2 \\
\hline 10 & 0 \\
\hline & \\
\hline
\end{tabular}

According to Figure 8 and Table 15, there were $30 \%$ or a total of 32 teachers who gave a six and above priority rating for educational improvement. However, $70 \%$ or a total of 73 teachers gave a 5 and below rating for the priority of educational improvement in The Bahamas. Therefore, many educators are of the view that not sufficient priority is given to educational improvements and a lack of attention is given to the enormity of the educational problems that currently exist in The Bahamas (Focus Groups, 2008 and Survey, 2008). These numbers indicate some level of concern when it comes to teachers' view concerning the level of priority that is 
placed on education, because it creates problems for student achievement and improved standards. But this is not to say that these results reflect the views of all Bahamian educators.

In-spite of the rating teachers gave for the priority placed on education by the government, the MOE must be given some credit because they are trying to address some of the educational issues. A senior education official stated that a 10 year strategic plan for education is in the developmental process. However, some educators feel as if this plan for education is very late in coming because at this point they should be working from it. It is obvious that educational development is given priority when it comes to collaborating on measures dedicated to these issues. However, whether it is given top priority when it comes to the implementation of these measures is another concern among teachers and this is further supported based on the data collected (Figure 8 and Table 15). If educational improvement is to be a successful process, all stakeholders directly involved must be given an opportunity to make their contribution (Miller, 2007). They must see that their contributions are valued and taken into consideration when it comes to educational reform.

TABLE 16: Common Themes provided by Teachers for the Importance of Educational Improvements

\begin{tabular}{|l|c|}
\hline \multicolumn{1}{|c|}{ COMMON THEMES } & TOTAL NUMBER OF RESPONSES \\
\hline Improve educational standards & 53 \\
\hline Compete globally & 47 \\
\hline Economic growth & 25 \\
\hline Competent and competitive workforce & 19 \\
\hline
\end{tabular}

This table provides the common themes derived from feedback that teachers involved in this study gave for the importance of educational improvements, in addition to the occurrence of 
their support for each theme. According to the data in Table 16, a total of 91 participants responses were economic related (compete globally, 47 responses; economic growth, 25 responses; and competent and competitive workforce, 19 responses). These results support the view that improvements in educational standards are reflected in a country's economy because education plays a vital role in maintaining a competitive market.

TABLE 17: Educators' Reasons for the Importance of Educational Improvements

\section{IMPORTANCE OF EDUCATIONAL IMPROVEMENTS}

Without educational improvements the society and education system would remain stagnant, which would probably lead to an increase in social ills.

Globally, technology is advancing, therefore if The Bahamas is to be competitive in the global market Bahamians must be properly educated not just based on local standards, but universal standards as well.

The overall progression of a nation is highly based on the level of education it provides; therefore it is vital that standards are improved.

Educational improvements are important to ensure that education reflects the demands of the workforce and to help encourage students to pursue studies in these areas.

Employers complain about the poor quality of the local workforce, especially when it comes to the more advanced positions. Many Bahamians perform poorly when it comes to those jobs that require application of knowledge and skills.

Educational improvements are important if more emphasis is being placed on improving standards in the elementary school area to ensure that students develop a strong foundation.

To provide an educational structure with diversity, that is, one that caters to improving technical and vocational skills, which is a must in the twenty first century.

It is important so that Bahamians can adequately contribute to the country's development and not be second class citizens in their own country.

Table 17 provides a general summary of the reasons that all educators (education officials, principals and teachers) provided for why educational diversification and improvements in Bahamian schools are important. One point made by a high school principal 
that should be highlighted is the fact that educational improvement "is vital in order for any country to sustain itself and to realize that any amount of growth or development is directly based on the educational level of a country". He added that "you can only develop as a nation if you invest in education. If you want to move a country from one phase to the next, education is the tool that will need to be use".

Evidence provided in this section of the thesis and in Table 17 indicates that exploring why educational improvements are important for The Bahamas is indeed warranted in supporting the arguments presented. This also supports the argument that educational improvements and the diversification of educational opportunities are paramount, a view also held by teacher participants involved in this study (Table 16 and Table 17).

Nevertheless, there are some possible challenges and concerns that need to be acknowledged because they might come up if the approach proposed by this thesis is implemented. Some of them include: 1) the fact that making computers and internet access available to all schools in The Bahamas is indeed an expensive venture, as well as upgrading them on a regular basis, 2) there is the possibility that the use of GIS technology can cause teachers to focused more on information related to global matters because they are readily available via the internet and be detracted from using or improving information that is unique to The Bahamas, 3) GIS databases are available for natural disasters such as volcanoes and earthquakes, but what about hurricanes that have an impact on The Bahamas and the Caribbean every year, and 4) will more schools in Nassau and Grand Bahama be introduced and better equipped to use this GIS technology as an educational tool when compared to Family Island schools? 
The BNGIS Center has been provided with a mandate by the government to expand their GIS initiative into areas, other than education. The center has taken their GIS school-based initiative beyond New Providence and Grand Bahama, which shows that they are committed to ensuring that all schools have an equal opportunity to be exposed to and take advantage of this pervasive technology. However, the BNGIS center must be commended for the job done thus far, considering the challenge it has with the lack of manpower, by not having sufficient GIStrained personnel to rapidly advance their GIS programs. The GIS center working closely with the MOE to develop a strategic plan to further develop the GIS-based program could ensure that the above challenges and concerns are effectively addressed. Therefore, there is no doubt that in order for the approach indicated in chapter one to be a success, the direct involvement of the BNGIS center will play a significant factor in this regard.

The flexible nature of focus groups also allowed the author to have teachers participate in the development of the sample tutorial called: 'GIS as an Educational Tool'. This provided room for in-depth discussions with teachers on: 1) how they view the learning and teaching experience using the approach promoted by this study; 2) whether they would use it as a teaching method; and 3) suggestions on what changes could be included to improve the module so that the it reflects the ideas of teachers and not just the author (Hoggart et al., 2002). Two common themes that came out of these discussions are: 1) The lack of parental involvement in their children's education; and 2) The dynamics of education are changing globally, so therefore the curriculum in The Bahamas needs to reflect these changes. A practical means of how this technology can be used as method to teach students subject content and how to apply that information in real life settings follows. 


\section{GIS as an Educational Tool: A Sample Module}

GIS offer useful tools for educators to teach students in various subjects, particularly the sciences, but the growth in its use in education is hindered by time limitations and access to the resources necessary to adequately learn the complexities of a GIS software package such as ArcView. The situation could be substantially improved by providing teachers with guidelines and sample lessons illustrating the use of this technology in a classroom environment. This would provide them with a more user friendly approach to using GIS and creating lessons that utilize the technology as a pedagogical tool. 'GIS as an Educational Tool Sample Module' provides an approach that will allow teachers to focus on using the technology as a means that enhances their teaching (Audet and Paris, 1997; Meyer et al., 1999; White and Simms, 1993).

This module demonstrates that the importance of GIS use in education is not so much the technology but its ability to help students to better understand subject content, and spatial interactions within their community. This module has not yet been tested by teachers, its purpose in this thesis is to act as a prototype of what could be done at a practical level. This module is being used as an example to support the central arguments presented in chapter one. It promotes a less complex option (Tinker, 1992 and TERC, 1995) that can be explored and developed in order for GIS and related technologies to be more easily accessible to more teachers and students. So instead of teachers attempting to learn or teach a full GIS package, the goal here is to select or identify a GIS tool or technique that can be used as a strategy during teaching or through student activities to practically reinforce what has been taught. One of the main objectives behind this sample module is to allow teachers to focus less on teaching GIS 
technology and more on using GIS as a tool that complements their curriculum. In this case teachers do not have be GIS trained, or find time to develop GIS-related lessons because they will be encouraged to use their regular subject lesson plans and utilize GIS methods to help improve and complement current teaching strategies.

This module guide provides some ideas and steps that can be considered when teaching with GIS. It is hoped that using the steps included in this section will help educators better assess the educational advantages that the use of this technology provides for both teachers and students. This approach to using GIS in education will help change teacher and student roles, communication, and methods of teaching and learning. Therefore, this section of the thesis provides a sample module that teachers can test in their classrooms.

\section{Module Rationale}

This sample module has been created to help overcome the many difficulties school systems currently experience with utilizing the technology such as the need for accessible data, and other technical obstacles. It has been designed as a means to helping improve teaching and learning methods in Bahamian high schools. Problems in Bahamian high schools with access to software and hardware are major reasons why the adoption of GIS or any other form of technological resource has been so slow in many classrooms. These are critical reasons why GIS has also been slow to diffuse into an educative role in many classrooms. While some progress has been made with the introduction of GIS in K-12 education, the effective use of the technology as an educational tool in the curriculum remains a major problem. 'Tourism' was selected as the topic for the module because teacher participants involved in the focus groups agreed that it would be an appropriate topic to use. This is a topic that students are familiar with, 
and it plays a vital role in the economy of The Bahamas. Students are more motivated to learn when the data pertain to their local community (Meyer et al. 1999 and Alibrandi, 1998). By developing and analyzing various ideas and information related to some local aspect of tourism in their surrounding community, students may find the information more pertinent to their lives and become more likely to be interested in the curriculum. Students can then use this knowledge to better understand broader global tourism and economic related issues and how these might affect their local economy. This is not to suggest that learning experiences should only focus on what students are familiar with, but it should show them how to use information learnt beyond the walls of the classroom.

The Bahamas' tourism industry is currently a leading provider of foreign exchange income for the entire country. Tourism is one of the industries with the strongest effect on the economy, because it helps in developing other sectors. The government continues to implement and support initiatives for effective management and promotion of the industry with special consideration to the role the environment plays in tourism development. Prime Minister Hubert Ingraham in 2008 created a new Ministry for the Environment. This signified the government's commitment to preserving the country's environment and its natural resources. This module focuses on using GIS as a teaching tool to assist in making students more aware of the significance of the environment and what part they can play to ensure its proper maintenance by providing them with an opportunity to contribute to tourism planning, tourism development and tourism marketing. At the same time students will gain knowledge about the importance of tourism and the environment in The Bahamas and why so much emphasis is placed on both. 


\section{Module Description}

The advantages of getting started at a simple level with GIS are many (Eylon, 1998). However, many individuals tend to be caught up in learning about the GIS-related technologies, and have ignored or abandoned exploring other uses of GIS. This module incorporates many of the ideas and feedback gained from teachers involved in the focus group discussions. The fact that teachers were involved at this level is significant because they are more likely to try out the ideas in the module because they were involved in its development. Their interest level is likely to be very high. The module contains the instructions for both teachers and students; online GIS sites that can be easily accessed (found in the module guide), objectives, strategies and activities that attempt to utilize GIS as a teaching means to help students better understand and apply the information learnt on tourism in The Bahamas. The module has been designed to make it more student-centered and exploratory with teachers playing a minimal leadership role. This will allow more communication to take place and questions to be asked from the students' perspective and responds to the educational theories of the need for active student involvement in learning outlined earlier in this thesis.

\section{Web-based GIS Software Description}

The module contains internet sites for web-based software. The first one is ArcExplorer, which is provided by the Environmental Systems Research Institute (ESRI). ArcExplorer-Java Edition for Education (AEJEE) was designed as an introductory-level desktop application to view, query, and analyze GIS data and conduct basic spatial processes on both Windows and Macintosh platforms. Puzzle GIS, a Java GIS development platform build on top of NetBeans6. The main goal of Puzzle GIS is to create a free, production ready and competitive tool as a valid 
alternative to commercial software. The other Web-based GIS software included is WorldWatcher software provides an accessible and supportive environment for students to explore, interpret, and analyze data in a manner which allows them to emulate the work of actual scientists. WorldWatcher is currently known as the GEODE Initiative. The GEODE Initiative currently supports a middle school and a high school curriculum initiative. Both initiatives integrate scientific visualization into an inquiry-based program of hands-on labs, group work, and discussions to enhance students' understanding of the scientific and social issues associated with our changing environment. Toward that end, the GEODE Initiative is engaged in a program of integrated research and development in the areas of learning, teaching and educational reform. The GEODE Initiative develops and studies curriculum, software, and teacher professional development.

Finally, My World GIS ${ }^{\mathrm{TM}}$ software is designed specifically for use in educational settings. It allows learners to explore and analyze geographic data about our world. My World is designed to meet the needs of students and teachers while keeping the constraints of educational settings in mind. It combines the power of a full-featured GIS environment with the support and structure required by novice users in an educational environment. PASCO has an array of licensing schemes to meet the needs of different K-12 and higher education institutions, including K-12 school, K-12 district, higher education department, and higher education campus site licenses. All institutional licenses offer an option for student at home use. The websites where the above mentioned software can be accessed will be available in the actual module. 
Design Considerations: Motivation, Technical and Resource Aspects, content and learning abilities

The process of designing this module could have included ideas and aspects from many other online course or technology-focused lesson(s), but whether these effectively address some of the major concerns that educators presently encounter with utilizing GIS and related technologies in Bahamian schools is an open question. The problems with many of the existing technology related courses are that they tend to focus on teaching about the technology and do not incorporate suggestions from teachers in their design (Tinker, 1992 and TERC, 1995). The design of this module used teachers input as a basic building block. This module provides modifiable guidelines for teachers to follow while teaching any lesson, but these guidelines give them the option to use a technology as a teaching tool in their lesson without having to worrying about training, infrastructure or not achieving lesson goals. The module may not be perfect, but it demonstrates the validity of the central arguments and approach of this thesis in a concrete fashion.

\section{Motivation}

Many course designs fail to mention 'motivation' as a major factor in the implementation and advancement of their ideas. Studies (Darling-Hammond and Berry, 1998) indicate that motivation is a major factor in increasing the use of the method(s) and reducing the level of nonsupporters. As with any new approach in education or the business arena, the motivation level of the individuals involved is vital. For the success of any idea or approach, you need the support of those directly involved in the developmental process, which means these individuals have to be inspired to use whatever it is. This level of motivation and commitment can only be obtained and 
maintained if these individuals are of the view that their suggestions are of some value to the success rate of the product at hand. In this case, teachers are key participants in determining the difference that GIS would make in Bahamian high schools. This is why the study and module design incorporated ideas from teachers because this will make a great difference in whether teachers will be enthusiastic about using this method. The feedback from teachers provided strong supporting evidence for the central arguments in this study.

\section{Infrastructure (Technical and resource aspects)}

With this approach to using GIS, teachers do not have to worry about the lack of infrastructure such as technical support when they do not understand a concept in a GIS course, or when there is a software or hardware problem. Teachers often lack the knowledge and technical expertise on what to do in such circumstances. Having or maintaining the appropriate resources should not be a major concern for teachers as they are not teaching about GIS, so therefore do not have to be concerned about having sufficient computers or adequate memory to host a GIS program. GIS as an Educational Tool Sample Module focuses on teachers using the tools of GIS to deliver the content of their various disciplines, but in a more dynamic, creative and diversified form. It provides ideas, which consider the fact that students learn differently as supported by the theories earlier discussed and allows teachers to accommodate a large number of these learning needs, if not all in one single lesson. 
Curriculum Requirements and Students' needs (content and learning abilities)

The best possible way to develop a design for this module was to ensure that it attempted to minimize the current concerns that educators presently have with using some form of technological resource in their classrooms. While considering how to design this module, curriculum requirements demanded by teachers played a major role; this includes providing students with sufficient content to prepare them for examinations. From examining others studies on GIS and education and analyzing feedback from teachers involved in this study, it emerged that providing students with relevant and accurate content was a major concern. In this regard, the module design provided substantial room for teachers to meet their curriculum requirements through content delivery and at the same time use a technological resource to complement and improve their teaching methods.

A major problem in many education systems seems to be getting students to interact during the learning process, but using GIS in education has been shown to actively engage students (Kerski, 2001 and Green, 2001). Also both Howard Gardiner's Multiple Intelligence theory and the Constructivist theory, encourage the use of interactivity methods to engage students. The impact this approach to using the technology would have on students' learning abilities was also considered. Students possess varied learning abilities, therefore teaching and evaluation methods should reflect this diversity. The proposed approach suggested by this thesis is just one means that provides numerous applications to help make this possible. This was viewed as the single most important aspect when promoting the use of any new method in education, which is the impact the approach, would have on students learning. 


\section{Discussion of Sample Module}

GIS is a highly dynamic field, growing at the very rapid pace of technological change and increasing number of applications. GIS is one of the few modern tools to live up to, and exceed, its early promise (Davis, 2001). But in this extensive and swift growth, and the potential benefits this technology presents for education have not been fully explored or adequately implemented. The use of GIS as recommended by this thesis helps provide the opportunity for students at any ability level to achieve some form of mastery in their subject areas. It provides visual and handson approaches to helping all students better and easily understand information and concepts being taught in class. For example, if you are teaching measurements in Mathematics or geography, GIS tools can help reinforce this concept and at the same time provide students with a practical learning experience. This attempt to using GIS also gives students the opportunity to be directly involved in the learning experience, discovering and constructing information on their own. According to Bruce E. Davis (2001), GIS is a visual methodology and technology, and it is best learned by illustration of its concepts and operations.

By developing a more easy and useable means to adopt GIS in education support the arguments of this thesis in terms of: the technology being able to address some of the educational problems in the Bahamian education system, by showing that the pedagogical benefits offered by GIS can assist in improving teaching methods and student achievement. But in order for this to come to fruition, there has to be a collaborative effort among educators and the GIS community. Furthermore, it will remove the focus from teaching students about the technology; and aim at developing students with spatial reasoning and applications skills and not merely GIS-skilled individuals. The concept of this approach to using the technology is significant because it 
addresses a major gap that exists in the literature on GIS and education. It is an area in the literature where there seems to be little or no research on using GIS as an educational tool or evaluating the difference this technology makes in education. A brief discussion of some of the reasons that teachers provided for selecting Tourism as the topic for the module will be given in the following section.

\section{Educators' Reasons for Educating Students about Tourism in The Bahamas}

During the focus group discussion, many teachers expressed similar reasons for supporting the topic of Tourism as a focus for student education. Many teachers stated that even though a topic like tourism might not come under their discipline, in The Bahamas all students should have a basic understanding of tourism and the enormous role this industry plays in the country's economy and overall development.

One teacher stated that she would like students to look at tourism and evaluate whether or not it is really as beneficial to The Bahamas as it is made out to be, given that so much of the country's resources are invested in this industry. This type of questioning will help students to think critically. Tourism may well be a perpetuating dependency rather than helping escape from it. Another teacher said students can use the GIS to upload the data to look at the different types of tourists, and to have a better idea as to where they are coming from. Where tourists originate can determine the source of the bulk of the revenue derived from tourism. It is the belief that all American tourists come to The Bahamas and spend large sums of money, but there are also the European tourists who come and visit more of the rural (Family Islands) areas, looking not just to be tourist, but to a take up home/land ownership eventually. Students can conduct a 
comparative study of tourists visiting a Family island to those coming to Nassau (the capital); in this way they would be able to see that while the capital is in New Providence, tourism is also having a greater impact on those Family Islands because tourists are making more long-term investments in terms of land-ownership and development. However, this in turn can create some social and political problems.

To take the above idea one step further, one teacher mentioned that there are tourists who come for sports fishing and the Ministry of tourism is now promoting ecotourism. For example, some tourists want to visit the Clifton Pier historical site because it is specific to a particular period in Bahamian history. Tourists visit the Family Islands to see the various ecosystems. So nature tourism will have an impact on those particular areas in the environment because it is being used as a means of attracting tourists. This means that proper management efforts have to be implemented to ensure the protection of those areas and to ensure that the environment is not damaged or changed. This approach to teaching "tourism" to students can help the appropriate individuals gain a better understanding of the needs of tourists. If the country is going to stay in this tourism industry, for sustainability purposes tourism personnel need to know what is it they need to do more of, especially on the rural islands (Family Islands) to attract more tourists to these islands. But at the same time students can have fun with this topic because they are provided with a number of activities that require their involvement in and outside the classroom.

With a topic like tourism and the environment students as well as teachers can question 1) whether it is worth sacrificing so much of the country's environment in terms of its natural and marine resources in order to develop one main industry?, and 2) is it a good approach to place so much dependency on one industry for economic stability? Education can be treated as a 
natural resource. If adequate investments are not made, and extraction exceeds investment then the resource will deteriorate overtime.

The GIS technology is rapidly changing, which leaves educators with little time to continually upgrade themselves. However, if the proposed approach to using GIS as recommended in this thesis is promoted, training would no longer be a major concern and Bahamian teachers can take advantage of the technology to help improved educational standards. Whether technology should be used in schools is no longer the issue in education. Instead, the current emphasis is ensuring that technology is used effectively to create new opportunities for learning and to promote student achievement. However, educational technology is not, and never will be, transformative on its own. It requires the assistance of educators to incorporate technology into the curriculum, align it with student learning goals, and use it for engaged learning projects. The details of the module developed by the author to illustrate the approach and arguments made are given in the next section.

It is hoped that this module on tourism will encourage others to pursue avenues of research and development to take advantage of GIS technology and methods to improve the quality of education. When used effectively, educators and learners will realize the potential of these technologies for transferring and displaying knowledge and making powerful connection between places. Hence, fully realizing this potential in schools will require careful stewardship. 


\section{SAMPLE MODULE PLANNING GUIDE}

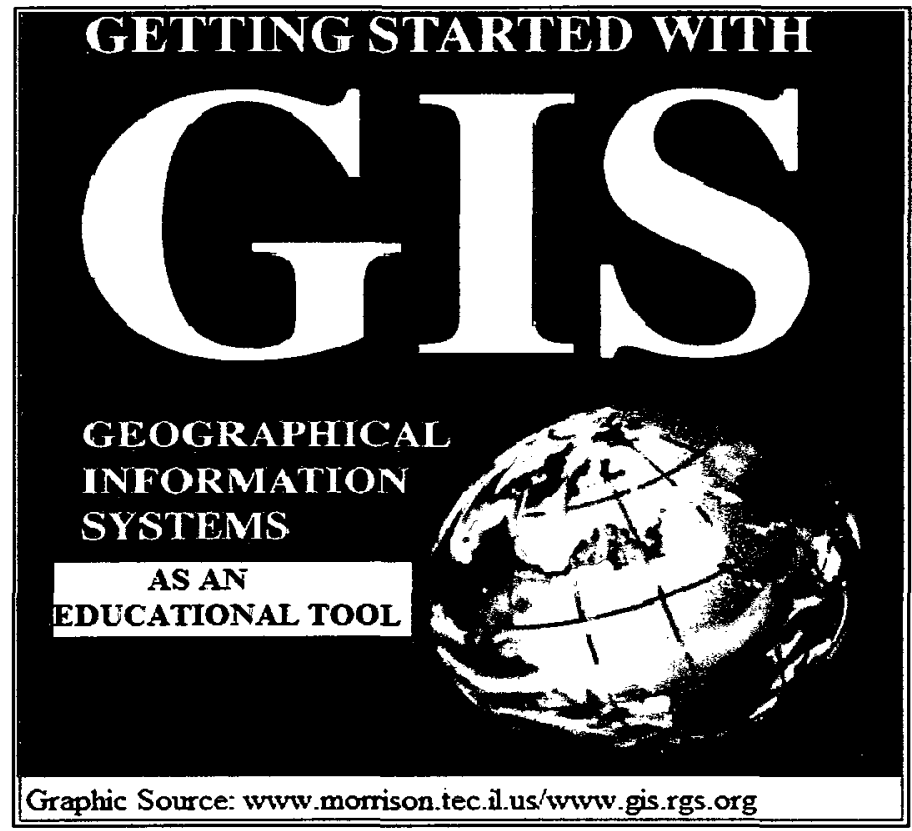

\section{Module Overview}

Using this module, teachers and their students will work together to build a coherent framework for information about their local touristic environment, which can be applied to help improve specific tourism data for any island in The Bahamas. Students will be able to use GIS tools to organize, analyze and update information provided by the teacher or gathered by them on an island of their choice. Students will find, integrate, and use tourism information culled from many sources, which will give them the opportunity to discover materials and answers to questions they might have on their own, with minimal teacher's guidance. The use of this technology as a learning tool provides students with the ability to relate schoolwork with aspects from everyday life, and the opportunity of lifelong learning. 


\section{Module Instructions}

Topic Tourism and the Environment

Where to begin Before using GIS as an Educational Tool: A Sample Module with students, it is recommended that the teacher review and complete the following ordered list:

1. The content for tourism is not included in this module because teachers prefer to select what and how much information students obtain for a topic. Also this was done to allow teachers to match up the included objectives and activities where appropriate for the content that would be provided to students during each lesson.

2. Teachers are to finish reading this section first and then take a look at the objectives and activities so that they can have an idea of where in the lesson GIS tools can be used to better assist them in content delivery or student involvement.

3. If students are going to be required to use computers or go outdoors to collect information ensure that the necessary procedures are in place. This includes ensuring that the necessary internet site, information and materials are readily available. Place students into Groups if there are not sufficient computers or set lab times. Teachers should go to the site(s) where students will visit prior to taking them out, and provide consent forms if an activity requires them to leave the school premise. 
4. Teachers must first work through the module in order to know what information will be taught for each lesson and how much time will have to be allotted. Once teachers have completed the module lessons, they will be ready to guide their students through the first lesson on tourism.

5. If during a particular lesson on tourism teachers plan to use a GIS tool to teach with or for students to complete an activity, they are to include how that tool would be used while teaching. For example, if students are required to know where the major hotels or resorts are on an island, let them know while teaching the lesson which tool(s) will be used to first, draw a map of the area, then plot the places. Also provide images of how the tools look.

6. If students are going to complete an activity, make copies of the instructions or if this is not possible then create an electronic copy for them to view on the computer or via PowerPoint.

Estimated time Four 45 to 60 minute class periods.

Materials

Students handouts from this lesson to be copied:

$\checkmark$ Tourism-related investigation sheets where applicable

$\checkmark$ Student activity sheet

$\checkmark$ Student assessment(s) 
National geography standards for High School

\begin{tabular}{|l|l|}
\hline \multicolumn{1}{|c|}{ Geography Standard } & \multicolumn{1}{|c|}{ High School Standard } \\
\hline $\begin{array}{l}\text { How to use maps and other geographic } \\
\text { representations, tools, and technologies to } \\
\text { acquire, process, and report information from } \\
\text { a spatial perspective. }\end{array}$ & $\begin{array}{l}\text { The student understands how to use } \\
\text { geographic representations or any other } \\
\text { graphics and tools to analyze, explain, and } \\
\text { solve geographic and real life problems. }\end{array}$ \\
\hline $\begin{array}{l}\text { The physical and human characteristics of } \\
\text { places }\end{array}$ & $\begin{array}{l}\text { The student understands the changing } \\
\text { physical and human characteristics of places. }\end{array}$ \\
\hline $\begin{array}{l}\text { The patterns and networks of economic } \\
\text { interdependence on earth's surface }\end{array}$ & $\begin{array}{l}\text { The student understands the increasing } \\
\text { economic interdependence of the world's } \\
\text { countries. }\end{array}$ \\
\hline $\begin{array}{l}\text { How to apply geography to interpret the } \\
\text { present and plan for the future. }\end{array}$ & $\begin{array}{l}\text { The student understands how to use } \\
\text { geographic knowledge, skills, and } \\
\text { perspectives to analyze problems and make } \\
\text { decisions. }\end{array}$ \\
\hline
\end{tabular}

Source: Malone et al., (2005). Mapping our world: GIS lessons for educators.

\section{Module objectives}

The students will be able to:

1. Provide definitions for: tourism, tourism management and tourism promotion.

2. Explain how tourism contributes to the livelihood of Bahamians.

3. Locate selected islands and provide figures of tourist arrivals on a map of The Bahamas.

4. Identify environmental sites that are commonly visited by tourists and explain how they are perhaps at risk of being altered.

5. Evaluate the impact of tourism development activities on the country's environment. 
6. Identify those major countries where less tourists are coming from when compared to the North American and European Markets. Design an online survey requesting what these people's interests might be as a means of trying to lure more of them to visit The Bahamas.

7. Conduct a comparative study of how tourism in The Bahamas has developed over time and whether the development of tourism has been environmentally friendly.

8. Examine the effect that environmental depletion would have on the tourism industry in The Bahamas.

9. Investigate coastal development and degradation in light of tourism and examine whether tourism is providing a sustainable economic balance for The Bahamas.

10. Examine the role that environmental conservation plays in effective tourism management and promotion for The Bahamas.

11. Describe how developing an electronic tourism catalogue for each island can improve tourism management and promotion for The Bahamas.

12. Present ideas on how the government can maintain an effective analysis of the state of the country's environment.

13. Illustrate why environmental stability, maintenance and preservation are vital to the sustainability of the tourism industry in The Bahamas. 


\section{Teacher notes}

Lesson

Introduction

Teachers can begin the lesson with a discussion, tape recording or video clip on tourism, the environment or both. Teachers can look for a readily available recording or video clip or create one of their own; this is found to be a good approach because they would know exactly what concept(s) students are to grasp at the beginning of the lesson.

\section{Use these questions as a guide.}

From your understanding explain the terms: tourism, tourism management and tourism promotion.

$\checkmark \quad$ Do the tourism industry and the environment share any type of relationship?

Name five islands which tourists frequent in The Bahamas.

After a brief discussion introducing the topic and concept for this lesson, it is suggested that teachers share with their students some of the on-going work in The Bahamas in reference to this topic. Teachers may want to have them explore specified internet sites, magazines or newspaper articles associated with this lesson. These resources should provide information on the latest research into tourism and the environment locally or internationally. During students' investigation, they will look at visual representations of tourism, its direct and indirect positive and negative benefits on people's livelihood and the environment; they will gain a 
better understanding of tourism management and promotion. Students will be challenged in the closing assessment to save a major species or environmental site from destruction from tourism development by using the data they gather in the course of their investigation.

\section{Online GIS access sites}

Teachers have been provided with four Web-based GIS software sites. Some are free and others you might be required to pay a small fee, but nothing compared to ArcMap or ArcView. The cost of an ArcView 9 software package can range from $\$ 1500$ to over $\$ 5000$. The price of the software is also based on the preferred type of license (single or concurrent) and the purpose of using it. These sites will allow teachers and their students to use GIS tools where applicable to carry out learning activities. This reduces the major concern of appropriate and adequate software.

\section{Web-based GIS Software and Sites:}

$\checkmark$ ArcExplorer is Web-based software provided by ESRI. ArcExplorer can be downloaded at no cost. Teachers are only required to complete a registration process. To gain access to: ArcExplorer-Java Edition for Education Version 2.3.2, to launch ArcExplorer Web to create a map go and ArcExplorer User Manuals go to:

http://www.esri.com/software/arcexplorer/download.html

Supported platforms: Windows, Macintosh 
File Size: $113 \mathrm{Mb}$

$\checkmark$ Puzzle-GIS are based on NetBeans 6.5 platform and no installation is required. It can be accessed at: http://puzzle-gis.codehaus.org/ Download Site: http://puzzle-gis.codehaus.org/download.html

Supported platforms: Windows-File Size: $44 \mathrm{Mb}$ Macintosh-File Size: $45 \mathrm{Mb}$

$\checkmark$ WorldWatcher Main Site:

http://www.worldwatcher.northwestern.edu/download.htm

Contains the full version of the WorldWatcher application and all associated files, including on-line help documents.

Supported platforms: Windows and Macintosh

WorldWatcher 3.0.6 for Windows: File Size-36.9 Mb

http://www.worldwatcher.northwestern.edu/windownload.htm

WorldWatcher 3.0.5 for Macintosh: File Size-37.4Mb

http://www.worldwatcher.northwestern.edu/macdownload.htm

$\checkmark$ My World GIS can be obtained at http://www.myworldgis.org/ This software is very affordable. K-12 classroom licenses for $M y$ World GIS begin at $\$ 99$ and PASCO offers a home edition for $\$ 59$. For specifics on pricing and purchasing My World for educational use, visit the PASCO website at http://www.pasco.com/myworld. 


\section{System Requirements:}

- My World GIS runs under under Windows 95/98/NT/2000, Macintosh OS X, Linux, and Solaris. My World requires Java 1.2 or later.

- My World GIS requires a mimimum of $128 \mathrm{MB}$ of RAM. $256 \mathrm{MB}$ is the recommended minimum, particularly for uses involving large data sets or spatial analyses.

\section{FREE 45-DAY TRIAL VERSION}

A free 45-day trial version of My World is available for download. This is a full-featured version of the software that can be used for 45 days from the date of first use. When you purchase My World, you will receive a license key that eliminates the 45-day restriction. It is not necessary to reinstall My World in order to upgrade from the trial version to the fully licensed version.

To download a free 45-day trial version of My World GIS, visit PASCO's My World Trial Registration Page at: http://www.pasco.com/products/software/myworld FreeTrial.cfm.

This section provides some of the skills that students will develop throughout the course of this module, in addition to some of the tools that will be used. Teachers may find that students will be required to use some tools that are not included in the module, but that is the idea of the whole discovery process explored earlier in the theoretical section.

Add layers to GIS-developed Maps of The Bahamas

View a hyperlink to a photograph or image

$\Theta Q \times x \times$ Zoom in and out of the map or mage

(i) Identify a feature to learn more about it 


\section{Measure tool \\ $\leadsto$ New line tool}

- Marker tool

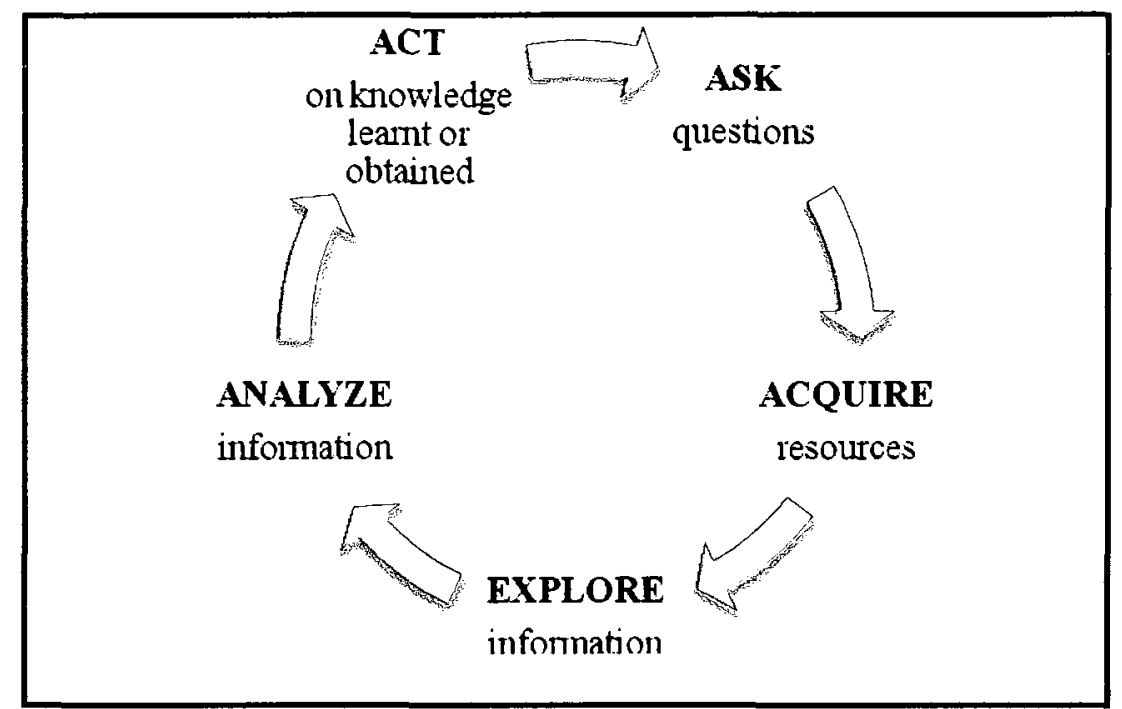

$\checkmark$ Using images (photographs, maps) to construct and analyze information.

$\checkmark$ Discover and critique findings through problem solving issues they will encounter and have to solve throughout the course of this module.

\section{Student Activities}

I. Use a GPS to plot points a Map of The Bahamas indicating the location of the tourist attraction sites.

II. Develop a simple GIS network design displaying historical sites in the country by each island. 
III. Create a timeline showing the changes in tourism arrivals in The Bahamas, including the types of tourists that frequent The Bahamas regularly.

\footnotetext{
? Before completing any lesson in this module with students, it is required that teachers complete it as well. Doing so will allow teachers to modify the objectives and activities to accommodate the time allocated for each lesson, as well as the specific needs of your students.
}

Extended/long-term Activities
(I) Devise a tourism database that can be used to input tourists' data by each island:

a) Select the top five tourist destination islands.

b) Teachers and students can decide on what information they want to be entered or displayed in the database.

c) A simple tourism database can be created to show the location, type and timing of events for both the tourist and the event manager.

(II) Create site maps using GPS (global positioning system) systems affixing plot points of interest (For example for the BGCSE coursework if students are looking at the catchment areas around the school, the use of GPS systems would make it 
more effective and easier) and this data can be uploaded in a GIS system to produce the map.

d) Map, draw or discuss the environmental impact of the physical environment (coastal pollution, erosion, destruction of wetlands, infrastructural development, development of coastal defense strategies), which are directly related to tourism.

e) Develop a simple electronic tourism catalogue sample that allows tourists input data such as: places and sites visited while in The Bahamas, hotels and resorts resided in.

\section{Culminating Activity \\ A Departmental Exhibition can be held for students to showcase} their major pieces of work on tourism and the environment. It allows students to show how GIS is more than a technology, but also how it assist them to learn subject content and apply this information to help solve and improve real life situations. This opportunity can be used to invite government officials or personnel employed in the Ministry of Tourism and Ministry for the Environment, in addition to education personnel to view students' ideas and their work on tourism. This can also be used as a Ministry of Tourism and the Environment publicity strategy to educate people about the importance of the environment for the maintenance of a competitive tourism industry, and making them 
aware of what they can do to ensure the proper maintenance of the environment. This exhibition would allow students to adopt and apply the constructivist paradigm to learning and to apply problem solving skills developed throughout the course of this module.

\section{Student answer sheets} And handouts

All of the investigations that students conduct, with the exception of the extended investigations, should include questions for students to answer as they work (an example is included at the end of the module). Separate answer sheets should be provided for students to write their answers on, except if it is a group activity. Remember that the answers for some assessments will vary, depending on what teachers require the students to do and answer. The "ArcMap Toolbar Quick Reference and "ArcMap Zoom and Pan Tools" are two optional handouts that can be used because students might be using an online GIS program where the tools might be different. It is recommended that teachers consider giving these and any other handouts to their students at the beginning of the lesson, so that they can have time to familiarize themselves with the new tool(s) to be used during the lesson. All of these handouts are located at the end of the module. 
Provide students with the question sheet that they need during the discussion of the lesson or while they work. Teachers can give this handout to students before or after providing them with the necessary content for that particular lesson. The sample that is included at the end of this module focuses on the first three objectives of the module, which should cover the first lesson to be taught.

\section{Rubric-based assessment}

The guidelines in GIS as an Educational Tool Sample Module allow and encourage your students to explore a topic that is practical and hands-on. A single letter or number grade would not be an accurate representation of the depth or completeness of their understanding of the topic taught or all the concepts they have dealt with. The sample rubric included will allow you to evaluate your student's performance in a number of different ways. A learner may show mastery of one particular concept taught, but perform another task at the introductory level or show no understanding. The rubric will also help you to identify the different level of students in your class, the type of activities they show mastery in and the specific ways they prefer to learn. You can add a letter grade if desired, but this approach would also help you to analyze the extent to which each of your objectives were achieved. 
Does not meet requirements: The student does not show any foundational knowledge of the topic and the product they produce shows no evidence of their understanding.

Introductory: The student has limited understanding of the standard. The product (assignment) he or she produced shows little evidence of meeting the standard.

Exemplary: The student has gone above and beyond a particular standard. He or she has a strong understanding of the topic and concept(s) and has the ability to mentor other students.

Mastery: This is the target level for all students. Performance at this level shows that they have a good understanding of the topic and concept(s) illustrated in the standard.

This rubric is just an example of what teachers can consider doing when providing a grade assessment for students. It have does not have used, teachers can create their own assessments.

\section{Conclusion}

Before beginning the assessment, briefly discuss with students what they did, problems encountered, how they went about solving them and findings retrieved where applicable. Use as much of this time to have students share and interact with each other. 


\section{SAMPLE OF STUDENT QUESTION SHEET}

1. After the opening discussion on tourism, what is your definition of tourism, tourism management and tourism promotion?

2. Identify three ways in which tourism contributes to the livelihood of Bahamians.

3. Tourism is vulnerable to external changes. What type of problems will this present for the Bahamian economy?

4. (a) If students are provided with a label map of The Bahamas that includes tourists arrival figures for a selected period you can have them open the GIS file and ask them to:

i. Identify $\mathbf{5}$ islands on the map and provide the tourists arrivals for these islands.

\section{OR}

ii. If students are provided with a blank map of The Bahamas without the tourist arrival figures, you can provide them with this information via handout or on the blackboard and ask them to label the map with any $\mathbf{5}$ islands (using the marker tool) and add the tourists arrival fees next to the islands on the map.

\begin{tabular}{|l|l|}
\hline ISLAND & TOURISM ARRIVAL FIGURES \\
\hline & \\
\hline & \\
\hline & \\
\hline & \\
\hline & \\
\hline
\end{tabular}

NOTE: You can provide students with an answer sheet for this assessment or have them answer the questions in their notebooks or folder sheet. 


\section{Icons Reference Guide Sheet}

\section{Chart GUI - Buttons}

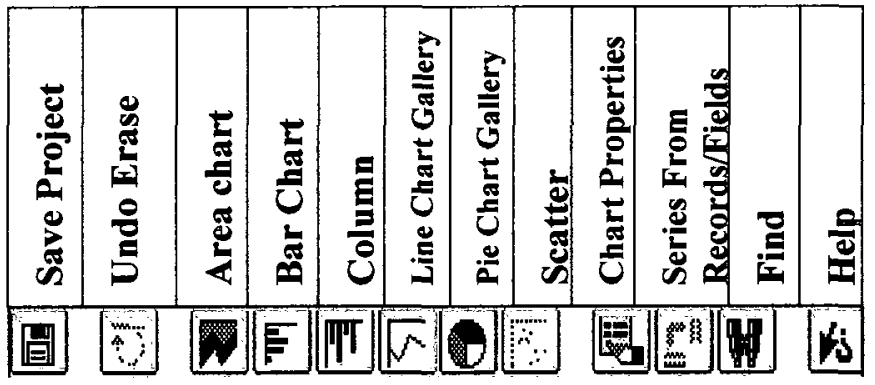

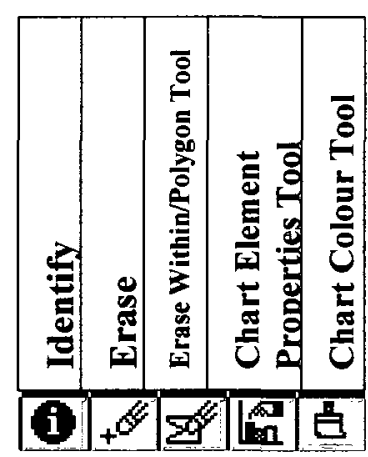

Chart GUI-Tools

\section{Layout GUI - Buttons}

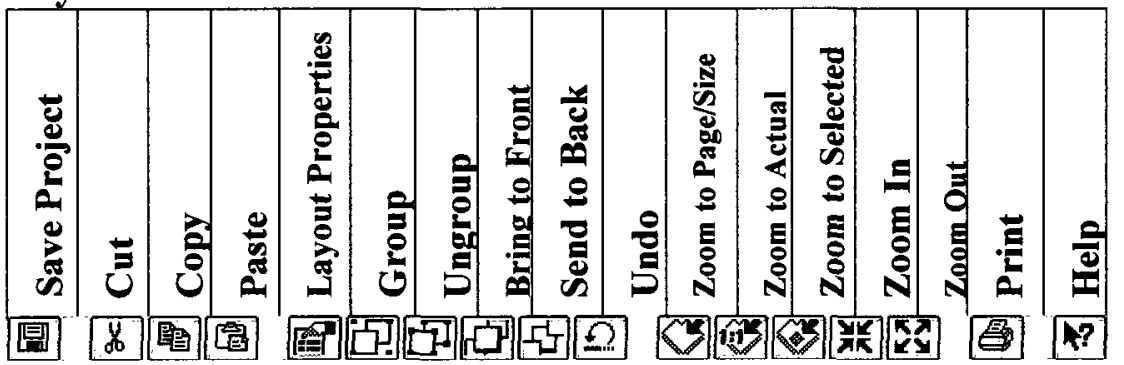

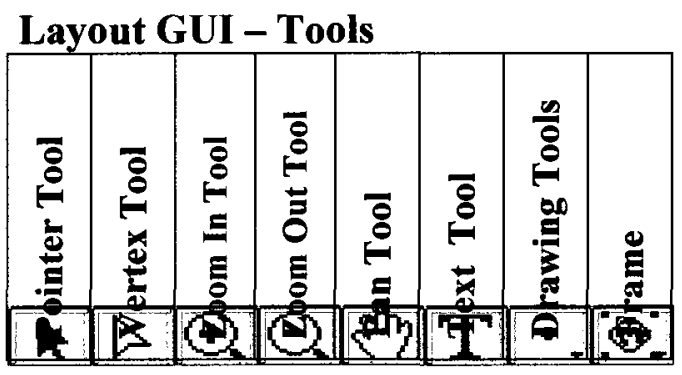

\begin{tabular}{|c|c|c|c|c|c|c|c|}
\hline 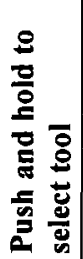 & 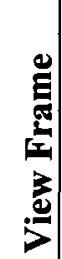 & 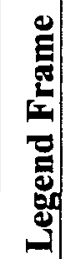 & 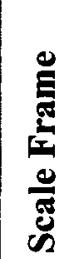 & 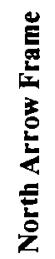 & 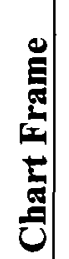 & 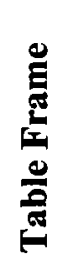 & \\
\hline
\end{tabular}




\section{CHAPTER SUMMARY}

Based on the evidence, the challenges of the Bahamian education system are there to see; this includes educational standards particularly in public high schools being a major concern. Both teacher and student participants involved in this study provided an extremely positive attitude to technology use in the classroom. Teachers can be change agents in schools. They are key drivers who play a major role in technology integration in the schools and classrooms. It is important for them and students to possess positive technology attitudes, since attitudes have been found to be linked to usage and intention to use, variables that determine successful technology integration in education. In other words, technology attitudes, whether positive or negative, affect how teachers respond to technology in an instructional setting or learning environment. This in turn affects the way students react to technology in schools (Teo, 2006) and its current and future usage. Despite the high level of technology in schools, the extent to which it is optimized depends on teachers having a positive attitude towards it (Liaw et. al., 2005).

Teachers' positive attitude toward technology use in this study could be attributed to their involvement in the research process. An important component for equipping teachers to use any form of technological resource should include opportunities for teachers to participate in focused collaboration. Teachers need to discuss successes and challenges to using the technology as a tool and feel that they have others who can share similar experiences as they experiment with technology use in their classroom. This study showed that establishing web-based discussion forums for teachers may be an effective mechanism for promoting positive attitudes toward the use of technological resources as a teaching aide in the classroom, thereby increasing the use of such resources in educational environments. In addition to this the Ministry of Education needs 
to support and encourage teachers to participate in both local and international training and professional workshops or courses, not only in their content area, but also in technological resources that can be used to help improve educational settings. This involves providing teachers with the time off for professional development.

Throughout this study, it has been argued that educational improvements should reflect a country's economic needs because of the enormous role it plays in this regard. The information provided here supports GIS use as an appropriate method for helping to equip students with some relevant skills for the workplace. The relationship between educational improvement and training and the goals of economic growth are two pillars of development that The Bahamas need to combine in order to ensure the success of national development and stability. This discussion on the importance of educational improvements for The Bahamas is an important building block for other arguments given in this thesis.

All groups (education officials, principals, teachers and students) surveyed for this study are strongly in favour of the use of some form of technological resources in high school classes. All groups were aware of the importance and benefits of technology use in educational settings, and all stakeholders directly involved in pedagogical improvements supported its use in the classroom. They believe that using technology facilitates students' success and enhances their learning. Everyone involved in this research expressed positive feedback to the overall objectives of this research. However, a question that can justifiably arise at this point is: to what extent are stakeholders committed to ensuring that this comes to fruition? It is hoped that this study and the approach proposed will lay the groundwork for further research and development that 
can move GIS and related technologies toward achieving the promise that they hold for classrooms in the twenty first century and beyond. 


\section{CHAPTER FIVE}

\section{SOME CONLUSIONS, OBSERVATIONS AND RECOMMENDATIONS}

\section{INTRODUCTION}

This study aimed to answer three research questions mentioned at the beginning of this thesis. The evidence of the discussion on the results supported the arguments, research questions and hypotheses presented in chapter one. The central argument presented in this thesis is that the use of GIS as a pedagogical tool can provide enrichment for The Bahamas' education system by presenting an effective approach to complement and improve the ways in which teaching and learning presently take place. The education system in The Bahamas continues to experience problems with student achievement and educational standards, there is currently little use of GIS in Bahamian schools but it is being used. It has been argued that the proposed educational approach to using the technology can be a change agent to help address these problems. Results obtained from the data collected throughout this study are promising because they support the arguments outlined at the beginning of this thesis. How long will it take to implement the adequate time, measures and resources for this to be achieved remains an unanswered question.

\section{Chapter Review}

The first chapter of this thesis presented a detailed introduction for the research conducted. This chapter explained how the thesis would be organized by providing a description 
of what would be included in each chapter. It presented the thesis' arguments, objectives and hypotheses.

To establish that using GIS as an alternative vehicle to complement traditional methods was viable, chapter two provided the context in which this research is situated. This included an overview of the Bahamian education system, and GIS and education. Chapter two provided a sense of hope and a positive support level for modern technologies to aid in educational improvements. Although GIS and related technologies have presented various challenges for educators, advancement in web-based resources are rapidly altering this situation by giving teachers an easier way to using the technology.

Chapter three is one of the most important sections of this research because it provided the research methods used for gathering the data and the theoretical concepts that validate the arguments and hypotheses put forth. It further outlined each research question and discussed how the data would be used to support them in this study. These research methods, even though time consuming in some cases proved to be successful because they were not cost effective and results showed that they provided the necessary data needed.

Chapter four provided an assessment of the feedback gained from individuals involved in this research. It analyzed the data retrieved and presented illustrations of the results to help validate the arguments and objectives put forth. The data supported the argument of GIS being a means to help transform and improve education in The Bahamas. This chapter also included the practical extension of the research. While this module is only a prototype, it provides an adequate example of the type of learning environment and lessons that could be developed from using the tools and techniques of GIS as teaching and learning strategies. Although the module is 
not a perfect solution to addressing the many barriers that hinder Bahamian teachers from utilizing GIS and related technologies in secondary schools, it does provide a feasible alternative to help improve educational achievement and participation in high school students.

\section{Strengths, Limitations and Challenges of Methods Employed}

The designing and implementation of research methods can be a tedious and challenging process. In this regard, there were a number of strengths and limitations to the methods (focus groups, interviews, survey and secondary methods) utilized in this thesis, in addition to a few challenges that were encountered during the implementation process.

Some strengths of the focus group discussions were: 1) it is an iterative process; each focus group discussion built upon the previous one, with slightly elaborated or better-focused themes for subsequent discussions; 2) it is a powerful research tool, which provided valuable spontaneous information in a short period of time and at a relatively low cost; and 3) the flexibility nature of focus groups, allowed individuals to thoroughly share how and why they felt a certain way about educational standards and developments in The Bahamas. However, three limitations to focus groups include: 1) the sensitivity of the issue being discussed made some participants hesitant to share their views and experiences freely, so it was important to assure confidentiality; 2) data analysis was time consuming because of the open-ended nature of the data; and 3) There was a case where one or two persons tried to dominate the discussion, but to ensure that all participants respond to questions asked, each individual was called upon to respond. It was also realized that by learning each participants' name helped in exploring certain 
ideas and concepts of the study, and it made them feel more comfortable (FrankfortNachmias and Nachmias, 1996).

Some strengths of the interview process included: 1) the probing and posing of follow-up questions, which contributed to gaining in-depth information on their views and experience of education in The Bahamas; 2) the scheduling of face to face interviews allowed the response rate to be high and the personal contact created a good rapport between the interviewer and interviewee; and 3) it was an inexpensive method and interviewees felt obliged to assist in developing an updated research on education in The Bahamas. There were also a few weaknesses to this process because even though participants signed a form of anonymity, one or two of the interviewees were still a little hesitant when it came to responding to questions relating to the standard of education and educational development being an utmost priority for the government. However, individuals were reassured that they would be kept anonymous and ethically, the anonymity form signed is viewed as a legal agreement.

Another limitation to this research method is that the analyzing of the data was time consuming because from pages of data, relevant data for each particular section of the study had to be identified. Some strengths of the survey included: 1) having the opportunity to pretest and ensure that it provided the data that was required for the study; 2) perceived anonymity by respondents was high; and 3 ) it provided a moderately high measurement of validity to support the study. A few disadvantages of this method were: 1) no responses to selective items posed a problem while analyzing some of the data; and 
2) transcribing the data and analyzing it was time consuming, especially when it came to open-ended questions because they had to be structured in a way to allow analysis.

Conceptual, methodological and economic justifications are used to describe the beneficial nature of the use of secondary data (Frankfort-Nachmias and Nachmias, 1996; and Kitchin and Tate, 2000). From the conceptual perspective, accurate data on the development and challenges of education in The Bahamas had to be obtained from the MOE and the Department of Archives in The Bahamas. Methodologically, the secondary data that was retrieved enable the replication of analysis. Therefore, perhaps the economic justification is the easiest to appreciate because it was less costly and timeconsuming. However, there were also some drawbacks with secondary data: 1) some sources did not provide significant and accurate information on education in The Bahamas; 2) dates and referencing of important educational events and individuals were poorly documented and much of the data was dated; and 3) the quality of some of the data describing the development of education in The Bahamas was poorly written and referenced, which made it difficult to analyze the information.

There were challenges experienced throughout the data collection process, which was expected, but they were minimal. The first challenge was planning the fieldwork and making travel arrangements at a time that would not interfere with the potential participants' employment responsibilities. Even though this was done prior to implementing the data collection procedures, a few adjustments still had to be made to ensure a smooth and effective process. There was also times when focus group meetings and interviews had to be rescheduled to ensure that all teachers of the history-geography 
department were present and interviewees would be able to spend adequate time in the interview. Then there was a situation of the schools being closed, due to the threat of a tropical storm, which caused the fieldwork to be postponed. This meant that an additional trip had to be taken to the study site and the extending of the data collection process. However, regardless of the challenges experienced, the entire process was thoroughly beneficial because in the end it provided the necessary data for the completion of the study.

\section{Limitations of the Thesis}

While this thesis discusses and analyzes how GIS technology can help enrich the Bahamian education system, the study only included three high schools and in some cases focused on the history-geography department of the selected schools. This population was selected to participate in this study because of ease of accessibility, due to time constraint and limited financial resources. Moreover, the teacher and student participants who took part in this study were teaching in urban schools in The Bahamas and the outcome in terms of supporting the arguments presented by this thesis might be different if participants from rural schools were included. Thus, this places a limitation on the generalizations that can be made on the findings of this study. The study relies very heavily on the honesty of its respondents. Some respondents might have a different attitude participating in this study, as they might perceive it as 'sensitive' to reveal the truth about the issues being discussed. Therefore, findings of this study should not be generalized to all teachers in The Bahamas, as the respondents involved were teachers on only one island in the country. 
The size of the total number of participants involved in this study is relatively small when compared to the total student-population and four thousand plus teachers in The Bahamas, thus again limiting the extent to which the findings of this study may be generalized. A further limitation of this study was that actual testing of the included module was not possible due to time constraint for the completion of this thesis and the time, effort and methods involved in carrying this out could constitute another thesis research. The possibility of testing the module would have strongly added support for the arguments previously mentioned because it would allow the consideration of factors such as gender, age and grade level. It would have also provided the opportunity to examine what difference this proposed approach would make in Bahamian high schools when compared to traditional methods.

But despite some of the obvious limitations to this thesis, the study accomplished what it had set out to do, that is providing a feasible initiative to using GIS in Bahamian high schools to assist in improving student achievement and educational standards. Furthermore, all of the arguments presented in this thesis were effectively supported by the data collected.

\section{Implications for Further Research}

Finally, the variables chosen in this study were limited and determined based on the thesis arguments. As a result, other significant variables that influence technology use attitudes are excluded, leading to a limited understanding of attitudes in this regard. For example, Teo et al., (2008) and Teo (in press) found evidence to suggest that that technology attitudes may be studied using the Technology Acceptance Model (TAM) with variables external to the model, such as subjective norms, facilitating conditions, and technological complexity. Outside the premise of the TAM, Teo (2007) found the perceived importance of technology, enjoyment, and 
anxiety to be associated significantly with individuals' attitudes. Future research may include comparison of the results of this study against a larger sample using a longitudinal design to examine technology use attitudes over time. Other variables could be added to examine their impact on individuals' attitudes that use technology.

The findings throughout this study are compelling for the research at hand. However, the small size of participating teachers sample suggests caution in generalizing the results of this study. It would be prudent to replicate this study with a larger number of teachers or use a sampling method under additional conditions such as longer collaborative sessions and long-term follow-up of primary measures. It is also important to validate the theory that positive attitude, for example, a high attitude score, is related to adopting innovations. Research should be conducted to see if there is a relationship between positive attitudes toward the use of technological resources and use of such resources in practice. This study provides a glimpse of selected variables that affect the attitudes of Bahamian teachers who engage in technology use. Future studies could include a systematic examination of all aspects of teacher education and how these interact to impact on current and pre-service teachers' attitudes, acceptance, and usage of the technology as a tool for instructional purposes and professional development.

Recommendations for further research include replicating this study with different populations in order to continue to validate the positive attitudes toward the use of technology as well as to investigate if the results are similar across curriculums. Investigating why students feel the way they do about technology through the use of a variety of qualitative methods and quantitative methods would be highly beneficial. This would provide information on such issues as why a student liked or did not like a certain technology, whether environmental or personal 
factors influenced those likes or dislikes, or whether time or work constraints inhibited their learning. Finally, one of the most obvious directions for further research is to fully develop a module that focuses on an entire teaching unit in one or more subjects. This could provide room for more practical applications using the proposed approach and detailed analysis to take place.

\section{Significance of the Study}

Results of the study will contribute to the information available to educators about the use of technology in the classroom, including, information about the importance of adjusting the use of technologies to accommodate the differences in learning style from student to student. There is a need for educators to understand students' attitudes toward the use of different types of technology as well as how these attitudes are related to their learning preferences. Determining the value of technology in the classroom is one of the most controversial issues challenging education today. Part of this challenge is understanding how technology lends itself to student learning.

Infusing technology into the curriculum can offer valuable lessons to educators as to what is appropriate in facilitating learning. Lessons learned when using technology in the classroom can be a) you can have too much technology in your classroom, b) technology can be intimidating if students have not been uniformly prepared prior to its use, c) students can be unforgiving if technology fails, d) in many instances, the process is more important than the product developed using technology, and e) technology can affect teaching style. Technology, and its tools do not always enhance learning, this is why the teacher's presence in the classroom and the use of traditional methods are still important. Moreover, it is necessary to continually reflect, evaluate, and adjust instruction when using technology. 
In the last ten years, the World Wide Web and technology have become increasingly pervasive in higher education, yet little empirical evidence has been generated to demonstrate the connections between students' learning styles and the use of this technology especially in the Bahamian context. It is becoming increasingly clear that technology, in and of itself, does not directly change teaching or learning (Lukow, 2002). Rather, the critical element is how technology is incorporated into instruction and its intended purpose. This integration of technology is so expansive across all areas of education that research is needed to explore the connections between its use, how students respond to its use in the classroom and what educational difference it makes; and this was a major objective of this research by obtaining feedback from educators and students on how the benefits of GIS can help enrich high school education.

The inescapable fact is that the "geospatial technology revolution" will continue at a fast pace which will require accommodation across multiple domains of research (Jackson, et. al, April 6, 2009), including education. It has to first be understood by The Bahamas government and the Ministry of Education (MOE) that there is a pressing need for continuous adaption to such technological change. Some countries may learn from the change they observe occurring in the world and make provisions to restructure and redirect resources and people to respond creatively, responsibly and aggressively to these changes. At the present time, a similarly focused approach to leadership must be emphasized in the matters of educational development in The Bahamas. The academic performance and educational standards of students, the results of the BGCSE for the past five years, coupled with employer feedback suggest significant deficiencies in the current education system. A major motivation of this study was to collect primary findings and recommendations in an effort to stimulate greater public support for and 
involvement in improving pedagogical standards, and subsequently the quality of the nation's future workforce.

It is obvious that many of the challenges which hinder educational improvements in The Bahamas are indicators of broader societal problems. However, more focus has to be placed on educational experiences that can create a better learning environment for students, one that helps them to develop the necessary skills and teach them how to apply these same skills to enhance the workplace. It is important that educators track and contribute to this progress in geospatial and technological research as they unfold, because it is essential to their future success (Jackson et al., 2009, April 6). The results indicate that both teachers and senior education officials agree on the same point that they should follow new developments in educational technology properly. Graddol (1997) supports this by stating that technology now lies at the heart of the globalization process; affecting education, work and culture. Using the suggested approach in the curriculum, rewards teachers by creating intellectually challenging and demanding learning opportunities (Audet and Ludwig, 2000).

The lack of parental involvement was a regular concern that came up throughout this thesis. The first approach that might assist in addressing the lack of parental involvement would be if the Ministry of Education (MOE) helps parents see education as a form of vertical mobility. This can be accomplished by hosting education and training seminars that are semi-structured, in a less-intimidating environment and where parents and their children are major participants. If parents are educated about how their involvement in their children's education can be a means for social and economic improvement, then they might be more motivated to get involved. In this way, the education system will produce quality students who are skilled and equipped to 
practically apply the knowledge they have acquired because all the essential persons would be involved.

The future now belongs to societies that invest and place high priority in the educational future of their citizens. What citizens know and can do holds the key to economic progress just as command of natural resources once did (Ashton and Green, 1996). Secondly, the government, the MOE and teachers have taken too much responsibility in making major decisions regarding students' education. By wresting away parents rights and responsibilities, public schools have consigned many of them to the role of spectators in their own children's education (Coulson, 2002). It is a well known fact that responsibilities breed responsibility. Therefore, until parents are given the opportunity to make important decisions about their children's education, "they will inevitably become marginalized" (Coulson, 2002, p. 134).

Teacher participants state that even though the MOE selects schools for the pilot or magnet programs explained in chapter three, at the end of the school year all schools are still evaluated on students' performances on end of term examinations and the BGCSE (Focus group and Survey, 2008). Teachers further added that, "this approach to evaluating all schools on the same scale is unfair to the extremely hard working teachers, when considering that most of the academically inclined students are usually sent to selected high schools" (Survey, 2008). If this is the case, then all schools should not be evaluated on the same academic scale because it shows a disregard for those students who are skilled in the technical and vocational areas. More initiatives in technical and vocational education need to be introduced because a skilled workforce is essential to supporting an increasingly sophisticated economy. Becker (2002) stated that, "new technological advances clearly are of little value in countries that have very few 
skilled workers who know how to use them." Economic growth closely depends on the interaction between new knowledge and a country's ability to learn. She further said, "large increases in education and training have accompanied major advances in technological knowledge in all countries that have achieved significant economic growth" (p. 7). It is ironic that the end of 2009 will mark two decades, since Trainor (1989) outlined the issues that prohibited the further development of education in The Bahamas, but the key issues he identified still exist.

There is no doubt that the geographical reality of The Bahamas presents major and costly challenges for the delivery of education and the equalization of educational opportunities. A practical approach to equalizing opportunity in these circumstances is, of course, to embrace the benefits of new technologies. The importance of education cannot be neglected by any nation. It is obvious that in The Bahamas, the role of education must become even more vital in a country that invests more than $50 \%$ of its economic resources in extremely vulnerable industries. This is why it is important that a new and innovative approach to educating students be adopted. GIS and related technologies have a major role to play in this respect and the time for questioning their utility is over.

Undoubtedly the recent advancement in information technology innovations and computer usage is rapidly transforming work culture and teachers cannot escape the fact that today's classrooms must provide technology-supported learning (Angers and Machtmes, 2005). Being prepared to adopt and use technology and knowing how that technology can support student learning must become integral skills in every teacher's professional repertoire. District and school policy and professional development workshops and training must be designed to 
positively influence teachers' adoption and usage of computer technology. Educational development investment must also anticipate assisting in creating a technologically literate workforce who in turn would generate a future generation that would be competent and confident to perform in a global, technology-intensive work environment. However, in the school settings, one of the major obstacles faced is the non-extensive usage of technology like GIS by the educators for classroom instruction. Clearly, something should be done to identify the root cause of this problem such as targeting the input of education decision makers in the MOE.

The economy of The Bahamas is an example of what happens when diversified educational opportunities for students are not available. Many students upon graduation are seeking employment in the Tourism sector. What about areas such as fishing, farming and manufacturing? These are sectors that help to make a country more self-sufficient when industries like tourism and banking succumb to their vulnerability in the global marketplace. The education system has to provide diverse educational experiences for students in order for them to develop or venture into areas that would diversify the country's economy.

Since many societal problems are so critical, countries "must build the best possible foundation for advancing the capabilities and wide use of geospatial technologies" (Jackson, et. al, April 6, 2009, p. 2), and in the case of The Bahamas that basis is its education system. Education officials involved in this study appeared convinced that technology as a teaching and learning aid is important if students are to be prepared to face the challenges of the globalized world. It is undeniable then that GIS and related technologies have become a potent production tool and they offer exciting approaches to teaching and learning, and if this technology is used extensively, and in an effective manner, it could bring progress that would help improve 
education radically, not just in Bahamian schools, but globally. Education ministers and officials, and school administrators must lead the way to encourage technological development of teachers since their support is vital in teachers attending information technology courses and workshops.

An overriding goal of public policy is to empower, not burden future generations and this involves governments implementing the necessary procedures to stimulate the economy, which directly depends on educational improvements of a country. As the easy open access to technologies like GIS proliferates, educators will be armed with more powerful means to help address not only educational challenges, but also societal problems (Jackson et al., April 6, 2009). These are not merely empty words, but they frame the responsibility (Jackson et al., April 6 , 2009) held by world leaders and educators in providing students with the best possible educational experiences. Knowledge of an innovation informs attitude. Positive attitude is prerequisite to adopting an innovation. Knowing the nature of a teacher's attitude is an important measure in predicting his or her predisposition to adopting new innovations such as the use of web resources in his or her established teaching and learning practices.

Where do we go from here? It is not solely up to the government and the MOE to make changes. If standards are to be improved, it will take the MOE, school administrators, teachers, parents and union leaders to negotiate on measures that will act as a catalyst for reform and not an impediment. All the major stakeholders mentioned throughout this study must be involved. There is no doubt that the major ingredient in schools performances is the teacher. But the single most important element is parents instilling a thirst for knowledge and excellence in their children. There is only so much the government can do. The government and teachers cannot go into the homes and turn off televisions and make students study or complete homework 
assignments. Even though it must be acknowledged that there are some students who can multitask, but this number is quite small. Students need to view learning as a privilege, one that is a creative and fun experience. Once a sound approach is agreed upon to address the problem of education by stakeholders, the wider community can be involved. However, the level of priority which educational development is afforded is initially up to education policy makers, which include the government and the MOE.

This thesis generally discussed how modern technologies can help alleviate two major problems the Bahamian education system faces in terms of skills development and improving the learning environment for students. Educational improvements go beyond structural expansion such as building more schools. Improvements in education also require a major restructuring of the curriculum and the Teacher Education Program at the College/University of The Bahamas. There is no doubt that implementing successful educational development practices will be inherently difficult, but it is not impossible to achieve.

As this technology has become cheaper, and more schools in The Bahamas have been linked to the internet, this thesis provided another opportunity for teachers and students to not only gain access to this vast information resource in education, but also be able to utilize and interact with GIS technology in ways that would provide the best possible learning environment for a diverse student population. This opportunity will no doubt help further enhance the Bahamian education system. However, many would probably just view this research as another document, but those who hold the best interest of Bahamians as important, and are committed to the future advancement of the country's education system and economy will see it as a voice for change. These individuals will listen and start to do what is necessary to make it possible. 


\section{APPENDIX A}

INTERVIEW QUESTIONS AND INFORM CONSENT DOCUMENT

\section{QUESTIONS USED FOR INTERVIEW}

1. Are you comfortable with the standard of education in The Bahamas? Explain your response.

(a) Do you have any concerns in regards to the level at which high school students are graduating?

2. In your view, would you say that educational improvements are important for The Bahamas? Explain your response.

(a) Technology is playing a major role in many school curricula globally. Do you think that implementing some form of technology in the High school system will help improve educational standards and help equip students for some form of employment?

(b) Do you think that some form of technology is vital for the further improvement and development of education in The Bahamas?

3. Do you think that educational standards in Bahamian high schools are declining? 
4. On a scale of 1-10, 1 being the lowest and 10 the highest, how would you rate the government's priority for educational development?

5. Do you have any final suggestions or comments concerning the Bahamian education system? 


\section{APPENDIX B}

\section{COVER LETTER AND QUESTIONNAIRE}

To Whom It May Concern:

My name is Sophia Miah, a Master of Arts student in the Department of Geography and Environmental Studies at Carleton University in Ottawa, Ontario, Canada. As a requirement for the Master of Arts program, I am conducting a field research study on a topic selected by myself, in which I will write a final thesis and present the results before an examination board. The topic is: Improving Standards in Bahamian High Schools: Using Geographic Information System as a Pedagogical Tool.

The purpose of this research study is to show how the use of a technology that has demonstrated the ability to improve both academic and practical (technical) skills, can be made easier and useable for Bahamian teachers to improve the traditional methods of teaching and learning. In addition to exploring students, educators and parents main concerns regarding the standard of high school education in The Bahamas.

I would like for you to fill out a questionnaire that will take 10 minutes to complete. This questionnaire consists of ten questions and requests no personal information from you in terms of name or place of employment. Therefore, your contribution will be kept confidential and you will remain anonymous. Your participation is voluntary and if you do agree to participate in the questionnaire you have the right to refuse to answer any questions, but once you have completed it you cannot withdraw due to the anonymous nature of the survey. There is no compensation or risks that will occur from your participation in this research study.

I will pick up the completed questionnaire on a day designated by you or I can wait for it if possible I am the only individual that will have access to this information and it will be secured 
in a locked cabinet at my residence. The information collected will be kept for a period of six to eight months while I am in the process of writing my research findings, immediately after which it will be destroyed. This research has been approved by the Carleton University Research Ethics Committee; you can contact the chair of the committee if you have any questions about the ethics of this research study or any of the following persons if you have further questions or concerns.

Sophia Miah

Researcher

Telephone: (242) 324-6424

Email: smiah@connect.carleton.ca
D. R. F. Taylor

Supervisor

(613) 520-200 Ext.8232

Fax: (613) 520-4301

ftaylor@ccs.carleton.ca
Prof. Antonio Gualtieri Chair Carleton University Research Ethics Committee Carleton University 1125 Colonel By Drive Ottawa, Ontario K1S5B6 (613) 520-2517

Email: ethics@carleton.ca

Sincerely,

Sophia Miah

(M.A. Student) 


\section{SURVEY QUESTIONS}

GENDER: Male

Female

STATUS: Educator $\square$
AGE: $18-25$

26-35

$35+$

1. Do you think public school education in The Bahamas is inferior when compared to a private school?
YES
NO $\square$
Provide an explanation for your response

2. How would you rate the academic standard at which high school students are graduating?
Above Average $\square$
Average $\square$
Below Average $\square$
Poor $\square$

3. Are you please with the level at which high school students are performing? Explain your response.

4. Are you comfortable with the standard of education in The Bahamas? Why or why not?

5. In your view, would you say that educational improvements are important for The Bahamas? YES $\square \quad$ NO $\square \quad$ Explain your response 
6. Technology is playing a major role in many schools curricula globally. What effect would the implementation of some form of technology in Bahamian High schools have on helping to improve educational standards and equipping students for some additional form of employment?

7. On a scale of 1-10, 1 being the lowest and 10 the highest, how would you rate the government's priority for educational development?

8. If provided with the opportunity, would you use some form of technology to help improve your lessons? Why or why not?

9. Do you think that some form of technology is vital for the further improvement and development of education in The Bahamas? YES $\square$

NO $\square$ Explain your response

10. What are your views in terms of the future of education in The Bahamas? 


\section{CONSENT FORM}

$\mathrm{I}$, have read the above letter and fully understand that Parent/guardian Name (Please Print) Child Name is participating in a research project.

I understand that the data collected will be kept anonymous and confidential. I accept the above conditions of the research project and volunteer for my child to participate.

Sincerely, 


\section{REFERENCES}

A country paper: An overview of education in The Commonwealth of The Bahamas. (2004, December). Ministry of education research and planning unit. Second global interagency consultation on education in emergencies and early recovery. South Africa: Cape Town.

Alibrandi, M. (1998). GIS as a tool in interdisciplinary environmental studies: Student, teacher, and community perspectives. Education resources information center, 1(2), 1-10.

Ahola-Sidaway, J., \& McKinnon, M. (1999). Fostering pedagogical soundness of multimedia learning materials. Canadian Journal of Educational Communication, 27(2), 67-86.

Anderson, W. L., Krathwohl, R. D., Airasian, W. P., Cruikshank, A. K., Mayer, E. R., Pintrich, R. P., Raths, J., \& Wittrock, C. M. (eds.). (2000). A taxonomy for learning, teaching and assessing: A revision of Bloom's taxonomy of educational objectives.

Addison, Wesley: Longman, Inc. Allyn \& Bacon.

ArcExplorer. Retrieved June 5, from http://www.esri.com/software/arcexplorer/download.html

Ashton, D. \& Green, F. (1996). Education, training and the global economy. Cheltenham, UK: Edward Elgar Publishing Limited.

Audet, R. H., \& Ludwig, G. (2000). GIS in schools. Redlands: ESRI Press.

Audet, R. H., \& Paris, J. (1997). GIS implementation models for schools: Assessing the critical Concerns. Journal of geography, 96(6), 293-300.

Audet, R. H., \& Abegg, G. L. (1996). Geographic information systems: implications for problem solving. Journal of Research in Science Teaching, 33(1), 21-45.

Aulls, W. M., \& Shore, M. B. (2008). Inquiry in education: The conceptual foundations for research as a curricular imperative. New York: Lawrence Erlbaum Associates. 
Background information on The Bahamas. Retrieved March 19, 2008, from http://www.state.gov/r/pa/ei/bgn/1857.htm

Bahamas Union of Teachers head speaks out on BGCSE exam grades. (2007, August 21). Retrieved May 10, 2009, from http://www.jonesbahamas.com/?c=45\&a=13815

Barnett, C. (2006). Postcolonialism: Space, textuality, and power. In S. Aitken and G. Valentine (eds.), Approaches to human geography (pp. 147-159). London: Sage Publications.

Barro, J. R. (2002). Education as a determinant of economic growth. In Lazear, P. E. (ed.), Education in the twenty-first century. Stanford, CA: Hoover Institution Press.

Baulch, S., MacDonald, R., Pulsifier, L. P., \& Taylor, D. F. R. (2005). Cybercartography for education: The case of the cybercartograpic atlas of Antarctica. In Taylor, F. (ed.), Cybercartography: Theory and practice (pp. 491-515). Oxford: Elsevier Limited.

Becker, S. G. (2002). The age of human capital. In Lazear, P. E. (ed.), Education in the twenty-first century. Stanford, CA: Hoover Institution Press.

Bednarz, S. W. (2000). Problem based learning. In Audet, R., \& Luwig, G. (eds), GIS in schools. Redlands, California: ESRI Press.

Bednarz, S. W., \& Audet, R. H. (1999). The status of GIS technology in teacher preparation Programs. Journal of geography, 98(2), 60-67.

Bedford, T., \& Burgess, J. (2001). The focus group experience. In. Limb, M., \& Dwyer, C. (eds.), Qualitative methodologies for geographers: Issues and debates. London: Arnold.

Bernhardsen, T. (2002).Geographic information systems: An introduction. $\left(3^{\text {rd }}\right.$ ed.) New York, NY: Wiley.

Bloom, S. B. (1981). All our children learning: A primer for parents, teachers and other educators. New York: McGraw-Hill Book Company.

Bloom, B. (1956). Taxonomy of educational objectives: The classification of educational goals. (ed.). Susan Fauer Company, Inc. Retrieved January 20, 2009, from http://en.wikipedia.org/wiki/Taxonomy_of_Educational_Objectives 
Bostock, S. J. (1998). Constructivism in mass higher education: A case study. British Journal of Educational Technology, 29(3), 225-240.

Bradshaw, M., \& Stratford, E. (2005). Qualitative research design and rigour. In Hay, I. (ed.), Qualitative research methods in human geography. $\left(2^{\text {nd }}\right.$ ed.). New York: Oxford University Press.

Briney, A. (2008, April 6). GIS: An overview of geographic information systems. Retrieved March 15, 2008, from http://geography.about.com/od/geographyintern/a/gisoverview.htm

Bruner, J. (1999). Infancy and culture: A story. In S. Chaiklin, M. Hedegaard, et al., (eds.), Activity theory and social practice (pp. 225-234). Aarhus N, Denmark: Aarhus University Press.

Bruner, J. S. (1996). The culture of education. Cambridge, MA: Harvard University Press.

Bruner, J. S. (1993). Explaining and Interpreting: Two ways of using mind. In G. Harman (Ed.), Conceptions of the human mind: Essays in honor of George A. Miller (pp. 123-137). Hillsdale, NJ: Lawrence Erlbaum Associates.

Bruner, J. S. (1986). Actual minds, possible worlds. Cambridge, MA: Harvard University Press.

Bruner, J. S. (1967). Studies in cognitive growth. New York: Wiley.

Bruner, J. S. (1961). The act of discovery. Howard educational review, 31(1), 21-32.

Callahan, R. E. (1964), Education and the cult of efficiency. Chicago: University of Chicago Press.

Cameron, J. (2005). Focusing on the focus group. In Hay, I. (ed.), Qualitative research methods in human geography. ( $2^{\text {nd }}$ ed.). New York: Oxford University Press.

Central Bank issues warning. (30 September, 2008). The Nassau guardian newspaper. Nassau, Bahamas: Nassau guardian printing department. 
Concept to classroom: A series of workshop. (2004). Inquiry-based Learning, Educational Broadcasting Corporation. Retrieved November 20, 2008, from http://www.thirteen.org/edonline/concept2class/inquiry/index.html

Conlon, M. (1997). MOOville: the writing project's own "private Idaho". T.H.E. Journal, 24(8), 66-68.

Coulson, J. A. (2002). Delivering education. In Lazear, P. E. (ed.), Education in the twenty-first century. Stanford, CA: Hoover Institution Press.

Cuban, L. (1986). Teachers and machines: The classroom use of technology since 1920. New York: Teachers College Press, Columbia University.

Darling-Hammond, L. (1998). Teacher learning that supports student learning. Educational Leadership, 55(5), 6-11.

Davis, B. E. (2001). GIS: A visual approach. ( $2^{\text {nd }}$ ed.). Albany, NY: Delmar Thomson Learning.

Department of education: General overview. (2008). Nassau, Bahamas: The Ministry of education. Retrieved October 15, 2008, from http://www.bahamaseducation.com/departments.html

Designing GIS software. Retrieved January 20, 2009, from http://www.geode.northwestern.edu/myworld/GISinEd Workshop.pdf

D’Oyley, V., Blunt, A., \& Barnhardt, R. (eds.). (1994). Education and development: Lessons from the third world. Alberta, Canada: Detselig Enterprises Ltd.

Dunn, K. (2005). Interviewing. In Hay, I. (ed.), Qualitative research methods in human geography. ( $2^{\text {nd }}$ ed.). New York: Oxford University Press.

Education in The Bahamas: Legions of smart kids having their minds shackled by Bahamas government bureaucrats. (2008). The Bahamas Guide. Retrieved March 5, 2008, from http://www.thebahamasguide.com/facts/education.htm 
Getting to know ArcView GIS. (1998). Environmental Systems Research Institute. Redlands, California: ESRI Press.

Exploring common ground: The educational promise of GIS. (1995). Redlands, California: Environmental Systems Research Institute, Inc.

Eylon, L. (1998). Small and successful: GIS for secondary schools in Scotland. Retrieved October 5, 2008, from http://gisvision.ibsystems.com/casestudy/sasfull.php.

Fifty percent of Bahamian students leave school without a diploma. (2008, June 20). The Nassau guardian newspaper. Nassau, Bahamas: Nassau guardian printing department.

Fitzgerald, C. (2002). Personal communication. In A. Doering (ed.). St. Paul.

Fitzgerald, C. (1990). Computers in geography instruction. Journal of geography, 89, 148-149.

Focus on the future: White paper on education. (1973). Nassau, Bahamas: Bahamas Government Printing.

Fowler, F. J. (1995). Improving survey questions: Design and evaluation. Thousand, Oaks: CA: Sage Publications.

Franfort-Nachmias, C., \& Nachmias D. (1996). Research methods in the social sciences. ( $^{\text {th }}$ ed.). London: Edward Arnold.

Fredrick, B., \& Fuller, K. (1997). What we see and what they see: Slide tests in geography. Journal of geography, 97, 63-71.

Gardiner, H. (1999). Intelligences reframed: Multiple intelligences for the $21^{\text {st }}$ century. New York: Basic Books.

Gardiner, H. (1983 \& 1993). Frames of mind: The theory of multiple intelligences. New York: Basic Books.

Geisert, W.E. \& Futrell, B.L. (2001). Computer anxiety and other factors preventing computer use among secondary school educators. Journal of Education, 45(2), 15-20. 
Getting started with GIS graphic. Retrieved May 20, from

www.morrison.tec.il.us/www.gis.rgs.org

Girasoli, A. (2006). Does the use of technology in a classroom lesson change students' attitudes towards learning? Retrieved February 20, 2009 from http://de.scientificcommons.org/18919772

Goodchild, M. F., \& Kemp, K. K. (eds). (1990). The NCGIA core curriculum in GIS. Santa Barbara, CA: National center for geographic information and analysis, University of California.

Grasha, A. F., \& Yangarber-Hicks, N. (2000). Integrating teaching styles and learning styles with instructional technology. College Teaching, 48(1), 2-10.

Green, D. R. (2001a). Preface. In D. R. Green, (ed.), GIS: A Sourcebook for Schools. London: Taylor \& Francis.

Greening, T. (2000). Computer science education in the $21^{\text {st }}$ century. New York: Springer.

Groot, R., \& McLaughlin, J. (2000). Geospatial data infrastructure: Concepts, cases and good Practice. New York: Oxford University Press, Inc.

Hall, E. R. (2002). The value of education: Evidence from around the globe. In Lazear, P. E. (ed.), Education in the twenty-first century. Stanford, CA: Hoover Institution Press.

Hardin, J., \& Ziebarth, J. (1995). Digital technology and its impact on education: The future of networking technologies for learning. Washington, D.C.: U.S. Department of Education. Retrieved March 15, from http://www.ed.gov/Technology/Futures/hardin.html

Hoggart, K., Lees, L., \& Davies, A. (2002). Researching human geography. London: Arnold.

Holliday, A. (1994). Appropriate methodology and social context. New York: Cambridge University Press.

Howitt, D., \& Cramer, D. (2005). Introduction to research methods in psychology. ( $1^{\text {st }}$ ed.). Harlow, England: Prentice Hall. 
Jackson, M., Schell, D., \& Taylor, D. F. R. (2009, April 6). The evolution of geospatial technology calls for changes in geospatial research, education and government management. Directions Magazine. Retrieved June 10, 2009, from http://www.directionsmag.com/article.php?article id $=3092$

Johnson, L., \& Lamb, A. (2007). Howard Gardiner and the learning needs of students. Professional development resources for educators and librarians, Retrieved November 7, 2008, from http://eduscapes.com/tap/topic68.htm

Johnson, D., \& Johnson, R. (1991). Learning together and alone. ( $3^{\text {rd }}$ ed.). Allyn \& Bacon: Sydney.

Kagan, S., \& Widaman, K. F. (1987). Cooperativeness and achievement: Interaction of student cooperativeness with cooperative versus competitive classroom organization. Journal of School Psychology, 25(4), 355-65.

Keiper, T. A. (1999). GIS for elementary students: An inquiry into a new approach to learning geography. Journal of Geography, 98(2), 47-59.

Kemp, K., Goodchild, M. F., \& Dodson, R. F. (1992). Teaching GIS in geography, The Professional Geographer, 44(2), 181-191.

Kerski, J. J. (2003). The implementation and effectiveness of geographic information systems technology and methods in secondary education. Journal of geography, 102(3), 128-137.

Kerski, J. J. (2001). The implementation and effectiveness of geographic information systems technology and methods in secondary education. Proceedings of the 21st Annual ESRI International User Conference, July 9-13, 2001. Redlands, CA: ESRI Press.

Kerski, J. J. (2000). The implementation and effectiveness of geographic information systems: Technology and methods in secondary education. Retrieved February 20, 2008, from http://gis.esri.com/library

Kitchin, R., \& Tate, N. (2000). Conduction research in human geography. Harlow: Pearson Education Limited. 
Koszalka, A. T. (2001, June). Effect of computer-mediated communications on teachers' attitudes toward using web resources in the classroom: Statistical data included. Journal of instructional psychology. Retrieved February 10, 2009, from http://findarticles.com/p/articles/mi_m0FCG/is_2 28/ai_76696356/pg_9?tag=content;col $\underline{1}$

Kumar, N., Che Rose, R., \& D'Silva, L. J. (2008). Teachers' readiness to use technology in the classroom: An empirical study. European Journal of Scientific Research, 21 (4), 603616.

Lazear, P. E. (2002). Introduction. In Lazear, P. E. (ed.), Education in the twenty-first century. Stanford, CA: Hoover Institution Press.

Liaw , S. S., Huang, M. H. \& Chen, D. G. (2007, December). Surveying instructor and learner attitudes toward e-learning. Computers and Education, 49(4). Oxford, U.K.: Elsevier Science Ltd.

Linn, S. E. (1997). The effectiveness of interactive maps in the classroom: A selected example in studying in Africa. Journal of geography, 96(3), 164-170.

Longley, P. A., Goodchild, M. F., Maguire, D. J., \& Rhind, D. W. (2001). Geographic Information Systems and Science. Chichester: John Wiley \& Sons, Ltd.

Lukow, E. J. (2002). Students' attitudes toward the use of technology in the classroom. Department of human performance \& health promotion, University Of New Orleans. Retrieved March 20, 2009, from http://www.celt.lsu.edu/cfd/THE/EProc05/Lukowedit.pdf

Mackaness, W. A. (1994). Curriculum issues in GIS in K-12. Retrieved March 15, 2009, from http://wwwsgi.ursus.maine.edu/gisweb/spatdb/gis-lis/gi94070.html

Malone, L., Palmer, M. A., Voigt, L. C., Napoleon, E., \& Feaster, L. (2005). Mapping our world: GIS lessons for educators, ArcGIS desktop edition. Redlands, California: ESRI Press.

Mandi, P. (1981). Education and economic growth in the developing countries. Hungary: Akademiai Kiado, Budapest. 
Marshall, S. (1983) Computer aided instruction in linguistic analysis. Computers and Education, $7,25-31$.

McGuinn, J. P. (2006). No child left behind and the transformation of federal education policy, 1965-2005. USA: University press of Kansas.

McGuirk, P.M. \& O'Neill, P.M. (2005) Using questionnaires in qualitative human geography. In Hay, I. (ed.), Qualitative Research Methods in Human Geography $\left(2^{\text {nd }}\right.$ ed.). Oxford: Oxford University Press.

Meyer, W. J., Butterick, J., Olkin, M., \& Zack, G. (1999). GIS in the K-12 curriculum: A cautionary note. The professional geographers, 51(4), 571-578.

Miller, P. J. (2007). The holistic curriculum. ( $2^{\text {nd }}$ ed.). Canada: University of Toronto Press, Inc.

Ministry of education annual report. (2004-2005). Nassau, Bahamas: Ministry of education Planning \& research section.

Moffet, J., \& Wagner, J. B. (1992). Student-centered language arts, K-12. ( $2^{\text {nd }}$ ed.). Portsmouth, NH: Boynton/Cook publishers, Inc.

Mouza, C. (2002). Learning to teach with new technology: implications for professional development. Journal of Research on Technology in Education, 35(2), 272-289.

Mungazi, A. D. (1991). The challenges of educational innovation and national development in Southern Africa. New York, USA: Peter Lang Publishing, Inc.

My World GIS. (2004). PASCO Scientific. Retrieved June 10, 2009, from http://www.myworldgis.org/

Myers, J. M., \& Halpin, R. (2002). Teachers' attitudes and use of multimedia technology in the classroom: Constructivist-based professional development training for school districts. Journal of Computing in Teacher Education, 18(4), 133-140.

New year's report to the nation. (2008, 17 January). The Tribune newspaper. Nassau, Bahamas: Tribune Printing Department. 
Okolo, T., \& Naidoo, T. (2005). What classroom is more beneficial? Hybrid classrooms versus traditional classrooms. Technologies of Writing Journal, 2(2).

Omrod, J. (1995). Educational psychology: Principles and applications. Englewood Cliffs: NJ Prentice-Hall.

Owston, R.D. (1997). The World Wide Web: A technology to enhance teaching and learning. Educational Researcher 26 (2), 27-33. Retrieved March 20, 2009, from http://edr.sagepub.com/cgi/reprint/26/2/27

Prime Minister to address nation on state of the economy. (2008, November 7). The Nassau guardian newspaper. Nassau, Bahamas: Nassau Guardian Printing Department.

Punch, K. F. (1998). Introduction to social research: Quantitative and qualitative approaches. Thousand Oaks, CA: Sage Publications.

Putting GIS in its place: proactive approach for beginners. Retrieved January 15, 2009, from http://gis.esri.com/library/userconf/educ06/papers/educ_1461.pdf

Puzzle-GIS. Retrieved June 5, from http://puzzle-gis.codehaus.org/

Raisian, J. (2002). Director's foreword. In Lazear, P. E. (ed.), Education in the twenty-first century. Stanford, CA: Hoover Institution Press.

Sadik, A. (2006). Factors influencing teachers' attitudes toward personal use and school use of computers: New evidence from a developing nation. Evaluation Review, 30(1), 86-113.

Salinger, G. L. (1995). Educational psychology: Principles and applications. Englewood Cliffs: NJ Prentice-Hall.

Sharan, S., \& Kussell, P. (1984). Cooperative learning in the classroom: Research in desegregated schools. Hillsdale, N.J.: Erlbaum Associates.

Slavin, R. E. (1983). Cooperative Learning. New York: Longman Smith, L. (2008, March). Globalization, EPA and the Bahamian education system. Nassau, Bahamas: Bahama Pundit. 
Smith, L. (2008, April 28). The Problems of Bahamian education. Bahama Pundit http://www.bahamapundit.com/education/

Some personalities in Bahamian education. (1992, November). Nassau, Bahamas: Department of archives.

Sternberg, R. J. (1996) Successful intelligence. New York: Simon \& Schuster.

Sternberg, R. J. (1985) Beyond IQ: A triarchic theory of human intelligence. New York: Cambridge University Press.

Sumner, L. (1995). Examination development for educational reform: Bahamas new secondary examination-BGCESE. Nassau, Bahamas: Bahamas Government Printing Department. Retrieved November 18, 2008, from http://researchjournal.cob.edu.bs/index.php

Teaching in the public education system in The Bahamas. (2004, August). Nassau, Bahamas: The Ministry/Department of education.

Teo, T., Lee, \& Chai, (2008). Pre-service teachers' attitudes towards computer use: A Singapore survey. Australasian Journal of Educational Technology, 24(4), 413-424. Retrieved November 5, 2008, from http://www.ascilite.org.au/ajet/ajet24/teo.html

Teo, T. (2006). Attitudes toward computers: A study of post-secondary students in Singapore. Interactive Learning Environments, 14(1), 17-24.

The BGCSE results. (2008, August). Examination and assessment division of the Ministry of Education. Nassau, Bahamas: Assessment \& Evaluation Division.

The Cognition and Technology Group at Vanderbilt (1990). Anchored instruction and its relationship to situated cognition. Educational Researcher, 19(6), 2-10.

The government commemorates majority rule. (2007). Nassau, Bahamas: The government of The Bahamas official website. Retrieved November 19, 2008, from http://www.bahamas.gov.bs/bahamasweb2/home.nsf 
The importance of education for development. (2006, December 29). Essay.se, Retrieved January 15, 2009, from http://www.essays.se/about/importance +of + education + for + the + development + of + country/

Theroux, P. (2002). Intrinsic motivation. Retrieved January 20 2009, from http://members.shaw.ca/priscillatheroux/motivation.html

Tinker, R. F. (1992). Mapware: Educational applications of geographic information systems. Journal of Science Education and Technology, 1(1), 35-48.

Total Environmental Restoration Contract (TERC). (1995). First national conference on the educational applications of geographic information systems (EdGIS) Report. Cambridge, MA: TERC.

Trainor, M. J. (1989). Public education in The Bahamas. In Collinwood, D. W., \& Dodge, S. (eds), Modern Bahamian society. Parkersburg, IA: Caribbean Books.

Tsitouridou, M. \& Vryzas, K. (2003). Early childhood teachers' attitudes towards computer and information technology: The case of Greece. Information Technology in Childhood Education Annual, 1, 187-207.

Unwin, J. D. (1991). Geographic information systems. ( $1^{\text {st }}$ ed.). The academic setting of gis, 1 , 81-90. Retrieved January 15, 2008, from http://www.wiley.co.uk/wileychi/gis/Volume1/BB1 ch6.pdf

Von, G. E. (1997). Ways of knowing: Constructionist explorations of thinking. Heidelberg, Germany: Carl Auer.

Von, G. E. (1995a). A constructivist approach to teaching. In L. P. Steffe \& J. Gale (eds.), Constructivism in education (p. 3-16). Hillsdale, NJ: Erlbaum.

White, K. L., \& Simms, M. (1993). Geographic information system as an educational tool. Journal of geography, 92(2), 80-85.

White, J. (1998). Do Howard Gardner's multiple intelligences add up? London: Institute of Education, University of London. 
Wiburg, K. M. (1997). The dance of change: Integrating technology in classrooms. Computers in the Schools, 13(1/2), 171-184.

William, V. T. (1974). Education: A beginning. Boston: Houghton Mifflin Company.

WorldWatcher. Geographic data in education (GEODE) Initiative. Retrieved June 5, from http://www.worldwatcher.northwestern.edu/download.htm, http://www.worldwatcher.northwestern.edu/windownload.htm and http://www.worldwatcher.northwestern.edu/macdownload.htm

Xue, Y., A. P. Cracknell, and H. D. Guo. (2002). Telegeoprocessing: The integration of remote sensing, geographic information system, global positioning system and telecommunication. International Journal of Remote Sensing, 23(9), 1851-1893.

Yen, M. (2003). Customize GIS education with supply chain management model. Retrieved January 15, 2008, from http://gis.esri.com/library/userconf/proc03/p0253.pdf

Yildirim, S. (2000). Effects of an educational computing course on pre-service and inservice teachers: A discussion and analysis of attitudes and use. Journal of Research on Computing in Education, 32 (4), 479-495.

Yuda, M., \& Itoh, S. (2006). Utilization of geographic information systems in education reform in Japan. Retrieved January 11, 2008, from http://www.agile2006.hu/papers/a098.pdf

Zerger, A., Bishop, D. I., Escobar, F., \& Hunter, J. G. (2002). A self-learning multimedia approach for enriching GIS education. Journal of geography for higher education, 26 (1), 67-80. 